\title{
State policy innovation and transfer: The role of bureaucratic professional communication networks
}

\author{
Rebecca Tatman Klase \\ West Virginia University
}

Follow this and additional works at: https://researchrepository.wvu.edu/etd

\section{Recommended Citation}

Klase, Rebecca Tatman, "State policy innovation and transfer: The role of bureaucratic professional communication networks" (2005). Graduate Theses, Dissertations, and Problem Reports. 2314.

https://researchrepository.wvu.edu/etd/2314

This Dissertation is protected by copyright and/or related rights. It has been brought to you by the The Research Repository @ WVU with permission from the rights-holder(s). You are free to use this Dissertation in any way that is permitted by the copyright and related rights legislation that applies to your use. For other uses you must obtain permission from the rights-holder(s) directly, unless additional rights are indicated by a Creative Commons license in the record and/ or on the work itself. This Dissertation has been accepted for inclusion in WVU Graduate Theses, Dissertations, and Problem Reports collection by an authorized administrator of The Research Repository @ WVU.

For more information, please contact researchrepository@mail.wvu.edu. 
State Policy Innovation and Transfer: The Role of Bureaucratic Professional Communication Networks

\author{
Rebecca Tatman Klase
}

Dissertation submitted to the Eberly College of Arts and Sciences at West Virginia University in partial fulfillment of the requirements for the degree of

\title{
Doctor of Philosophy
}

in

Political Science

Donley T. Studlar, Ph.D., Chairperson

Nancy L. Adams, Ph.D.

Neil B. Berch, Ph.D.

Kevin M. Leyden, Ph.D.

Allan S. Hammock, Ph.D.

Department of Political Science

Morgantown, West Virginia

2005

Keywords: policy transfer, communication networks, bureaucracy, U.S. state, public health Copyright 2005 Rebecca Tatman Klase 


\section{ABSTRACT \\ State Policy Innovation and Transfer: The Role of Bureaucratic Professional Communication Networks}

\section{Rebecca Tatman Klase}

The central question of this research is, "what is the role of state administrative agencies in the innovation and transfer of public policy?" One of the theoretical perspectives of the study of public policy examines the "borrowing" of one nation or U.S. state's policy by another followed by adaptation to the new jurisdiction. The past focus of most of this research has been on legislative policy adoptions. This study draws upon a different perspective, bureaucratic adoptions of public policy.

A two-fold approach is employed, using both quantitative and qualitative research techniques. Information was gathered on both state agencies and their lead officials by telephone, in person, and through written survey instruments. Further documentary data were drawn from a variety of sources on state public health agencies and other political and economic characteristics of individual U.S. states. This information was used in two ways.

First, a detailed depiction describes the professional communication networks of state public health agency officials. The literature on policy transfer assumes the use of such a network, but past research has neither described the network and its mechanisms of communication nor substantiated its existence. The primary finding of this section is that such a communication network exists but that it occurs on an ad hoc rather than systematic basis. This research also demonstrates the importance of various specific communication mechanisms to state public health officials for the transfer of policy and programmatic information.

Secondly, this research addresses the possible differences between legislative and bureaucratic policy adoption. Using OLS regression, two different models of the determinants of policy innovation are tested. A comparison is made between legislative adoption of policy and bureaucratic adoption of policy. The central finding is that the determinants of legislative policy adoption do different from the determinants of bureaucratic policy adoption.

This research demonstrates the importance of examining policy innovation and transfer from the perspective of multiple political and policymaking institutions, in particular, the bureaucracy. It also broadens our understanding of the coalitions of policymakers that exist that create U.S. state public policy. 


\section{Acknowledgements}

I first became interested in this research in a seminar on state politics and policy under the tutelage of my first dissertation director, Chris Mooney. When he left West Virginia University, I continued working with Don Studlar. I wish to thank them both for their endless conversations, guidance, and encouragement.

I also appreciate the assistance and time contributed by other committee members, fellow graduate students and faculty at West Virginia University, and comments by various colleagues at professional conferences. 


\section{Dedication}

I dedicate this work to my family, Kenneth, Marietta, and Carrie, whose endless patience and love have sustained me. I also wish to thank all the friends and family who have walked the journey with me. 


\section{Table of Contents}

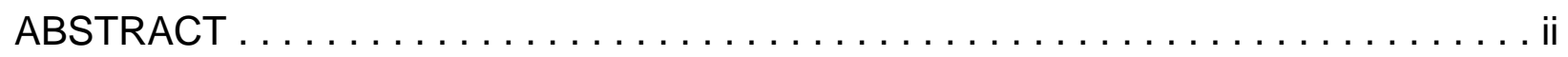

ACKNOWLEDGEMENTS $\ldots \ldots \ldots \ldots \ldots \ldots \ldots \ldots \ldots \ldots \ldots \ldots \ldots \ldots \ldots \ldots \ldots i i$

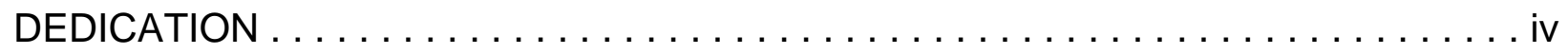

LIST OF TABLES $\ldots \ldots \ldots \ldots \ldots \ldots \ldots \ldots \ldots \ldots \ldots \ldots \ldots \ldots \ldots \ldots \ldots$

LIST OF FIGURES $\ldots \ldots \ldots \ldots \ldots \ldots \ldots \ldots \ldots \ldots \ldots \ldots \ldots \ldots \ldots \ldots$ vii

CHAPTER ONE: INTRODUCTION $\ldots \ldots \ldots \ldots \ldots \ldots \ldots \ldots \ldots \ldots \ldots \ldots$

CHAPTER TWO: THE ROLE OF THE BUREAUCRACY IN POLICYMAKING $\ldots \ldots 23$

CHAPTER THREE: LITERATURE AND THEORY ON POLICY TRANSFER . . . . . . 50

CHAPTER FOUR: THE PROFESSIONAL COMMUNICATION NETWORKS

OF STATE BUREAUCRACIES . . . . . . . . . . . . . . . . . . . . . . . 110

CHAPTER FIVE: AN EXPLANATORY MODEL OF STATE PUBLIC HEALTH

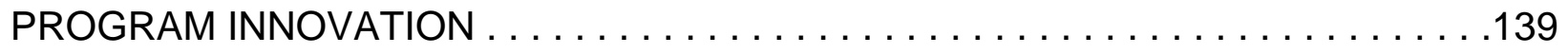

CHAPTER SIX: CONCLUSION . . . . . . . . . . . . . . . . . . . 161

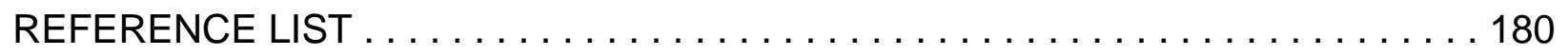

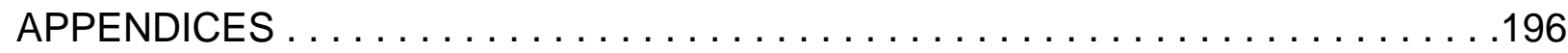

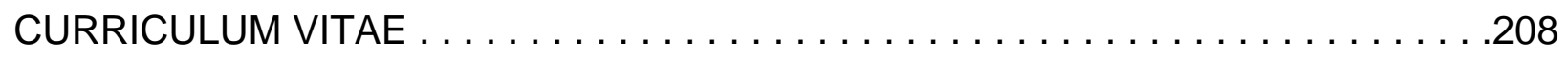




\section{List of Tables}

Table 4-1: Mechanisms for Sharing of Information on Public Health

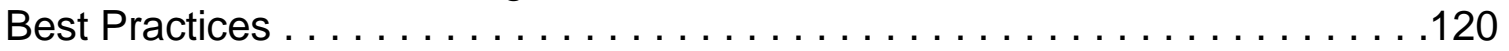

Table 4-2: Types of Information Shared by Telephone and E-mail . . . . . . . . . . 124

Table 4-3: Meetings/Conferences Attended by 30\% or more of Survey Respondents in a Functional Area . . . . . . . . . . . . . . . . . . . . . 126

Table 4-4: Journals, Newsletters, and Publications Read by $20 \%$ or more of survey Respondents in a Functional Area . . . . . . . . . . . . . . . . . . . 129

Table 4-5: Sources of Information on Public Health Best Practices . . . . . . . . . . 131

Table 4-6: Most Important Sources of Information on Best Practices . . . . . . . . . 134

Table 5-1: State Health Innovation Index . . . . . . . . . . . . . . . . . . 141

Table 5-2: Determinants of Legislative Policy Innovation . . . . . . . . . . . . . 152

Table 5-3: Determinants of Bureaucratic Policy Innovation . . . . . . . . . . . . . 155 


\section{List of Figures}

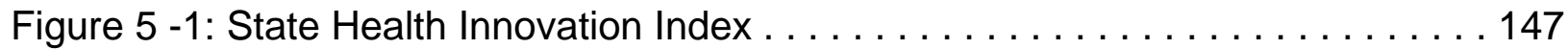




\section{CHAPTER 1}

\section{INTRODUCTION}

The quest for sound, resourceful, public policy has been the goal of both elected and appointed officials of government as well as active citizens throughout our history. Because it is a core governmental activity, it has held the attention of numerous political scientists who have attempted to explain the policy process from many different perspectives and consequently to develop theories of the policymaking process. One of these theoretical perspectives examines policy innovations (the adoption of new programs) and how these innovations are shared or transferred to other government jurisdictions. This area of research is commonly called policy transfer or policy innovation and diffusion.

In this study, I develop a theory of policy innovation and diffusion that focuses on the role of the bureaucracy, in particular state public health departments, in this policymaking process. As part of this study, I explicitly examine the professional communication networks of the bureaucratic elites of these departments since a presumption exists that policy information is communicated among and to them as part of this process. I also compare two models of policy transfer, one for state legislators and another for state bureaucrats, to determine if the process differs from one institution to another.

\section{Organization of the Study}

In this chapter, I describe the research question of the study and three particular foci that, I argue, are important aspects of the bureaucratic role in policy innovation and 
transfer. These areas are professional networks, administrative capacity, and intergovernmental relations. In the second chapter, I present some of the research literature and theories that look at the role of bureaucracies in the policymaking process. Chapter 3 is an extensive discussion of the theories and literature on policy innovation and transfer, both comparative U.S. states and comparative nations. Based on surveys of state health department administrators, chapter 4 describes the professional communication networks that provide the mechanism for the transfer of policy and programmatic information. The next chapter asks whether the determinants that explain policy transfer and innovation among state legislatures are also found to be important when the institutional focus changes to state agencies. Included is an OLS regression model to quantify this comparison. The final chapter concludes with a restatement of the primary findings of this study and suggestions for future research.

\section{The Study of Policy Innovation and Transfer}

There is a long tradition of U.S. state policy diffusion research that examines the "borrowing" of one state's policy by another (for example, Berry \& Berry, 1990, 1999; Canon \& Baum, 1981; Gray, 1973a; Mintrom, 1997; Mooney, 2001; Walker, 1969). U.S. states, because of their large number and relative comparability of government form and policy actors, present an ideal opportunity for empirical analysis of policy transfer. The unit of analysis for most of the body of work on policy innovation and transfer is a governmental jurisdiction. However, some of the more recent studies have examined the behavior of individuals as policy entrepreneurs (e.g., Mintrom, 1997). This area of study is of interest to political scientists because it not only has theoretical 
but also practical implications. Policy transfer provides an important policy development tool for state administrators because it germinates policy ideas and it serves as a way of evaluating likely program outcomes before implementation occurs. Therefore, practitioners as well as academics can utilize findings in this area.

Like any policy process, policy transfer will involve a multitude of policy actors. While several studies have examined the role of the legislature in state policy innovation and diffusion, few have considered the bureaucratic role. The resulting lack of information has led to a focus on legislative adoption of policy while neglecting the important role that bureaucracies play in both agenda setting and program/policy development (Elling, 1999). This study examines the role of state bureaucracies in policy innovation and transfer.

\section{Research Question}

The central question of this research is, "What is the role of the state bureaucracy in policy innovation and transfer?" The bureaucracy has been a neglected policy actor in previous state policy transfer research. This research will examine the bureaucratic role in the policy transfer process in state health policy. The exclusion of this important actor is of special concern in health policy because states are so predominant in this area (Leichter, 1997). Because it is a fairly technical area, much of the decision-making about policy is delegated to the state bureaucracies. A focus on health policy will also provide empirical evidence of professional communication networks in these communities and consider the differences between legislative and bureaucratic policy transfer. 
Many terms are used to describe a policymaking process where the policies of other political entities are studied in a search for solutions to problems. Variously called policy transfer, diffusion, learning, or lesson-drawing, these terms represent a general phenomenon with some difference in the precise definition and exact process being studied by the researchers. For the purpose of this study, a general definition can be used that is perhaps best clarified by Rose (1993). Rose prefers the term "lessondrawing" which he describes as an analytical search for "a program for action based on a program or programs undertaken in another city, state, or nation, or by the same organization in its own past" (p. 21). He emphasizes that the search is for practical, action-oriented programs that are meant to produce desirable outcomes as the result of action by government officials. A critical factor, he believes, is the fungibility or the transferability of programs. Without this quality, programs lack a critical element essential to lesson drawing.

\section{Theories of Public Policy}

Various theories exist that explain variation in public policy among U.S. states (Anderson, 2003). One of the most important foci for comparative U.S. state research has been the effect of socioeconomic conditions among the states, in particular the level of available resources (e.g., Dawson \& Robinson, 1963; Dye, 1979; Nice, 1994). The importance of institutional factors has also been an area of study. For example, variation in the strength of governorships (Bernick, 1979; Beyle, 1968; Dilger, 1995; Sigelman \& Dometrius, 1988) and in state legislature professionalism (Karnig \& Sigelman, 1975; Miller, 1965; Ritt, 1973) both have been demonstrated to have an 
effect on policy outcomes in states. In comparative U.S. state research, the role of political culture is often included as an explanatory variable in studies of policy variation (Almond \& Verba, 1965; Elazar, 1984) as is the role of political ideology (Erikson, Wright, \& Mclver, 1989). Interest group theory also contributes to our understanding of public policy variation (Brace, 1988; Browne, 1985; Gray \& Lowery, 1988; Nownes \& Freeman, 1998; Wiggins \& Browne, 1982). All of these theories offer different descriptions of the process by which state policy is made.

Those who study policy transfer have also made important contributions to our understanding of variation in state-level policy in terms of policy outcomes. Although the theoretical contributions of these lines of inquiry are important, they are sometimes limited because the focus on the determinants of policy outcomes leaves out the dynamic aspects of the policy process.

\section{Substantive Importance of the Research Question}

The United States is undergoing a transformation in intergovernmental relationships. Under the current trend of devolution, the federal government is deferring to state government for the development and administration of many programs. The role of state-level political actors is becoming more important as major social programs are designed, implemented, and evaluated at this level of government (Leichter, 1997).

A critical underlying concept of devolution is the role of individual states as "policy laboratories." Past federal programs were often laden with extensive, detailed requirements for states in the administration and implementation of specific programs. In recent years, however, states have been given more latitude in how programs will be 
carried out given their particular requirements (Brown, 1998). For example, most states now have multiple waivers that allow them to offer differing versions of the Medicaid program. Under these conditions, many variations of a given program exist at the same time. This type of policy and administrative environment encourages the transfer of programs and policy information among states. One of the assumptions of policy transfer is that as these deviations development, states will begin sharing programmatic and policy information with one another, perhaps leading to policy transfer.

Another important factor that has contributed to the idea of states as laboratories of change is the growing capacity of state government (Bowman \& Kearney, 1988; Fox, 1997; Leichter, 1997; Reeves, 1990). Over the past two decades, state government has grown in size, scope, and maturity. Governors, state legislatures, and state bureaucracies have become better equipped to develop solutions to problems that exist within their boundaries. Thus, instead of "looking to Washington" for direction, they develop new programs or policies that take into account their own particular economic, political, and social circumstances.

In recent years, due in part to an economic downturn, most states have faced a serious fiscal crisis. In addition, rising health care costs and increasing responsibilities to provide a minimal level of health care to some citizens, especially children, have further exacerbated problems for state government. Because of balanced budget requirements, states are in the unenviable position of being asked to provide social services to a large segment of their population just when revenues are declining. States have often risen to the challenge by adjusting budgets and searching for solutions to 
problems that are more economical. Policy transfer is one of the ways that state administrators search for answers to these problems.

States also have become more adept at "looking across the border" when considering possible solutions to problems. Lesson-drawing (Rose, 1993) is a common response for a state searching for policy alternatives. States often examine the ways in which other states have developed programs that address similar problems or needs as those that they are facing. Both positive and negative lessons can be learned from such a process. While programs can often be transferred from one state to another, adaption that takes into account the particular nature of the adopting state is essential. This phenomenon is called "policy reinvention" (e.g., Glick \& Hays, 1991).

\section{Sources of Policy Transfer}

According to Rose (1993), policy borrowing begins with both common problems and experiences. Rose, as well as other researchers, has described various mechanisms of policy transfer. A full discussion of these mechanisms is beyond the scope of this paper. However, a few examples of the communication of policy ideas will be given in this section.

Policy transfer occurs in all branches of state government. Numerous resources which provide information on "model programs" or "model legislation" are available to state officials. For example, the Council of State Governments identifies "creative approaches to significant state problems" through its Innovations Awards program (Council of State Governments, 2004). The National Governors Association adopts policy statements at its meetings and focuses on particular issues common to many 
states through its Center for Best Practices (National Governors Association, 2004). Another organization that "fosters interstate communication and cooperation" is the National Conference of State Legislatures (National Conference of State Legislatures, 2004). While each of these groups serves a different branch of state government, they all share a common purpose. Each group provides resources that aid in the communication of policy and programmatic ideas that have been used by various states. In addition to these professional associations, federal agencies also sometimes provide model state legislation. Among the agencies doing this are the Office of Advocacy, Small Business Administration, and the Federal Railroad Administration, Department of Transportation. Specific professional associations for state health officials, such as the National Association of Public Health Laboratory Directors, also serve as a conduit for the sharing of programmatic and policy information among states. Interest groups also frequently develop and promote model legislation or policy for state government. These groups may be organized by a particular profession, regional area, or ideology. A recent search on the Internet for model legislation identified such diverse groups as the American Civil Liberties Union, the American Academy of Pediatrics, and the Maritime Law Association of the United States. Other examples of organizations that provide model legislation are universities (The Center for Law and the Public's Health, Johns Hopkins University), unions (American Federation of State, County and Municipal Employees and the AFL-CIO) and non-governmental organizations (The National Alliance for Model State Drug Laws). These are all 
examples of groups that have developed model legislation for states as a way of promoting particular policy agendas.

\section{Professionalism and the Capacity for Policy Transfer}

One of the key questions of the current research is, is professionalism important to policy transfer among state bureaucracies? The existence of ideas or sources for policy transfer does not necessarily mean that such policies will be adopted by states. In order for policy transfer to occur, a state must have the capacity to carry out new or innovative programs. One aspect of this capacity is professionalism of governmental institutions. Numerous researchers have used the term, professionalism, to describe composite measures that reflect the capacities of a particular institutional actor. Examples include state legislative professionalism (Squire, 1992; King, 2000), administrative professionalism (Sharkansky, 1971; Grady, 1999), and state judicial professionalism (Vines \& Jacob, 1971). In a study of local government innovation, Bingham (1976) found that four aspects of the environment in which a government operates affect innovation: intergovernmental resources, professionalism, private sector influence, and slack resources availability. This study will focus primarily on the second, professionalism, as it relates to professional communication networks.

\section{State Administrative Agencies}

The role of state administrative agencies in the formation of public policy is increasingly important (Bowling \& Wright, 1998). Over the past thirty years, state agencies have grown in quality. Well-educated, experienced professionals head most agencies. The growing capacity of state administrative agencies is a function of both 
institutional (macro) and personal (micro) characteristics. Not only are state agencies being asked to do more, they are now capable of doing more.

Policy transfer often involves a number of key people and groups (Dolowitz, 1996). However, any occurrence of policy transfer will ultimately involve the bureaucracy through the implementation process. A principal, such as the governor or state legislature (or sometimes the federal bureaucracy or legislature), may direct the bureaucracy to implement programs that have been borrowed from other jurisdictions. In other instances, the bureaucracy may be the instigator of policy innovation and/or transfer (Anderson, 2003). The professional networks that develop among bureaucrats of similar agencies across state lines also represent a resource that facilitates the policy transfer process (Dolowitz, 1996). Thus, it is important to consider the factors that explain the bureaucracy's role in policy transfer.

The basic assumption of policy transfer is that states sometimes adopt certain policies because they have been used to solve similar policy problems in other states (Rose, 1993). The existence of policy alone is not sufficient for transfer; there must also be a mechanism for the sharing of knowledge and information among jurisdictions and policymakers. This enables states to acquire knowledge about the policies of other states and consider the adoption of such within their own state.

The specialization and common knowledge base that is found in state bureaucracies is conducive to this process. State health officials can attend a number of conferences, read professional journals, and build informal relationships that facilitate the exchange of policy information. Professional organizations are often important 
facilitators of this diffusion of policy innovations (Gray, 1973a; Welch \& Thompson, 1980). Chi and Grady (1991) have found that the lateral transfer of information between state administrative officials is an important source of information on innovative policies. The same level of specialization, however, is not found in state legislative committees. Nor do legislators have the extensive policy specialists available on their staffs that are available to agency heads. There are few, if any, opportunities for all state legislative health committee heads to interact with one another. The lack of narrow, policy specific rather than more general, legislative professional associations inhibits the opportunities to share policy information with other states.

Gill (1995) has described various models of legislative/administrative interaction. Generally, these models portray a symbiotic relationship between the legislature and the bureaucracy with the legislature having budgetary control and the bureaucracy having varying levels of discretion. All of the models acknowledge the role of agencies in agenda setting, although to differing degrees.

Of special interest is the Miller and Moe model (cited in Gill, 1995). They argue that an agency's power comes from its technical expertise and possession of information. This is especially true in functional areas that are highly technical, such as health policy. Mosher (1982) describes the bureaucracy as becoming increasingly filled with professional elites. According to Mosher, most agencies (like health bureaucracies) have a single occupational group (in this case, medical doctors) whose special skills and knowledge are essential to the organization. Because of the close connection between the agencies and the professional organizations of these elites, the 
two tend to influence each other. Therefore, this model helps to explain why technical agencies such as state health offices have a greater level of power over the legislature when determining policy.

The functional specialization that occurs in a bureaucracy is especially conducive to policy transfer (Rose, 1993). Agency heads are likely to be much more interested in the activities of their counterparts in neighboring states than in the activities of other functional areas within their own state (Sharkansky, 1970). This relationship is partly based on physical proximity but is also related to an attitude, on the part of these administrators, that those working close by are likely to have similar problems and circumstances. State agencies become an important part of policy communities who actively and regularly exchange information about policy ideas (Robertson \& Waltman, 1993; Sharkansky, 1970). This policy specialization is one of the major components of bureaucratic power in the policymaking process (Meier, 1993). The acquisition of bureaucratic power is one of the reasons the bureaucracy can be an active policymaking actor.

Fiscal federalism in the United States is often called "picket fence federalism" (Sanford, 1967; Wright, 1988). Driven by the federal grant-in-aid system, coalitions develop among administrators at different levels of government who are working in the same functional area. Once these alliances or subsystems develop, they combine professional with administrative expertise to dominate the functional area. The creation and continued development of these coalitions is further encouraged by the dispersion of power that exists in the American political system (Walker, 1981). Because it is 
difficult to maintain cohesive and powerful political parties in the decentralized and fragmented U.S. system, policy coalitions often dominate the policymaking process. These coalitions are sometimes portrayed in a negative light because they restrict entry through information control (often to the very legislators who approved and funded the programs). These very same coalitions, however, are likely to facilitate policy transfer, since they are in frequent contact, share similar professional norms, and deal with similar problems within the parameters of the shared federal/state policy system.

\section{Hypotheses}

The basic model of this research is one that incorporates three factors to explain the state bureaucracy's role in policy transfer. These factors are professional networks, administrative capacity, and intergovernmental relations.

\section{Professional Communication Networks}

Professional communication networks have become increasingly important to both government and the private sector. Globalization and the ever-expanding development of communication technologies are two driving issues that shape both industry and government. With these developments come challenges for government, including states, as they seek to respond to a rapidly changing world. The growing focus on technocrats requires specialization and sophistication within state bureaucracies. These factors, specialization, a rapidly changing environment, and communication technologies, lead to a need for communication among bureaucrats within a common policy area. 
According to Mintrom and Vergari (1998), one of the limitations of current research in policy innovation and transfer is the separation that has developed between the study of policy transfer and policy networks. Berry and Berry (1999) assert that policy transfer research that is based on a national interaction model assumes the existence of a national network of state public-sector officials who communicate with one another on new policy adoptions. One of the most important avenues of communication is through "professional forums" (Walker, 1981, p. 79). Communities of policy experts (many of whom are administrators of agencies) frequently exchange information about ideas and activities. Some of this activity occurs through formal associations of state officials that allow for interaction at national conferences. This is especially true for health policy, which is a highly professionalized and specialized area (Peterson, Rabe, \& Wong, 1986).

\section{Administrative Capacity}

The communication of policy information, however, does not automatically lead to innovation within a state. The administrative capacity to make policy changes must also exist. One finding of the state policy transfer research is the importance of socioeconomic explanations for policy variation among states. In general, the finding is that states with greater income and wealth are more likely to be early innovators. Often this is described as states with higher levels of "slack resources" (Nice, 1994; Rogers, 1983). While these studies focus primarily on financial resources, I believe the argument can be taken a step further and include other resources such as personnel levels and characteristics of state policy elites which make them better able to deal with 
technical issues and policy information. This more extensive measure can be termed as "administrative capacity" (Barrilleaux \& Berry, 1996; Grady, 1996). It is expected that states with high levels of administrative capacity will be policy innovators.

\section{Intergovernmental Relations}

States rarely work independently while developing programs and policy. Very little policymaking occurs outside of the interdependent, federal structure of American government. Thus, any study of public policy should consider the intergovernmental relationships, in particular fiscal ones, which shape U.S. public policy.

Berry and Berry (1997) describe one particular model of policy diffusion as the "vertical influence model." In some situations, they argue, states emulate national government policies rather than the policies of other states. According to the authors, the national government can be thought of as a widely respected state leader. The authors dismiss federal-mandated policy as uninteresting since state discretion (and variation) is eliminated. They are interested, however, in situations where states retain discretion but the federal government provides incentives for policy adoption. If this were true, it would be expected that states with high levels of intergovernmental aid will be policy innovators.

As evidenced by this examination of literature, the bureaucracy plays a variety of roles in the policymaking process. The growth of bureaucratic power, primarily due to delegation of authority from Congress and the president, in combination with the expertise of agencies and their officials, is extensive. This power and expertise allows the bureaucracy to be an important, sometimes independent policymaker. The purpose 
of this study is to frame bureaucratic policymaking and bureaucratic power within the context of policy transfer and innovation.

\section{The Importance of Health Policy}

There are many reasons why health policy is an important area for study. First, it represents a major component of public policy at both the national and state and local levels. Second, health care spending consumes an ever-increasing portion of our nation's resources and has a major impact on both individual, corporate, and government budgets. Health policy is also a key component of intergovernmentalism, particularly of fiscal federalism. Finally, in recent years, health policy has experienced many changes, in part due to the rising costs and government's attempts to maintain equity for citizens within this changing system (Rushefsky, 2002).

First, health policy stands as a primary functional area of public policy for both the national and state government. It is also part of a broader system of social policy that has an impact on a broad array of social and economic issues within the United States. In the United States the health care system is structured as a private, marketplace driven system that is financed through an array of mechanisms, including government-sponsored insurance for particular groups. This means that health policy decisions, particularly those related to provision of health care, are interwoven through the entire economic and governmental policy arena.

Public health and health care spending plays a very important role in both state public policy and, in particular, in state budgets. Nationwide, 15 percent of the gross domestic product is spent on health care. Health care is the largest service industry in 
the United States and is the second largest industry, second only to durable goods manufacturing (Kronenfeld, 2002). Almost half of this spending is from public sources with private insurance and individuals paying the rest. On average, U.S. states spend almost $\$ 4,000$ per capita on health care (Kaiser Family Foundation, 2005). Among the primary functional areas of state budgets, health care ranks second only to spending on public education (National Association of State Budget Officers, 2004). Medicaid is the highest single area of state spending having recently surpassed the amount states spend on K-12 education.

At their 2005 winter meeting, the nation's governors brought attention to what they consider the most pressing problem for state government, the ever-increasing burden of Medicaid expenditures on state budgets (National Governors Association, 2005). Overall in fiscal year 2003 , over $21 \%$ of state expenditures were made to support the Medicaid program (National Association of State Budget Officers, 2004). In some states, such as Missouri and Tennessee, Medicaid accounts for almost one-third of state expenditures. Because Medicaid is a means-tested entitlement program, growth in the expense of this area is very difficult to control. Like private insurers, citizens, and employers, states must deal with health care expenditures that are growing at a significantly higher rate than that of inflation and consequently of revenues. At the same time that states have faced growth in expenditures to provide services, the federal government has shifted more of the burden of financing this program to them. Because third-quarters of these expenditures are made to the elderly, in part due to the rising numbers of elderly and their need for long-term care, this program threatens to 
consume larger and larger percentages of state operating revenues. In addition, another nine percent of state budgets went towards health care programs in fiscal year 2003. The government, both federal and state, has made numerous attempts to control the cost of health care in America. However, recent attempts to do so primarily by costcutting measures in the Medicaid and Medicare programs have only been successful at slowing the rising costs.

Health policy is a prime example of the interdependence of state and federal government, in particular as it relates to fiscal federalism. Like many government policy areas, service provision occurs through a mixture of state and federal programs. Many public health programs are either federally funded or are a combination or state and federal funds. Examples include programs for immunization, maternal and child health, health insurance such as SCHIP and Medicaid, and environmental health. Often, although not always, the direct service provision is made at the state and local level with funding provided by both state and federal government, often through categorical grants.

According to a 2002 report by the Institute of Medicine, "an effective public health system that can assure the nation's health requires the collaborative efforts of a complex network of people and organizations in the public and private sectors, as well as an alignment of policy and practice of governmental public health agencies at the national, state, and local levels" (IOM, p. 96). However, the assessment of this report is that the public health network as currently configured is weak. In particular, it issues an indictment of the existing public health infrastructure because it failed to provide the 
necessary protection needed in light of growing concerns of bioterrorism and newly emerging and re-emerging diseases and conditions.

In 2003, the Centers for Disease Control and Prevention (CDC) launched a "strategic process" called the "Futures Initiative" in part to respond to some of these criticisms (Centers for Disease Control and Prevention, 2004). As part of this initiative, the organizational structure of $C D C$ was redesigned to focus on a return to the core values of public health and prevention. In addition, it continued to recognize the shared governance of public health policy between federal and state and local partners. This is especially true with the growing emphasis on bioterrorism issues. This report states that CDC has only two core goals one of which is "people in all communities will be protected from infectious, occupational, environmental, and terrorist threats." This statement demonstrates the importance of public health policy not only as a governmental activity but also of broader significance as it intersections with other policy areas in the U.S. such as environmental policy, domestic security, and labor/economic issues. Another focus of the organizational restructuring was a return to serving public health partners, the most important of which are state and local health departments.

Another aspect of this report describes CDC's new "strategic orientation." Many aspects of this new orientation are particularly germane to policy communities and networks, the topic of this research. Some of these orientations include to:

- Inform and guide health system actors

- Focus on partnerships and strategic alliances

- Provide incentives for participation and cooperation 
- Engage a full array of health system actors, including communities and the private sector.

The refocusing of interest and emphasis within the public health community on partnerships demonstrates the vital role of state and local health departments in both the creation and delivery of public health policy.

\section{Research Methodology}

The U.S. states make an ideal population for the study of policy variation. In comparison with nations, the states provide a much larger database for which many important characteristics do not vary (such as national government structure, economic system, etc.). This eliminates some of the explanatory variables that might exist for variation in national policies. The large number of cases increases the types of statistical techniques that are available for analysis. This very benefit, however, has limited the richness of comparative-U.S. state policy transfer research - a distinction that is characteristic of comparative-national policy transfer research.

This study uses a three-fold approach, both qualitative and quantitative, to study professional communication networks in state public health bureaucracies. First, exploratory analysis was conducted by interviewing over 30 state public health agency professionals. These professionals represent state health directors and department heads of all seven functional areas common to state health agencies. In addition, one or two federal officials were interviewed whose departments paralleled each of the seven functional areas. 
This qualitative research was followed with a mailed survey (Appendix B and C) sent to eight officials in all 50 states (state health directors and heads of the seven functional areas). With this survey, information was gathered in the following areas: sources of programmatic and policy information, professional background (educational and work experience), association memberships and conference attendance, and people who are sources of policy ideas. Since retrospective gathering of data would be difficult and highly biased, this portion of the data is static. Documentary data were also collected from a variety of sources to test models of policy transfer using OLS regression analysis.

The unit of analysis for this study varies. During elite interviews, respondents were asked questions about both themselves (individual-level analysis) and their state. The professional network information, which was gathered through surveys, uses the individual bureaucrat as the unit of analysis. The unit of analysis is again the state for the third phase of analysis, a regression model using primarily documentary data. In combination these different elements of research are used to develop a picture of how bureaucracies play a role in policy innovation and transfer.

\section{Expected Findings}

In this study, I plan to bring attention to the role of state bureaucracies in policy innovation and transfer. Because members of state bureaucracies are relatively accessible in comparison to some political actors and policymakers, a study of this type should yield new insights into the policy transfer process among U.S. states. Chapter 2 describes some of the theoretical literature that depicts the bureaucratic part in 
policymaking and builds an argument that the bureaucracy should be an important consideration in the study of policy transfer. Chapters 4 and 5 do so, by describing the communication networks of state bureaucracies and by comparing the bureaucratic role with state legislatures in policy transfer.

In chapter 3, I bring together two bodies of literature that although working within the same theoretical framework are often not found juxtaposed. There is a disconnect within the body of literature between comparative U.S. state and comparative national policy innovation and transfer studies. Rarely do researchers in either of these areas use findings from the other to inform their own work. Although rich in detail, studies that examine policy transfer between countries often focus on the differences in economic, political, and social factors that might account for the transfer of policy between political units. The policy transfer research on American states has been centered primarily on geographic diffusion in recent years. Both areas of study have generated numerous hypotheses on the mechanisms of policy transfer. Yet few offer empirical evidence to test these theories. Based on hypotheses generated from this combined literature, I examine policy transfer in U.S. states.

This study will build upon previous research on policy transfer by focusing on a novel angle - bureaucracies in the U.S. states and those administrators that populate them. It brings a novel dimension to our understanding of policymaking and the role played by policy transfer. It will also demonstrate the importance of studying a broader policy area, public health, rather than focusing on the adoption of a single program or innovation. 


\section{CHAPTER 2}

\section{THE ROLE OF THE BUREAUCRACY IN POLICYMAKING}

The Founding Fathers paid scant attention to the administration of the state enterprise when writing the U.S. Constitution. Some of the responsibility for the day-today operation of the national government was given to the President while other tasks were reserved for Congress. For example, the President was given authority to make treaties with other nations, serve as Commander in Chief of the Army and Navy, and appoint ambassadors and judges. Congress had authority to raise revenue and spend it, pass the nation's laws, and declare war. Between the two, Congress was seen as the predominant branch with primary responsibility for administering the acts of government. Nevertheless, in some of its earliest actions Congress began to delegate authority to the President. For example, they allowed the President, and consequently his agents, to conduct trade with Native Americans tribes (Kerwin, 2003).

Citizens did not hold in high esteem the small, limited national bureaucracy that existed at that time (Wood \& Waterman, 1994) preferring to deal with longer-standing state governments. However, under the new structure of stronger national government, increased responsibilities and authority began to develop. It quickly became apparent that even a limited federal government would require more than a few presidential advisors and secretaries to carry out governmental activities. As the state apparatus grew in scope, size, and complexity, the bureaucracy became an equal, if not superior, partner with the President and Congress - often referred to as the "fourth branch of government." 
In this chapter, I will describe some of the predominant theories of how and why bureaucracies play a role in policymaking. It begins with a discussion of the sources of bureaucratic power. This is followed by information on administrative capacity, state administrative agencies and authority, and policy networks. The chapter closes with an examination of some of the roles of bureaucracy in policymaking: policy implementation, expertise and specialist, rulemaking, regulation, and adjudication.

The literature on bureaucratic policymaking and the interplay between executive agencies and the other branches of government is extensive. It primarily examines these relationships at the national level. It can be argued, however, that the basic national structure of division of authority among branches is quite similar to that found in U.S. states. This includes a system of checks and balances, a chief executive who directs agency actions, a legislature that delegates authority to agencies, a judiciary that provides oversight and review, and an extensive bureaucratic structure that is an active partner in governing. Thus, it should be possible to extrapolate many of the theories and findings of this literature to state government.

\section{Bureaucratic Power}

Numerous researchers have argued the importance of administrative agencies as both formal and informal policymakers. This area of research has demonstrated the limiting nature of the politics/administration dichotomy (Wilson, 1887; Goodnow, 1900) that views the bureaucracy as a neutral policy actor that simply implements the political decisions of the legislative branch. From the early work of Truman (1955) and Dahl (1956) to the more recent work of Meier (1993), Hill $(1992,1995)$, and Anderson (1997), 
researchers have portrayed the bureaucracy as an active participant in the political process. In fact, some (Yates, 1982) argue that the bureaucracy is essential to the democratic process in pluralist societies.

In order to study the role of bureaucracies in policy transfer, it is important to understand the sources of bureaucratic power and authority in the policy process. An underlying argument of this research is that bureaucracies are not only influential in policy transfer but are also likely to predominate the process.

Meier (1993) presents five primary sources of bureaucratic power: "policy environment, public support, the bureau's special knowledge, the cohesion of bureau personnel, and bureau leadership" (p. 57). He indicates that the latter four will have differing levels of significance in different agencies depending on that agency's policy environment. In the context of the current study, all of these potential sources of power are important because they represent components of the bureaucracy's influence in a policy network. In order to assess the characteristics of particular bureaucracies that contribute to policy learning (a specific aspect of policy formulation), it is important to understand how bureaucracies influence policymaking.

Meier finds that much of the policymaking influence of bureaucratic agencies is rooted in the discretion given to them by legislatures. Policymaking influences are especially strong in distributive bureaus such as those found in federal health agencies. He argues that "distributive bureaus ... can become so powerful that they not only dominate policy implementation but also control the policy initiation stage" (p. 106). This argument is crucial to the current study. Policy transfer by health agencies is only 
important if they actually influence both the political agenda and actual program operations.

Rourke (1984) argues that administrative power is based on two basic resources: possession of a body of knowledge and the ability to mobilize a constituency. With respect to policy transfer, the policymaking power that originates in information possession is very important. According to Rourke, this expertise is especially critical to the influence of the professional employees of a bureaucracy, as opposed to the political appointees. He finds that the bureaucratic role in policymaking is not only a result of technological expertise. It is also a function of bureaucrats' knowledge of "how to work the system." They generally are very familiar with the internal workings of the agency as well as cognizant of the other political actors within their issue space.

One of Rourke's important findings is that bureaucrats within agencies have highly developed skills and that their primary loyalty is to their profession with a secondary allegiance to their organization. If bureaucrats are found to be instrumental in the policy learning area, these professional orientations are likely to have a profound effect on both the formation and communication of policy information. Rourke concludes that much of the innovation and creativeness within a bureaucratic agency come from professionals. One characteristic of this innovation is that the bureaucracy provides a "setting in which experts in and out of government can get together to work on policy problems. Sometimes this exchange occurs long before these problems become legislative issues or matters of public debate" (p. 151). Rourke portrays the predominance of expert bureaucrats as not only descriptive but also as necessary. He 
finds that provision of honest technical advice is the most important role of bureaucracy in the policymaking process.

In a similar vein, Anderson (1997) supports the view of administrative agencies as formal policymakers. He states:

especially in complex, industrial societies, the technicality and complexity of many policy matters, the need for continuing control of matters, and legislators' lack of time and information have caused the delegation of much discretionary authority, which often includes extensive rulemaking power, to administrative agencies. Consequently, agencies make many decisions and issue many rules that have far-reaching political and policy consequences. (p. 66)

These descriptions seem to be especially applicable to health agencies because of the complexity of information needed to understand the medical field and to consequently formulate programs and policies.

Meier (1993) describes the growth of bureaucratic power as a natural occurrence, a result of the increasingly complex nature of society. He argues that legislatures have been forced to turn to bureaucracies for their expertise. This is both a function of the complexity of information necessary to formulate policy and the increasing public demand for government action on social problems.

\section{Factors Leading to Bureaucratic Policymaking}

Much of the growth of the bureaucracy can be attributed to two factors, the delegation of Congressional authority and conflict between the President and Congress for control of the bureaucracy. Congress has found it necessary, or at least prudent, to 
continue to delegate much authority to agencies (Wood \& Waterman, 1994). Despite the decentralization of Congress into ever more narrowing subspecialties, individual members of Congress, especially in the House of Representatives, must remain policy generalists with at least a surface knowledge of many different policy areas. They must also address the demands of constituencies that are local rather than national in focus. The result is often vague, general legislation that authorizes and funds programs but leaves programmatic and implementation detail to executive agencies.

Elected officials in recent years often argue that "government," meaning the bureaucracy, has grown too large and should be reduced. Whether this is simply political rhetoric to win campaigns or is actually occurring is an empirical question. The evidence on this topic is mixed. One group of researchers (Hill, 1995; Rourke, 1984) believe that bureaucracies continue to be strong policymakers that evolve and reinvent themselves in response to political pressures to sublimate their role, and that attempts to restrict bureaucratic power have lead to increased rather than decreased policy dominance by agencies. Other researchers (Gormley, 1989; Wood \& Waterman, 1994) argue that elected political actors have reigned in the growth of bureaucratic power, particularly as independent policymakers. A third group (Durant, 1991) indicate the evidence is somewhat mixed with growth in some areas and less independent policymaking authority in other areas.

Institutional competition between the President and Congress has also contributed to the enhanced policymaking power of agencies (Hill, 1995). Rourke (1993) argues that this competition between branches of government for bureaucratic 
control is a major component to understanding the creation of public policy. According to Rourke, this rivalry for control of the bureaucracy was purposively created by the Founding Fathers with the President serving as the chief executive officer but Congress controlling "the extent of their power and the scope of their resources" (p. 687). He argues that they devised a "two bureaucracy" system with three specific agencies (War, State, and Treasury) under presidential control and all other organizations within the sphere of Congress. The balance between congressional and presidential control has shifted throughout our history with either branch dominating at various times. Rourke refers to this power-sharing arrangement as "joint custody." Some of the consequences of this battle for control include a more pluralized White House with its own bureaucratic apparatus, an "increasingly technological" Congress with a large professional staff and research capacity, and a more powerful bureaucracy that is not only shaped by but helps to shape the other two institutions.

Since World War II, both Congress and the President have developed new restraints on bureaucratic power (Hill, 1995). The President has increased the number of political appointees (reaching three levels down within an agency in some cases), chosen "anti-bureaucratic" appointees who often subvert agency programmatic goals, cut budgets, increased the staff of and centralized decision making to the Office of the President, established and substantially increased the power of the Office of Management and Budget, and reformed the civil service system. Congress has selected younger, more policy-focused leadership with less emphasis on seniority, increased the competitiveness of party control in regions of the country (in particular the 
South), developed a powerful system of subcommittee chairpersons, created a "perpetual reelection machine," increased oversight and investigatory powers, and increased the openness and visibility of Congressional actions. Despite these actions, federal agencies have managed to retain much independence and control of policymaking. Wood and Waterman (1993) have put forth one explanation for why these combined efforts to control the bureaucracy have been rather ineffective. They argue that the result of these many changes along with attempts by courts and interest groups to intervene in bureaucratic action has resulted in "multiple principals" whose joint efforts are not summative but sometimes diminutive as they counteract one another. Bureaucracies retain the power to "regenerate political power and seek autonomy" (Hill, 1995) as adaptive organizations with their own vision of democratic purpose.

\section{State Administrative Capacity}

In general, state government has grown in the past decade. In their study of state administration, Bowling and Wright (1998) assert "a revolution has occurred in the administrative establishments of the states over the past five decades" (p. 52). According to Bowling and Wright, this development is important for four primary reasons: (1) the devolution trend of federal to state programmatic control has lead to extensive networks between federal and state agencies; (2) there has been increased state autonomy as the federal government moves more of the locus of control to statelevel decision makers; (3) states have become "laboratories of democracy" that develop variations in public programs as they adapt them to their own conditions; and (4) there 
has been an increasing significance of state administration, the "hidden component of government" (p. 53). The importance of this change is that states have "moved to center stage" (p. 57) serving not only as laboratories of democracy but also as lead innovators in terms of both policy and administration.

State agencies have also grown in size in recent years. From 1985 to 1995, all but two states experienced growth in the number of state employees, in some cases, doubling in size (Elling, 1999). While this growth slowed, it has continued throughout the late 1990's and early 2000's (U.S. Census Bureau, 2004). Moreover, state bureaucracies have become more sophisticated through administrative reorganizations. They have also adopted many management tools (such as Total Quality Management, TQM) from private business that have enhanced their ability to efficiently administer programs (Elling, 1999). Well-educated, experienced professionals head most state agencies. The growing capacity of state administrative agencies, therefore, is a function of both institutional (macro) and personal (micro) characteristics. Not only are agencies asked to do more; they are now capable of doing more.

The implementation of many federal programs is being devolved to state administrative agencies (Bowling \& Wright, 1998). Program finance and implementation responsibility flows from the federal to the state level via administrative agencies, primarily through intergovernmental fiscal transfers. This process essentially bypasses state legislatures. Under these circumstances, state agencies have developed increased capacity through program-specific experience, federal-sponsored training, and linkages among themselves and federal administrators. 


\section{State Administrative Agencies}

In comparison to other U.S. state governmental institutions, the study of state administrative agencies has been quite limited. One of the primary works in this area is that of Glenn Abney and Thomas P. Lauth (1986). Abney and Lauth conducted an extensive survey of state and local administrative officials in the 1980's. The purpose of their study is to "analyze the relationship between state and city administrators and their respective political environments" (p. 1). They find that the characteristics that differentiate state administrators from other political actors are a "mixed blessing" (p. 5). While the expertise and technical competence of administrative agencies contributes to the successful design and implementation of public policy and programs, such expertise also provides a source of independent power and preferences that sometimes differs from political principals such as chief executives and legislators. This means that those principals sometimes find it difficult to direct a sometimes wayward administrative agency and its lead officials. Similarly, the administrative discretion that is characteristic and often acquiring through the consensus-making atmosphere of politics can both aid and impede other political officials.

Abney and Lauth find that agency administrators see themselves as performing a two-fold role. First, they are administrators tasked with the implementation of public programs. However, they are also part of a larger political system and as such must interact with elected officials, interest groups, and constituents. These two tasks required separate skills and foci. While one requires technical, rational decision- 
making, the other requires interaction with the broader governmental system where political considerations become more important.

An important finding of Abney and Lauth's work is that the external (to the agency) political actor that has the most influence on the administrators' "task choice" is the state legislature. They also find that "the more agency heads perceive a need to engage in external relations with such political actors as the governor and legislature, the less likely they are to be able to substitute professional policy preferences for those of elected leaders" (p. 39). This implies that agency officials see policymaking as a cooperative process between themselves and legislatures and that the level of independent policymaking by agency officials may vary from state to state. Governors have less influence than legislatures on agency officials, perhaps because they are inattentive.

According to Richard Elling (1999), "state administrators devote as much as onefourth of their time to policy development" (p. 291). He argues that the politics/ administration dichotomy that posits a distinct separation between the administrative role of bureaucracies and the political role of other government officials is unfounded. While agencies officials are professionals that are expected to perform technical administrative tasks, those tasks cannot be divorced from the political aspects of policymaking. Modern policymaking is a complex task that requires the resources of bureaucratic officials. First, they "know how to best deal with problems" (p. 291). This is a function of both their technical expertise and their knowledge of state government and a state's problems. Second, they are given extensive discretionary authority from 
elected officials. A lack of administrative discretion is both impossible and would be unwise on the part of elected officials. Without discretion, agency officials would find it difficult if not impossible to improve upon policy implementation over time. A third reason, according to Elling, for the influence of bureaucrats upon policymaking is the relationship that develops between agency officials and their clientele. The beneficiaries of state programs often become supporters of the programs and the agencies that are tasked with their administration. Elling finds that state agency officials report that half or more of the legislation that is passed actually originates with the bureaucracy. Both elected officials and agency heads see the policymaking process as one that is improved by the active involvement of state agencies.

\section{Policy Networks}

A number of theories have been developed that describe the networks of actors that are critical to the policymaking process. These theories vary on a number of factors including (1) the actors involved in policy formation; (2) the degree of stability or fluidity of the network; (3) the currency or exchange mechanisms of the network; and (4) the power relationships among the actors. One constant among these theories, however, is that all include the bureaucracy as an important policymaking actor.

Heclo (1978) is one of the first to describe policymaking networks that move beyond the traditional hierarchical structure of government. He finds that coalitions of policy participants form around single, specific issues. He argues that the creation of these "issue networks" is inevitable given the growing complexity and size of government programs, in particular those programs designed to address large social 
issues. Issue networks cross institutional lines but are comprised of people who deal on a daily basis with a specific policy sector. They also represent necessary bridges between branches of government, especially vital in the current climate of party decline. The complexity of current public policy is not problematic for members of the network since they share a common professional identity and language. Because the currency of these networks is information rather than formal power, multiple opportunities exist for even mid-level bureaucrats to offer leadership in policymaking.

According to Ripley (1988), “a large portion of the interaction between Congress and the bureaucracy represents the ongoing activities of subgovernments: clusters of individuals with shared policy interests and easy access to each other who make most routine policy decisions" (p. 339). Ripley views subgovernment policymaking as occurring in the "iron triangle," which is routinized policymaking involving Congressional subcommittees in close relationships with bureaucratic agencies, often with the participation of interest group representatives. Policymaking by these subgroups is dominated by the bureaucratic agencies unless the issue is highly visible or politically sensitive. Ripley argues that the importance of policy networks crosses all areas of policy but is particularly important in distributive policy where governmental resources are given to particular segments of society.

An important element that connects subcommittees with bureaucratic agencies is EACH agency's formal congressional liaison office (Ripley, 1988). The staff members in these offices interact on a regular basis with members of Congress and their staff. Their job is to "sell policy positions favored by the executive branch and to promote a 
sense of congressional confidence in whatever part of the executive branch they are representing" (Ripley \& Franklin, 1987, p. 57). By influencing legislation and the policy aims of Congress from the beginning rather than reacting to a delegation of authority, bureaucrats become proactive policymakers. In fact, this relationship becomes so entrenched that presidents sometimes have difficult imposing their own policy preferences into the system.

Constituent service is one type of activity in which members of Congress and their staffs engage. Although not policymaking in a broad sense, this case-by-case decision-making accumulates into and represents the general policy interests of both the agency and the elected officials. Liaison offices are also quite active when agency officials are asked to testify before Congressional committees. This routinized interaction between agency and Congress supports the basic infrastructure of the policy networks.

Sabatier (1993) finds shortcomings in many of the theoretical frameworks found in the study of public policy and proposes a different view of policy networks that he terms "advocacy coalition." His basic premise is that previous researchers have failed to take into account the process nature of policy. Policymaking, according to Sabatier, is better explained as a process that occurs over time, often a decade or more, with a focus on "the interaction of actors from different institutions who follow and seek to influence governmental decisions in a policy area" (p. 16). His conception is one that recognizes the central focus of intergovernmental interactions and the value systems that are inherent in public policies and programs. This recognition of the importance of 
different institutions and levels of government in the policy process contributes to a broader understanding of how policy is made in today's environment.

In his study of state environmental policy, Ringquist (1993) presents an integrated model of policy influence that identifies the key elements of policymaking as the economic and political characteristics of a state, relevant organized interest groups, and elements of the political system, such as parties, government institutions, and attitudes of political elites. He argues that the political role of interest groups is particularly important at the state level, in part because they generally represent the dominant economic interests in the state and are not as diversified as at the national level. However, the influence of these groups requires the use of government intermediaries to produce public policy. In fact, he argues that government institutions, in particular bureaucracies, provide not only political and management capacity that is integral to policy but also provide a neutral arena where organized groups can reach policy equilibrium. The relationships that develop between agencies and their affiliated clientele groups are critical to the success of government programs.

One of the most influential studies on the policymaking process is by John Kingdon (1995). Kingdon argues that policy gets made when three streams converge: the political, problem, and policy streams. Within the policy stream, bureaucrats are an essential element as one of the chief sources of "solutions." Although not as important as political appointees within the executive branch when setting the agenda, career civil servants are very important to other aspects of policymaking. "Implementation is one major preoccupation of career bureaucrats" (p. 31). Innovation often occurs in the 
day-to-day implementation of programs, particularly when a program is not going well, thus leading to changes. Kingdon also finds that bureaucrats are an important source of program alternatives who are tasked with analyzing the viability of possible solutions.

In general, these researchers present a picture of bureaucracies as vital components of the policymaking network. They are also instigators of policy ideas, program alternatives, and evaluation mechanisms. As such, they not only respond but also initiate public policy.

\section{Bureaucracy as Policy Implementer}

The bureaucracy is the chief implementer of all public policy. Bureaucracies are seen as persistent and dominant, generally uncontrolled by outside forces, and often the chosen instrument for addressing the public's interests (Ripley \& Franklin, 1987). The programs and policies of state government are initiated through either legislative or budgetary action. Legislation initiated by either the governor or the legislature and passed by the legislature is then forwarded to the administrative agencies for implementation. The federal government also relies heavily on state agencies to develop programs and implement policy through the grant-in-aid system (Elling, 1999). No matter what the original source, however, most public policy ultimately passes through state agencies (Bowling \& Wright, 1998).

The role of bureaucracies in policy implementation has been the subject of numerous studies. Lipsky (1968) finds agencies to be crucial in this process. He argues that our understanding of this role should be reversed - that policy is actually made by program implementation rather than the supposed policymakers. Much of this 
is due to the high levels of discretion given to bureaucrats. He refers to them as the primary actors in a "hierarchy of influence" that differs from the assumed "hierarchy of authority."

The role of bureaucracies in policy implementation is examined in the classic study, "The Politics of Policy Implementation" by Nakamura and Smallwood (1980). Nakamura and Smallwood emphasize the complexity of the implementation stage of public policymaking. According to these authors there are three integrated functions that represent the environment within which policy gets made: policy formulation, policy implementation, and policy evaluation. In each of these stages or governmental functions, bureaucracies play a key role. During the policy implementation phase, the agency officials play a vital function as the formal implementers of public policy. According to the authors, bureaucrats serve as intermediaries, "individuals or groups that are delegated responsibility of formal implementers to assist and carrying out public policies" (p. 47). In particular, state and local intermediaries play an important task in the delivery of services. This diffusion of responsibilities among various levels of government can "allow the attitudes norms, expectations, and perceptions of state and local intermediaries to shape policy implementation to meet these intermediaries preconceptions of policy goals" (p. 48).

One of the earliest references to communication networks among policy actors is found in this work by Nakamura and Smallwood. Building on earlier work by Walter Williams, the authors assert that communication networks or linkages between "policy makers, implementers, intermediaries, recipients, lobbyists, and others" are essential to 
the implementation process" (p. 59). While not explored in depth, this contention that such a network exists is an important first step in the recognition of connections that exist within a policy community but outside of the formal structures of government.

The role of state agencies, however, is not solely one of administrator (Elling, 1999). Both state and federal legislation and federal grants often grant tremendous discretion to the state agency to make decisions on how best to deliver particular programs and services to their constituency. Pressman and Wildavsky (1973) undertook one of the earliest studies of implementation. In this case study, the authors tell of the implementation of an economic development program in Oakland, California. Their key finding is that despite meticulous planning, devoted commitment by many players, appropriate authorization and appropriations from Congress, and an "innovative spirit" displayed by federal and local agencies, the actual technical implementation of the program was much more complicated and contentious than ever imagined. This may be best reflected in their lengthy subtitle, "How Great Expectations in Washington are Dashed in Oakland; or Why It's Amazing that Federal Programs Work at All, This Being a Saga of the Economic Development Administration as Told by Two Sympathetic Observers Who Seek to Build Morals on a Foundation of Ruined Hopes."

Pressman and Wildavsky demonstrate that from the very beginning of a program, bureaucracy plays a decisive role in the formulation of policy. Although the legislative intent of the law that authorized and funded the program was clearly meant to serve rural areas, a resourceful head of the Economic Development Agency found ways to direct program resources to urban areas such as Oakland. The authors also present 
one explanation for why organizational knowledge is vital to policymaking. Organizations "deal with the collective efforts of men" (p. 125) and are focused on the generation and processing of knowledge. Yet, the participants must do so in a collective manner. Information flow is fundamental to their ability to do so. Throughout the study, Pressman and Wildavsky identify important roles in policy development and implementation that are played primarily by agency officials.

In some cases, the bureaucracy not only serves as implementer but also plays a more active role by drafting or commenting on proposed legislation. Interviews with state health officials demonstrate a wide-ranging view of the appropriate relationship between legislators and administrators. In some states, agency officials are forbidden to have any contact with legislators during the legislative session without obtaining clearance from the governor's office. In other states, agency heads actually register as lobbyists and actively promote their agenda and participate in law making.

Whether the involvement is pre and/or post legislative action, the bureaucracy plays a formative role in the design of public policy and programs as the actor who "fills in the details" for the often vague framework of new policy initiatives. Due to the delegation of authority given to agencies, the implementation process provides an unparalleled opportunity for the bureaucracy to play a decisive role in policymaking.

\section{Bureaucracy and the Budget Process}

Since the rise of the executive budget, the President, the Office of Management and Budget, and heads of agencies have played the lead role in federal budget making. The same can be said for governors, their staff, and state agency heads. 
The development of appropriation legislation is one of the central examples of joint policymaking by Congress and the bureaucracy (Ripley, 1988). Agency officials seek minimum uncertainty throughout the budgeting and appropriation process. By establishing and maintaining relationships with members of subcommittees and through careful preparation for budget hearings, agencies often overcome the natural tendency of legislative members to view all budget proposals as laden with opportunities for cost cutting. Agencies that "play the budget game" well and inspire the confidence of members of Congress tend to be subject to less oversight, thus enhancing the agency's independence in policymaking. In fact, Ripley finds that although the possibility for Congressional oversight is high, in reality there is little political payoff for members of Congress who frequently engage in oversight of agencies. Thus, agencies find themselves in a position to assertively use their broadly delegated policymaking powers.

\section{Bureaucracy and Bureaucrats as Specialist}

One of the primary characteristics of a bureaucracy is the functional specialization contained therein. Unlike chief executives or legislators who must deal with multiple policy areas, bureaucrats focus on a single policy area. Not only does their daily work require specialization in a single policy area, but they also tend to come from professions related to that policy area. They become specialists not only in their functional area but also in the administration of policy within that area. They not only gather information, they also produce it. Thus, they become an important part of policy communities who actively and regularly exchange information on policy ideas. 
The program information that bureaus possess is useful to members of Congress (Ripley, 1988). The utility of program information is vital in a number of ways. First, bureaus engage in activities that help members of Congress increase their knowledge about programs. This aids their decision-making and enhances their personal reputation for expertise in particular areas. It also enhances the ability of the members and their staffs to provide constituent services related to the agencies. It is important to remember that information is rarely a neutral commodity (Ripley \& Franklin, 1987). Bureaucracies can further enhance their power by using the information exchange as a persuasive technique. This occurs through the framing of information and timing of its release. Through skillful manipulation of information, agencies are often able to maximize support for their own policy goals within Congress.

State legislators tend to have more limited capacity for generating policy ideas, not only because of their need to understand a multi-faceted array of policy areas but also because of their restricted resources. Many state legislators can be characterized as citizen legislators - participants in part-time legislatures. They often have limited staff support and resources, especially when the legislature is not in session. Thus, they are reliant on state bureaucracies as the best or consistently available resource for specific technical and policy information.

Again, Kingdon (1995) provides insights into the importance of bureaucrats as specialists. Their impact is actually "the product of several resources" (p. 33). Longevity gives bureaucrats not only a long-term history of a policy but also the ability to "wait out" elected and appointed administration officials. Expertise is also the purview of 
bureaucrats; they have the experiences of program administration and the knowledge of congressional politics. Bureaucrats combine their long-term relationships with interest groups and people in Congress with connection to a clientele to form the classic "iron triangle" of policymaking.

\section{Rulemaking, Regulation, and Adjudication}

There are three primary functions of agencies that occur directly under their own autonomy with only limited oversight by executive and legislative agents: rulemaking, regulation, and adjudication. Each of these functions, both independently and in conjunction with one another, enhances the ability of bureaucrats to be crucial agents in the development of policy.

\section{Rulemaking}

Certainly one of the most influential and active means of bureaucratic policymaking is accomplished through the rulemaking process. For a variety of reasons, legislatures are limited in their ability to write specific, extensive laws to be faithfully executed by administrative agencies. Legislatures are generalists who must become conversant with multiple policy areas. The compromises of the art of lawmaking require general rather than specific legislation. The more detailed the legislation, the more likely other legislators will find reason to oppose a bill. Most state legislatures are composed of part-time citizen legislators who are not employed in the business of government year around. Therefore, state legislatures often pass laws, including budgets, which are broad directions of policy, leaving the details of program 
design and implementation to state agencies. One of the primary ways that agencies provide specificity to these laws is through rulemaking.

Concurrently, bureaucracies are composed of people with expertise from a wideranging and diverse variety of professional specializations. They are also generally able to focus primarily on policy development and program implementation. In contrast with bureaucracies, part of the resources of legislators and their staff must not only be devoted to policymaking but also to the continual struggle of oversight and power shifting between the executive and legislative branches (Kerwin, 2003). Unlike legislators who must devote time to issues such as elections, fundraising, and party building, bureaucrats are always "in session" (p. 30). This means agency officials can more quickly respond to changing conditions, emergencies, and "on the ground" assessment of problems.

Rulemaking is the intermediary step between the creation of law and the achievement of the desired outcomes of that particular law (Kerwin, 2003). However, rulemaking goes beyond simply implementing precisely prescribed legislative-stipulated policy. It also gives agencies the ability to prescribe policies themselves. As defined in the national Administrative Procedure Act of 1946, "rule means the whole or part of an agency statement of general or particular applicability and future effect designed to implement, interpret, or prescribe law or policy" (APA, 1946). This definition clearly expands the role of bureaucratic agencies beyond that of simply implementation and into the realm of policymaking. Similar statutes exist in all 50 states that provide control over and clarity to the rulemaking operation of government agencies but also codify the 
role of agencies as primary participants in policymaking. The rulemaking process allows a professionalized bureaucracy to set goals, design programs, establish standards, and otherwise plan activities of government that encompass most elements of modern society.

The extent of this power cannot be underestimated. Kerwin (2003) believes that rulemaking causes agencies to rise from a constitutionally inferior status to become the equal of Congress, the president, and the judiciary. These rules "carry the same weight as congressional legislation, presidential executive orders, and judicial decisions" (p. 3). Agencies are in a unique position to achieve this co-equal status, again, due to their expertise in both subject matter and in the procedures and policy actors of a particular policy area. Kerwin also argues that the rise in rulemaking is inevitable and the natural consequence of the demands placed upon government by people asking for an evergrowing set of public solutions to societal problems. Simply put, statutes and rules must co-exist. Therefore, the actions of Congress are immobilized without the parallel actions of bureaucratic agencies.

\section{Adjudication}

Another aspect of bureaucratic policymaking is closely aligned with rulemaking. Administrative adjudication (described in section 554 of the Administrative Procedure Act with similar provisions in most state counterparts) is the process by which an agency official, called an administrative law judge at the federal level, issues an order following due process procedures prescribed in the Act. During adjudication, a specific case (individual or company) that falls under the jurisdiction of an agency's authority is 
heard in a judicial-type hearing. Although an employee of the agency (the other claimant in the dispute), the administrative law judge plays the role of impartial decision maker (Cooper, 2000).

The quasi-legislative authority of agencies in the rulemaking process is clearly a mechanism of policymaking. Although adjudication deals with individual cases, this form of administrative power is as important, if not more important, as other aspects of policymaking. One reason this is the case is that there are far more adjudication decisions than rulemaking judgments (Cooper, 2000). While each individual adjudication decision only affects one person or company, the accumulation of these decisions in related areas becomes a form of policymaking.

\section{Regulation}

A major contribution of Lowi (1972) is a categorization of policy into different types and the beginning of a theoretical argument that different types of policy affect politics and government differently. One of the primary types of policy identified by Lowi is regulatory policy. Like rulemaking, regulation is primarily the purview of administrative agencies. The purpose of regulatory policy is to place limits on individuals, companies, or groups and their activities or behavior. The bureaucratic administrators of regulatory policy, as in rulemaking, are given broad direction from legislative bodies. However, the detailed definition, implementation, and enforcement of regulations are left to agencies, both state and federal.

In recent years, regulation has grown tremendously in scope. Not only are more activities a part of regulatory activity but the level of regulation by federal, state, and 
local government is generally increasing. One aspect that is of particular interest to bureaucracies is the growth of government contracting. According to Cooper (2000), contracts, by their very nature, are regulatory. Government at all levels is becoming increasingly reliant on contracts with non-governmental agencies for the delivery of public goods and services. In addition, the scope and number of intergovernmental contracts and grants continues to grow. Although the basic purpose of the contract is to specify an agreement between government and another party (sometimes another government), it is also necessary to include provisions that govern the enforcement of the contract's provisions. This broad trend towards regulatory responsibilities for bureaucratic agencies provides another avenue for independent authority with little oversight from principals such as legislators.

The continued importance of these three instruments, rulemaking, adjudication, and regulation, emphasizes how vital bureaucratic agencies are to our system of government. Questions arise about the advisability of giving this amount of power and discretion to a part of government that is sometimes seen as less directly accountable to the people. Movements have been undertaken to increase administrative responsibility and enhance oversight by both chief executives and legislatures. Despite this, bureaucracies remain a powerful and in many ways independent policymaker in the U.S. system.

The role of the bureaucracy in policymaking is well established. The bureaucracy at both the federal and state level is well entrenched in governmental action both as implementer and developer of public policy. The intergovernmental 
relationships that have developed within policy areas strengthen the influence of agencies. While this institutional focus is important, it is only a beginning to a thorough understanding of how public policy is made. As Sabatier (1993) argues as he describes an advocacy coalition framework, studies that focus on the components of policymaking such as institutions fail to take into account the dynamic nature of the policy process. In this chapter, I have delineated some of the ways in which bureaucrats and administrative agencies make public policy. Bureaucratic expertise combined with delegation of authority from elected officials leads to source of independent power for this agencies. Bureaucracies not only implement but also create policy through a variety of mechanisms including rulemaking, adjudication, and regulation. They also play an important function in policy networks, facilitating the policymaking process by providing a conduit for information exchange. 


\section{CHAPTER 3}

\section{LITERATURE AND THEORY ON POLICY TRANSFER Introduction}

As an area of theoretical study, policy innovation and transfer transcends a number of traditional boundaries found in political science research. Comparative policy studies have been done that examine policy transfer among various countries, primarily focusing on industrial democracies in Europe, the United States, and Canada. This body of research is based on case studies and provides rich, in-depth analysis generating broad theories of policy transfer as a form of public policymaking. Some studies of comparative U.S. state policy transfer also employ case studies. However, a basic underlying assumption of much of this work is that U.S. states are examples of functional equivalency and represent 50 unique cases. Thus the small $\mathrm{n}$ problem does not exist in these studies, and various quantitative techniques can be used for analysis and hypothesis testing. In combination, these studies have contributed to the development of a broad, intricate theory of policy transfer with a comprehensive understanding of the mechanisms, conditions, determinants, and participants of the policy transfer process through testing of specific hypotheses.

Another strength of the study of policy transfer is the broad lens through which it views the policymaking process. Because most studies use political entities as the unit of analysis, they often examine entire policy networks or communities rather than focusing on the role of single institutions of government or other policy actors. The caveat to this statement, however, is that many researchers channel their studies by 
measuring policy innovation solely as legislative adoption. Case studies are able to consider the temporal aspects of policymaking. Not only the role of particular policy actors but also their interactions are sometimes a focus of policy transfer research. Studies can incorporate both socioeconomic factors and political factors as they affect policy adoptions. This broad approach leads to studies that often provide important insights, not only into policy transfer, but also into the general policymaking process.

Studies of policymaking often focus on a single policy area such as education, health, or fiscal policy. Some policy transfer research also does so. However, many policy transfer studies are more expansive and incorporate multiple policy areas viewing a U.S. state or country as policymaker in general. While there is some debate about whether or not policy innovation and transfer should be aggregated this way, these studies can provide broader snapshots of the policymaking process within political units.

The literature on policy innovation and transfer has developed into a broad theoretical area with important findings that relate not only to policy transfer but also more generally to an understanding of how public policy is made. Numerous specific hypotheses have been tested and contribute to the body of knowledge in this area. The literature that follows examines this research area in detail.

\section{Literature on Policy Transfer among U.S. States}

According to Frances Berry and William Berry (1997), the body of research on U.S. state policy transfer falls into two camps: that which emphasizes the importance of factors internal to the state and that which views external factors (geographic diffusion) as the catalyst for policy transfer. Jack Walker (1969) initiated research on policy 
transfer among U.S. states in a study that demonstrated the influence of socioeconomic conditions (an internal variable) on the propensity of a state to be an early policy innovator. Other examples of research that argues the importance of internal variables include Canon and Baum (1981), Berry and Berry (1990), Hays and Glick (1997), and Mintrom (1997).

Berry and Berry (1997) refer to one type of external determinants model as the "national interaction model" (p. 24). This subset of policy research can be further delineated as models of policy borrowing (Walker, 1969), policy competition (Walker, 1969; Berry \& Berry, 1990); and public pressure (Berry \& Berry, 1990). The regional diffusion model is also a form of the external determinant model.

The seminal work on the diffusion of policy innovation among states is by Jack Walker $(1969,1971)$. In this research, he looks at the factors that determine the speed with which states adopt new programs. With respect to this research, an innovation is defined as a program or policy which is new to the states adopting it, no matter how old the program may be or how many other states have adopted it. This definition of innovation is the standard used by most research that follows in this theoretical area.

Walker develops an innovation score for each state that is based on 88 different programs. For each program, he measures the number of years in between the time a state first adopted a new program and the time that a particular state adopted a similar program. A composite index is developed based on all of the programs by which states are categorized as to their degree of innovativeness. 
Walker considers a number of factors that might be predictors of a high innovation score. The first is demographic factors. He finds that large, wealthier, more industrialized states are likely to be early innovators. He also considers political factors such as the degree of interparty competition and a state's system of legislative apportionment. Here he finds a strong relationship between innovation and urbanization, but little support for political variables as determinants of innovation when economic conditions are used as control variables.

Walker is concerned not only with the speed of adoption, but also with the spatial patterns of diffusion of new programs. He finds evidence of regional clusters of states that emulate one another in policy adoptions, often following the lead of pioneer states. Walker introduces the concept of specialized communication systems, “... which cut across traditional regional lines and bring officials from many different regions into contact with each other and with federal and local officials, journalists, academic experts, and administrative consultants" (p. 894). Thus, he lays the groundwork for the existence of policy communication networks, which are a topic of future studies. In general, Walker finds that the regional emulation of policy leaders is a shortcut used by policymakers, a key argument that officials must satisfice in their search for policy information and alternatives.

An important aspect of innovation that Walker identifies is the role of relationships among state governments. He argues that once an innovation has been adopted by a number of states, not only do the possible risks go down for a state newly adopting the same policy, but the policy is also seen as a legitimate role for government 
or even a requirement. He finds that these accepted standards or norms are most pronounced on a regional basis with particular states serving as innovation leaders on a regular basis.

One of the few studies that considers the role of public agencies in innovation is that by Lawrence Mohr (1969). Using local departments of public health as cases, Mohr attempts to identify the determinants of innovation. Mohr focuses on public health agencies because in the decades immediately preceding his study, these agencies had experienced a radical shift in paradigm - moving from a model of infectious disease control to one of control of chronic diseases and leadership in disease prevention. Interestingly, this same shift in paradigm is often argued in current public health practice as bureaucracies reassess their role in a broader society (a medical vs. prevention model). Mohr seeks to examine which local agencies have adopted new programmatic goals and why. As is also the case for Walker, Mohr credits the work on innovation diffusion in other academic disciplines as contributing to the discussion on the diffusion of public policies.

The dependent variable of Mohr's study is similar to the one that will be used in the current study. For each of the cases, he does a count of innovative (non-traditional) services that are adopted. He hypothesizes that innovation is directly related to the motivation to innovate, inversely related to the strength of obstacles to innovation, and directly related to the availability of resources for overcoming such obstacles. Mohr's study is interesting in the groundwork it lays for later studies. For example, he finds that the health officer's perception of the extent to which the role of local health officer 
requires interaction with others, especially outside the health department, to obtain ideas, support, approval, and resources or activism is related to a propensity to innovate. This concept, activism by particular individuals who advocate for change, is called policy entrepreneurs in later studies. It also implies the existence of networks and communication as important to innovation. Mohr finds that resources, as measured by expenditures, strongly correlate with innovation. While less sophisticated statistically (due to the era in which it was written), this study contributes a number of lines of direction for future research in innovation diffusion. In particular, it examines determinants of diffusion, recognizes the importance of policy area-specific networks, and develops a multi-causal model as explanatory of propensity to innovate.

Another early study on the diffusion of innovation among states is that by Virginia Gray (1973a). Gray believes that, in general, U.S. state public policy studies have focused too heavily on state expenditures with a resulting lack of attention to political explanations of cross-state differences in policy. The policy areas on which she focuses are education, welfare, and civil rights. She chooses these areas for two specific reasons. First, she argues that they represent the have-have not struggle described by V. O. Key "as the essence of politics" (p. 1174). These particular policy areas are also chosen for study because, according to Gray, they are ones "whose adoption was free of federal influence because in expenditure analyses it has been found that federal spending often has a substantial impact on state ... spending patterns" (p. 1174). Gray observes that it is important to separately examine policy innovations rather than 
aggregating various policies to describe various states as innovators, since a state might be an early innovator in one policy or program area but not in others.

Gray finds that the general pattern of state policy innovation can be described as an initial period of slow adoption, followed by a rapid period of adoption by a larger number of states. This is followed by a slower adoption rate involving fewer states. In other words, she finds (as have researchers in other disciplines) that policy adoption among states follows the S-shaped cumulative normal distribution with a high number of adopters towards the middle of the time period during which adoptions occur and fewer early and late adopters. Unlike Walker, Gray finds that diffusion patterns vary according to the policy area studied. She argues that differences in diffusion patterns are probably related to varying amounts of resistance between policy areas. She also indicates that regular diffusion patterns might be altered by the insertion of federal influence through grants.

Gray is also concerned with the factors that influence states to be first or early adopters (by her definition, one of the first ten states to adopt a law). In contrast with Walker, Gray feels that a model that includes political as well as economic factors better explains policy diffusion. She finds that wealthier states are more likely to be early innovators. She also finds that both early and late innovators are most likely to be influenced by political and economic factors, while the middle innovators are more likely to develop new programs due to interaction with other states that were early innovators. Based on these early works, a number of researchers have further refined the theory of policy innovation and diffusion. Generally, their work has followed two veins. 
Some researchers have looked more closely at the determinants and environment of policy innovation, often by separating adopters from non-adopters. Others have attempted to better measure innovation speed.

Another early article on innovation is by Robert Eyestone (1977). He finds that there are three characteristics which make a state likely to adopt an innovation: (1) properties which are intrinsic to the particular state; (2) state politics; and (3) effects of interaction with other adopting states. An important point that he introduces is that the regional diffusion model is also applicable to other groupings of states. States might adopt an innovation because states with similar characteristics other than geography have done so. Walker (1971) terms this phenomenon as discovering "the league in which a state has chosen to play" (p. 369). Despite their differences in findings, the work of Walker, Savage, and Gray can be characterized as studies that attempt to explain the factors that determine which states will be early adopters of innovative programs.

Continued work in this theoretical area was conducted by Robert Savage (1978) who develops a measure of U.S. state innovativeness that covers a wide period of time separated into three eras: the nineteenth century, 1900-29, and 1930-70. Some researchers (see exchange between Walker, 1973, and Gray, 1973b) criticized Walker's measurement of state innovation as having limited generalizability and possible sampling error because of the somewhat narrow choice of programs that he used to determine whether a particular state was innovative. In part, Savage's research is an attempt to overcome possible shortcomings of Walker's index. Savage's measure 
begins with a database of 181 policies across multiple broad policy areas. To further answer Gray's concerns about Walker's innovation index, Savage also includes a computation of the length of time between initial adoption by a state and the subsequent adoption in a particular state. These measures, across policy areas, are then combined into a single innovativeness index. The index is weighted to give higher values to early adoptions. He demonstrates that states with high innovation scores at particular periods of time do not necessarily remain so in later periods. However, he does find a number of states that have consistently been innovators such as California, Minnesota, and Ohio. Thus, he disagrees with Gray's dismissal of a general innovation factor in favor of a theory that sees innovation as policy and time specific. Savage's study is a contribution to future research by further establishing the idea that states can be thought of and measured as innovative in comparison to other states.

Susan Welch and Kay Thompson (1980) look more closely at the impact of federal incentives on policy innovation. Earlier, Eyestone (1977) theorized that federal intervention would speed the diffusion process. Welch and Thompson's research, based on 57 state policies, finds that federal incentives speed the diffusion of policies among the states. The increased diffusion is most pronounced in the middle to late portion of the diffusion cycle.

Welch and Thompson find that much of the influence of federal incentives is a result of the interdependence of federal, state, and local budgets. The authors acknowledge the general pattern of states as developers or inventors of policy. However, they find that the federal government often provides both legislation and 
incentives to encourage other states to adopt new policies. These incentives take the form of either categorical grants for funding new programs or sanctions requiring certain actions by states in order to receive particular funding. They find that policies with positive incentives from the federal government diffuse more quickly than those with negative sanctions.

According to Welch and Thompson, there also exist internal pressures that encourage compliance with federal policy priorities. These include picket fence federalism (ties between state, local, and federal officials within a single policy area), professional organizations who advocate for the adoption of new policies and programs by their state, organized groups of state officials (such as professional associations) that promote the dissemination of information about policies, and state-wide policy coalitions that advocate for federal grants in a particular programmatic area. There are in addition to the external pressures placed on state policymakers, primarily through the federal grant-in-aid system. Thus, they conclude that both internal and external pressures on diffusion have important implications for policy transfer.

The role of federalism in the policy diffusion among federal, state, and local governments is the focus of a study of antismoking policies by Charles Shipan and Craig Volden (2004). In particular they are interested in determining whether a statelevel policy adoption is more likely to occur if diffusion occurs from local to state government, state to state government, or federal to state government via mandates. This study looks at three particular antismoking policies: restrictions on smoking in government buildings, restrictions on smoking in restaurants, and restrictions on out-of- 
package sales. As is the case for other policy areas, they find that factors internal to a state determine whether or not it adopts a particular policy. There is also evidence of geographic diffusion of antismoking policies (for restaurant smoking restrictions).

However, state-to-state diffusion is only part of the picture. Federal mandates also play an important role in policy adoption (as evidenced by out-of-package sales restrictions). A growing mandate for state-level policy change occurs when many local governments adopt a particular policy often led by policy entrepreneurs and health organizations internal to the state. The authors also find that interconnectedness occurs among similar policies and that pressure on state authorities to adopt a new policy sometimes diminishes as adoption success occurs in multiple local jurisdictions.

Henry Glick and Scott Hays (1991) take into account another aspect of the diffusion process, reinvention. They argue that although specific policies can be grouped into broad, general categories and considered a single policy adoption, in reality these policies might differ substantially from state to state as they are adapted to a particular environment. Essentially, the generally accepted practice of conceptualizing the dependent variable, adoption, as dichotomous, may be in error because it assumes a functional equivalency that may not exist. The authors argue that it is important to go beyond the determinants and patterns of adoption and look at how a policy changes from state to state during the diffusion period. They term this process as reinvention.

To Glick and Hays, reinvention includes two aspects: (1) revisions made to an innovation borrowed from another state due to differing circumstances of the adopting 
state; and (2) revisions that occur within a state's policy due to the myriad of actors involved in the policy process. Based on data collected from 38 states on living will laws, the authors conclude that early adopters tend to have more restrictive laws that are often revised at some point in time to become more facilitative. The authors state that this reinvention is an important component of information sharing and learning. States do not adopt uniform policies, in part because over time, information about policy design and success and failure becomes available. Late adopters, although low scoring on an innovation index, tend to adopt programs that both better reflect the implementation experience of early adopters and better address the current problem environment in their particular state. Late adopters, when compared with early adopters, are more influenced by political factors such as lobbying. Early followers tend to engage in less reinvention than later adopters. Moreover, like other policy adoption researchers, the authors find that regional proximity is an important predictor of diffusion patterns and is an important factor in reinvention.

In 1992, Glick again examines the question of reinvention. In this study he revisits the idea of how an innovation changes over time and whether or not the early re-inventions have similar or different effects on late adopters as compared to early adoptions. Using right-to-die decisions as cases, Glick finds that reinvention does occur as policies are transferred and sometimes returned to an early innovator state. One interesting contribution that is possible in judicial innovation, but not necessarily in legislative studies, is the use of methodology that demonstrates direct knowledge or information of other states' policies. This is possible because judicial innovation can be 
studied and measured through an examination of judicial precedents. Judicial policymaking is important and needs to be considered in the context of the larger policy network. When interest groups are unsuccessful in the legislative or other political arena, they often turn to courts as an avenue to affect policymaking.

Glick also finds that courts often address different policy issues than do legislatures. Thus, according to Glick, neglecting the role of courts in policymaking again limits the generalizability of policy transfer studies into the broader realm of policy studies. Glick acknowledges, however, that his study demonstrates one of the major difficulties of policy transfer research. Large studies that aggregate multiple policies are limited to dichotomous adopt/not adopt dependent variables. A single-policy study such as Glick's right-to-die analysis allows for more in-depth examination, including the study of reinvention. However, such studies may not be generalizable to other policies.

Like Glick and Hays, Frances Berry and William Berry $(1990,1992)$ further refine how policy innovation is measured. Through the use of event history analysis (EHA), Berry and Berry predict the probability that a state will adopt a policy during a particular year. This method overcomes a limitation in previous research identified by the researchers. They argue that the segregation of previous research into either models of determinants of innovation (internal) or models of regional diffusion (external) are too limiting. Rather, regional diffusion should be viewed as one possible explanation for diffusion.

Berry and Berry use event history analysis (EHA), a more complex quantitative method of analysis than that often employed for the study of diffusion. In EHA studies, 
the probability of adoption for each individual state is predicted on a yearly basis using a pooled cross-sectional time series analysis. Cases become case-years. Thus for a comparative U.S. state study, each state becomes a case for each year of the database. The dependent variable is dichotomous and coded as adopted or not adopted in that particular state and year, and probit is used to analyze the model. Using this technique, researchers measure independent variables such as economic condition on a yearly basis also. Independent variables are measured for each of the states and years and may be static or dynamic. This means that models of diffusion using EHA better model the temporal nature of the diffusion process than previous research that examines adoption versus non-adoption alone. Unlike Glick and Hays, Berry and Berry assume that a policy can be adopted only once by each state and do not examine the reinvention of policy.

Berry and Berry's first study is centered on state policies regarding lotteries. As possible explanations for policy adoption, they consider internal (political and economic factors) and external determinants in an attempt to create a more unified theory of state innovation. Based on Mohr's theory of organizational innovation, Berry and Berry also include possible obstacles to innovation as explanatory variables. In the case of lotteries, they include the influence of organized groups who oppose the lottery and the income level of the population (poverty rates equate with an inability to afford lottery tickets). To provide alternative explanations related to Mohr's obstacle to innovation theory, Berry and Berry include in their model variables that would help a state overcome the obstacles to a particular policy. In particular, they argue that geographic 
diffusion is an example of this because information from other states' attempts to adopt an innovation is "a critical resource ... for overcoming an obstacle (uncertainty)" ( $p$. 400). Overall, the authors argue that their unified model shows support for all essential elements of Mohr's theory of policy diffusion and demonstrates the interactive effect of various explanatory variables.

Based on analysis of their unified model, Berry and Berry find that a number of factors provide an explanation for which states will adopt a lottery. Economic factors are associated with lottery adoptions. Those states that are in worse fiscal health are more likely to adopt a lottery. Political factors also predict the likelihood of adoption, as lotteries are more likely to be adopted in an election year. Berry and Berry also find support for Mohr's theory of obstacles to innovation. They consider two socioeconomic variables: level of personal income, and proportion of a state's population that adheres to a fundamentalist religion. They find that the probability that a state will adopt a lottery is lower as each of these two variables declines. This study further finds that lottery adoption is more likely when a single party controls both the legislature and the governorship and when a similar policy is adopted by states in the same region. Interestingly, they do not find support for the unified government hypothesis that if a party controls both the governorship and legislature, obstacles to lottery adoption will be lower and the likelihood of adoption of a lottery will increase.

As Berry and Berry demonstrate, another contribution of using EHA is that it not only explains determinants of policy innovation but can also be used to predict the probability that a particular state will adopt a policy at a particular point in time. Thus, by 
considering the general characteristics of various states, the robustness of this model can be further tested.

In another article, Berry and Berry (1992) examine the factors that contribute to the adoption of taxes by states. Using a model and method similar to their earlier study (a pooled cross-sectional time-series utilizing event history analysis), they find that tax adoptions can best be explained by the concept of political opportunity. These political opportunities are created by three conditions: "(1) the presence of a long time until the next election, (2) the existence of a fiscal crisis, and (3) the presence of neighboring states that have previously adopted a tax" (p. 715). Like their earlier study, the EHA method of analyzing data is useful in that it takes into account both the temporal and spatial aspects of policy diffusion.

For the purposes of this study, Berry and Berry examine the diffusion of two types of state tax: gasoline and individual income. Like their study of lotteries, they find little support for a relationship between innovation and party control. With respect to taxation, the strongest relationship is found to be between diffusion and the election cycle. States are more likely to adopt a tax immediately after gubernatorial elections and least likely immediately preceding a similar election.

Berry and Berry also find a relationship between policy diffusion and the fiscal health of a state. States with poorer fiscal health are more likely to adopt new taxes. As have other researchers, they find support for the idea that diffusion occurs regionally. Because fiscal health and regional proximity tend to covary, the regional diffusion model is somewhat weakened when fiscal health is used as a control variable. According to 
the authors, this covariance is an example of the complexity of the policy innovation process. This state taxation study, like their study of lotteries, further verifies some of the theoretical findings of earlier studies that model the policy diffusion process. These studies consistently support the importance of both internal determinants and of policy borrowing among neighboring states. Like Mohr, Berry and Berry continue to argue that a unified model that incorporates both internal and external explanations of policy adoption more accurately portrays how states learn from one another.

During the 1990's, researchers continued to use EHA to examine the determinants of policy adoption and transfer. Christopher Mooney and Mei-Hsien Lee (1995) utilize event history analysis to examine whether different patterns of policy adoption occur for different types of public policy. In particular, they investigate whether the adoption of morality policy differs from other policy types. Morality policy is defined as "those which seek to regulate social norms or which evoke strong moral responses from citizens for some other reason" (p. 600).

According to the authors, previous studies of comparative U.S. state policy adoption examine three different dimensions: (1) diffusion - the geographic and temporal patterns of the spread of policies; (2) reinvention - how policies are modified as they diffuse; and (3) determinants - those factors the affect the likelihood of adoption or non-adoption by states over time. In their study, all three dimensions of policy adoption are considered.

Using state-level abortion regulation policy (pre-Roe) Mooney and Lee conclude that policy type does matter to some extent. Along some dimensions, morality policy 
does not seem to differ from other case studies of policy transfer. The authors find evidence of a regional diffusion process similar to that found by other researchers who have examined a variety of policy types. They argue that this is consistent with Walker's theory that states learn from their neighbors. The rising then falling rate of policy adoption found in economic-based policy is also observed in abortion policy. However, Mooney and Lee find that the institutions of government, in particular state legislatures, do not deal as well with morality policy due to its polarized nature, as with other types of policy. They surmise that alternative venues such as courts are more likely to be used to affect policy change when a highly contentious morality issue is involved. In the case of morality policy, public opinion and interest group strength are determinants of policy adoption.

In a study of the administration of state Medicaid programs, Shad Satterthwaite (2002) examines the diffusion of managed care options for in-state Medicaid programs. Like some other researchers, Satterthwaite theorizes a model of innovation that includes both internal determinants (economics factors, social and political characteristics, health needs, and public opinion) and external determinants (regional diffusion and federal share of the program cost). A factor included in the model that is somewhat unique to the case (Medicaid) is whether or not the state has been granted a waiver from federal guidelines specific to managed care options. He finds that both internal and external determinants explain the adoption of Medicaid managed care. The likelihood that a particular state will adopt managed care increases as more neighboring states adopt this innovation. He also finds that wealthier states are more likely to adopt 
and that the level of federal contribution to the overall Medicaid costs is important. He argues that the latter is due to the decreased risk for state partners associated with higher levels of federal dollars. The most important factor in determining policy adoption is policy legacy or whether states had previously applied for managed care federal waivers for their Medicaid program. However, Satterthwaite does not find evidence that either the problem environment (overall population health status as measured by infant mortality rate) or a state's fiscal condition are statistically significant variables in this model.

In a study of local government innovation, Richard Bingham (1976) argues that one of the factors that affects innovation is the organizational environment of the government entity. He finds four aspects of this environment that affect innovation: intergovernmental resources, professionalism, private sector influence, and slack resource availability. With regard to professionalism, he indicates that numerous researchers have shown a relationship between innovation and the educational level of administrators. Another aspect that may be related to innovation is the desire of toplevel administrators to be seen as progressive and a leader in their field (Lee as cited in Bingham, 1976).

Bradley Canon and Lawrence Baum (1981) offer one of the earliest studies that looks at the judicial role in policy innovation and diffusion. In a study of state court systems over a wide time span (1876 - 1975), they analyze the diffusion of 23 innovative tort doctrines. Again, they visit the question of whether or not innovativeness is characteristic of particular institutions and, if so, what specific institutional factors 
determine this innovativeness. Using these doctrines and the time at which they were adopted by the states, Canon and Baum develop an index of innovation scores similar to that used by Walker. Because of the lengthy time period of analysis, they also develop separate innovation indexes for pre- and post-World War II.

The first question asked by this research is whether innovativeness can be considered as a characteristic of a state overall. To test this idea, they compare the judicial innovativeness score for each state with the legislative innovativeness index score developed by Walker. They find a moderate correlation $(r=0.276)$ between the two indices. This limited correlation can be possibly explained by the shared demographic characteristics of the state than will influence both judicial and legislative innovation. They argue, therefore, that innovativeness is not necessarily an overall trait of a state.

As is the case for innovation by state legislatures, Canon and Baum examine whether or not judicial professionalism, essentially a measure of resources, is related to policy innovation. Although they find a moderate relationship between professionalism and innovation, when controlled for demographic factors such as population, industrialization, and urbanization, the relationship is no longer significant. Thus, they argue the demographics of a state best explain innovation by the judiciary. They do not find evidence either of consistent innovativeness by states. States that were innovators in some areas of tort law were followers in others.

Further paralleling the state legislature literature, Canon and Baum also examine whether judicial innovation will follow patterns of regional diffusion among neighboring 
states. Here their findings differ from those of Walker's study of legislative innovation. They find only weak evidence that judicial innovation occurs in regional patterns. In general, Canon and Baum find that the most important implication of their study is that innovation and diffusion may operate differently among courts than other more explicitly political institutions such as legislatures. The explanation for this, the authors argue, is the reactive rather than proactive nature of courts in comparison to other government institutions.

Lawrence Baum (1990) argues that the role of the judiciary in policy innovation has continued to be neglected as an area of study for political scientists. On the surface, courts seem to be ill suited for innovation because of their structural limitations and inability to initiate issues. Baum also argues that courts have fewer resources and less of an incentive to innovate than do legislatures. However, Baum believes that the judiciary can play an important role in policy innovation, especially when the policy is relevant to judicial policy. Courts are especially well suited to the information transfer that theoretically precedes policy diffusion. Although judges, the policymakers, do not have the time and resources to conduct regular and comprehensive reviews of all new judicial decisions, those that are relevant come to their attention through briefs written by litigants' attorneys. Once a court, especially an upper court, decides to adopt a policy, the hierarchical structure allows for faster dissemination and more uniform adoptions.

Baum finds that the determinants of judicial policy innovation and diffusion are somewhat different from adoptions made by state legislatures. Important factors that 
lead to policy diffusion among judiciaries are case volume (courts of populous states tend to adopt more innovative policy than those of less populous states), ideology of the court (more liberal courts tend to be more receptive to interest group pressure and adopt more innovations), and possibly judicial entrepreneurship (judges who are interested in achieving recognition are more likely to innovate). In general, Baum believes that studies of judicial innovation may not contribute as much to our understanding of innovation and diffusion as other studies in this area. However, in the broader context of judicial policymaking, he feels judicial innovation studies can contribute to the broader literature.

Jill Clark (1985) brings attention to the dynamic nature of policy diffusion. She finds that there is a need for a new measure of policy diffusion - "scope of change". She begins by returning to the differing views of Walker (innovativeness as a characteristic of a state) and Gray (a sequential pattern of adopters that differs by policy area). Clark finds that rather than focusing on the rate of policy adoptions, it might be more important to consider the scope of change.

This argument goes beyond measurement into a theoretical one, according to Clark. Essentially, researchers are asking the wrong question and should focus on the substance of policy changes and adoption rather than the process. She also finds the focus on case studies and particular policies to be limiting in the study of the amount of policy change. She argues that the timing of adoption should be used as an independent variable with policy scope (meaning program coverage) serving as the dependent variable. She finds that both policy leaders and laggards tend to adopt 
policies with broader program options than do followers. The major contribution of Clark's work is the focus on policy content that leads to an examination of not only policy diffusion but also policy reinvention.

Policy entrepreneurs are the primary focus of studies by Michael Mintrom (1997) and jointly with Sandra Vergari $(1997,1998)$. They define policy entrepreneurs as people who "seek to initiate dynamic policy change" (1997, p. 739). Policy entrepreneurs are not simply people who "see policy gaps and even think of solutions" (1998, p. 130). They are those who go the next step by taking the risks necessary to bring policy ideas into action. Anyone within a policy community (legislators, interest group representatives, bureaucrats, other elected state and local officials) might be an entrepreneur. Mintrom and Vergari see entrepreneurs as the linchpin of policy innovation studies because not only do such studies bring together research on the act of policy adoption and its determinants, but it also examines the process of innovation and transfer of policy ideas.

In one study, Mintrom (1997) lays the groundwork for why policy entrepreneurs should be a centerpiece of diffusion studies. He believes studies of policy innovation diffusion have not asked questions of how and why ideas become salient and reach the public agenda. A focus on entrepreneurs leads to an assessment of the process rather than focusing solely on policy adoption and its determinants. Mintrom finds that policy entrepreneurs play many roles in the diffusion process by generating new ideas, communicating those ideas within policy communities, crafting arguments and 
strategies to sell the idea to different audiences within the political framework, and in general, energizing the diffusion process.

Like some other researchers who study diffusion of innovations among U.S. states, Mintrom (1997) utilizes event history analysis to model the adoption of a particular policy adoption across time by U.S. states. In this case, the innovation under study is school choice. In order to test the hypothesis that the presence of policy entrepreneurs increases the likelihood that a state will adopt the innovation, he compares a model containing alternative explanatory variables with one that contains the same explanatory variables but also includes the presence or absence of a policy entrepreneur in the state. He finds that policy entrepreneurs play an important role in an item reaching the legislative agenda and their presence increases the chance of adoption by the legislature. An important aspect of this particular piece of research is the distinction made between legislative consideration and legislative adoption. Mintrom finds, for example, evidence of geographic diffusion as a determinant of legislative consideration but not as a factor in explaining legislative adoption. He indicates issue-specific policy and political concerns are more of a factor than the policies of neighboring states when an issue is being approved.

In an additional examination of charter school initiatives by U.S. states, Mintrom and Vergari (1997) rate state charter school legislation along seven different dimensions in order to compare the relative permissiveness of various states' legislation. The scale runs from zero to ten with ten representing the most permissive charter school laws. They find that one of the factors that seems to lead to more permissive laws is that "a 
receptive climate for local public entrepreneurship is evident" (p. 47). They argue that permissive legislation provides incentives for the active involvement of entrepreneurs in policymaking.

In another study of state education reforms, Mintrom and Vergari (1998) express concern over the separation that has emerged between research on policy networks and research on innovation diffusion. They argue that by separating these elements, researchers lose sight of the important role of ideas in politics. Studies of policy diffusion must take into account not only the process of innovation and diffusion but also "the social milieu from which policy ideas emerge and gain attention" (p. 126). The authors find that one of the problems of diffusion studies is that they do not give enough attention to the "mechanisms through which policy ideas are communicated" (p. 127). In order to address this concern, Mintrom and Vergari study how policy networks play a role in the dissemination of information related to a particular policy innovation. One of their key findings is that "ongoing interactions among network members permit the formation and dissemination of judgments concerning the character of actors who propose innovations" (p. 128). In other words, the existence of the network itself is not sufficient for diffusion of policy innovations. To be effective, networks need a welldeveloped communication system that allows network members to develop relationships and conclusions about the reliability of information and ideas from other participants. The ascendancy of policy entrepreneurs within the network will result if such a communication system exists. 
Mintrom and Vergari's focus on policy entrepreneurs and policy networks leads to an examination of the types of networking activities that are used. They contend that two types of policy networks exist. Entrepreneurs use external policy networks (made up of people from other states who are interested in the same policy area) to develop ideas for policy innovation. Mintrom and Vergari believe this external network provides a venue for entrepreneurs to not only share policy ideas, but also to develop a strategic framework to sell the idea to the broader policy community. However, policy entrepreneurs do not necessarily have regular mechanisms for convincing elected and appointed officials to adopt their ideas. Thus, they use internal policy networks (the policymaking community within their own state) to connect to the political system and urge adoption of the proposed innovation. Via this combination, networks become the mechanism through which policy entrepreneurs "articulate their ideas for policy innovation onto legislative agendas" (p. 131).

The importance of geographic diffusion patterns, in particular the finding that states are more likely to adopt an innovation if neighboring states have also done so, comes into question in a study by Craig Volden (2003). Volden argues that although previously the search for programmatic alternatives was often limited to neighbors, states are now likely to search more broadly for policy information and alternatives. This is due, in part, to the development of widespread communication mechanisms such as e-mail. His research on Children's Health Insurance Programs demonstrates that states emulate others with similar conditions including "ideological leanings, per capita income, managed care structures, and budgetary considerations" (p. 26). The 
existence of neighboring state networks for policy diffusion might in reality reflect states searching for other states with similar settings. Another important finding of this research is that policy adoptions through the legislative process appeared both "more partisan and more focused on success elsewhere than those that were adopted through the administrative agencies" (p. 27) further supporting a hypothesis that legislative adoptions might differ from administrative adoptions.

Christopher Mooney (2001) also questions the regional factor as a consistent determinant of policy diffusion. Arguing that the statistical models used in previous research are flawed, he reanalyzes data from two previous studies (Berry \& Berry, 1990, 1992). Mooney states that the theoretical underpinning of a geographical determinant of diffusion is based on a social learning process. The central element of social learning is communication, thus it must be demonstrated that communication has occurred before an assumption can be made that diffusion has occurred. One of the issues Mooney raises is the general positive tone in this area of research.

Consideration is only taken of those policies that are positively diffused. Researchers do not examine those instances where the possibility for emulation exists but states choose to not adopt.

Information, however, is a more complicated concept than a simple communication model might convey. Mooney discusses different types of information that might affect policy diffusion. He believes that information can have both positive and negative effects and should be broken down into different types of information. Substantive policy information allows policymakers to determine if a considered policy 
might be beneficial to the adopting state. Political information includes an analysis of whether the "political risks of adoption are low" (p. 105). An apparent regional diffusion effect might in reality be a nationalized policy with learning occurring simultaneously throughout the country. So, the regional information effect might not be constant over the evolution of the policy diffusion. Thus, Mooney argues that complexity rather than simplicity is likely to characterize geographic-based policy learning.

As discussed earlier, event history analysis (EHA) has become one of the predominant analysis tools in the study of policy diffusion among U.S. states. Mooney points out that one of the assumptions of this analysis method is that the hazard rate, or risk of a particular state adopting a policy in a particular year, is constant across time when in reality it might not be. One of the outcomes of this error is that the regional effect will be biased towards the positive and may not accurately reflect the true estimate of the parameter. In his reanalysis of the Berry and Berry studies, Mooney reconceptualizes the regional effect by including two separate variables to measure the latent variable. He includes the traditional EHA measure, adoption by neighboring states, but revises it to allow for a non-linear variable that reflects differing adoption effects on the dependent variable, depending on whether a neighbor is the first or subsequent adopter. Gray (1973a) hypothesizes this type regional effect. He further revises the traditional EHA model of analysis by using piecewise regression to allow for and measure the change in the regional diffusion effect over the time period of study.

The Berry and Berry (1990) study of state lottery diffusion between 1964 and 1993 finds, among other things, that a constant, positive regional effect exists for 
diffusion of this particular policy. In his reanalysis of the data, Mooney finds that the regional effect was positive before 1978 but after that time the presence of a lottery in a neighboring state "appears to have no impact at all on whether or not a state adopts a lottery of its own" (p. 116). The replication of the 1992 study of state income taxes, 1916 - 1937, finds no evidence of a regional effect on policy adoption. This finding is inconsistent with that of Berry and Berry.

Beyond the theoretical and methodological findings of Mooney's study, he returns to the concept of social learning and the role of information in policy diffusion. He theorizes that the types and quality of information changes over time as a policy diffuses among states. He brings attention to the fact that information is not value neutral and might well be framed by policy entrepreneurs and others to advance or impede policy diffusion. He also emphasizes that thorough analysis of information networks is necessary to properly conceptualize and model the role of information in policy diffusion. Sources of information, whether national or regional, affect potential policy adoptions in different ways.

While Mooney argues that reinvention is the result of social learning, Scott Hays (1996) finds that there are other possible causal factors that might lead to reinvention. Acknowledging the importance of social learning, Hays argues that another simultaneous process occurs during reinvention. In this case he refers to how the particular circumstances within a state (an internal determinant argument) affect reinvention. Important factors include characteristics of the state's political institutions, 
"level of need for the policy's anticipated remedy" (p. 633), and political support for the policy.

To test his hypotheses, Hays selects three policies that are purposively different in order to examine reinvention under different conditions. The policies selected are child abuse reporting laws, crime victim compensation laws, and public campaign funding laws. Note that again the function is on laws with a focus on legislative adoptions. In order to move beyond adoption to reinvention, he develops a measure of comprehensiveness for each state for each of the three policies.

Hays' findings illuminate some of the commonalities and differences regarding reinvention when studied from the perspective of different policies. In general, he finds that policies tend to become more comprehensive over time, especially for laws that are less controversial. This supports a hypothesis of a social learning effect on diffusion and reinvention. Although counterintuitive, he finds that there is a negative relationship between comprehensiveness and societal context. States with greater problems tend to have less comprehensive policy adoptions. Then he examines the role of legislative professionalism as a factor in policy adoption and reinvention. He states that the use of professionalism as an explanatory variable is problematic because it correlates so closely with innovation. Hays observes that less professional states (who also tend to be later adopters) tend to learn from early adopters and thus adopt more comprehensive policy. Findings on political structures, in particular party control and ideology are mixed and differ by the policy under consideration with ideology differences becoming more relevant as laws become more controversial. The importance of Hays' 
study is that he again brings to our attention the reinvention nature of policy diffusion across states.

Hays and Glick (1997) return to the study of living-will laws and examine the role of agenda setting in policy innovation. Specifically, they question why particular issues while placed on the public agenda often never reach the adoption stage. They build on their earlier model (1991) by adding agenda-setting variables. They argue that various agenda-setting forces exist within a state that might influence the adoption of living-will laws. These include the state courts as judicial policymakers, the issue attention cycle in both the professional and mass media, and the work of interest groups and policy advocates.

Hays and Glick theorize that the adoption of living-will laws, because they represent a type of morality policy, might not be explained by the determinants often found to be vital to policy diffusion (see Mooney \& Lee, 1995). To test their theory Hays and Glick develop three different models of adoption. In the first, they examine the typical state context variables found to influence policy adoption including interparty competition, per capita income and education of state citizens, and "a tendency toward general policy innovation" (p. 503). They also include measures of the ideological tendency of a state including party political control and public opinion liberalism (as measured by Erikson, Wright, \& Mclver, 1993). This model is specified based on factors demonstrated by previous research to be associated with policy diffusion and innovation. 
The second model looks more closely at agenda setting by specifying factors that might encourage the public to demand legislative consideration of living will laws. One factor is the number of right-to-die cases considered by the court system based on the idea that frequent court action will result in demands for legislative action. The authors also consider the overall number of similar cases across the nation. Another concern is the importance of right-to-die as measured by national public opinion data. The fourth variable included in this model is the number of articles published on the topic in the mass media. Consistent with the geographic diffusion argument, also included is the number of neighboring states that have adopted living-will laws. Finally, the authors include a variable that measures demand specific to this issue: the percent of the state population that is Catholic.

Using EHA, the authors test the three models. They find that the first model based on state context variables does not provide a good explanation for the adoption of living-will laws among U.S. states. Their second model, however, better explains adoption with four of the variables statistically significant. Positive relationships are found between the adoption of living-will laws and the number of articles on the topic published in the mass media, positive national public opinion on the right-to-die, and a lower percentage of Catholics in the state. They find a negative but statistically significant relationship between adoption and the number of neighboring states who have adopted, thus disputing the geographic diffusion argument.

In their third model, Hays and Glick combine the first two models of both agendasetting and state context variables. This model turns out to be the strongest. Seven of 
the variables are statistically significant and encompass both state context and agenda setting explanations. A positive relationship is found between adoption of living-will laws and interparty competition, democratic control, ideological liberalism, coverage in the mass media, and public opinion on the issue. A negative relationship is found with percent of the population that is Catholic and number of neighboring states who have adopted. There is no support for the hypotheses that educational and income level of the populace or an overall tendency to innovate by the state affect policy adoption. The role of court cases is also not statistically significant.

In general, Hays and Glick demonstrate that agenda setting is an important component of policy adoption. Strong forces for placing an item on the public agenda are likely to influence whether or not a state adopts a particular policy. Like the Mooney and Lee article (1995), this research again demonstrates that issue type (in this case mortality policy) is likely to affect the determinants of policy adoption.

As has been discussed, few studies of policy diffusion examine the role of bureaucracies in policy innovation and adoption. However, there are a couple of studies that are exceptions. In a study of pay-for-performance, Patricia Ingraham (1993) looks at the diffusion of these systems from the private to public sector and then among U.S. states and even among countries. She argues that although widespread use of pay-for-performance in the private sector should provide much detailed information on the success of such programs, in reality adoption by states was not based on critical evaluation. Instead they relied on informal communication among bureaucratic and elected policymakers with formal evaluation of programmatic success 
occurring well after adoption at the federal and state levels. Of particular importance, the evaluation research questioned the transferability of the program from the private to public sector. Ingraham argues the importance of quality evaluation research as a component of diffusion not only as a decision tool, but also as a look inside the considered policy and its potential implementation.

James Gow (1994) also specifically studies innovation in the context of public administration. He focuses on two aspects of innovation: totally new programs developed by a public bureau or bureaucrat (innovations) and the knowledge transfer surrounding innovations (process). He begins the study by making a distinction between the new product (research and development) innovations that are normally the subject of innovation study and the knowledge-based innovations that are the hallmark of bureaucracies. Because study of innovation and diffusion in the realm of public organizations focuses on ideas and knowledge, he argues that study must also include an examination of the process of knowledge diffusion and the effect it has upon organizations and the people within them.

Gow finds fault (as do other researchers as he points out) with the adoption/nonadoption approach to innovation research. This narrow conception limits innovation and adoption studies. First, it does not acknowledge the variation in adoptions that might occur including strength of adoption, partial or full adoption, and reinventions (or evolutions of adoptions). Also, focusing on the act of adoption (or non-adoption) ignores the process by which exchanges of knowledge occur among participants - the important ideas that develop around innovation adoptions. 
Gow raises an important distinction between traditional scientific and practical applied research. Public administrators, he states, do not utilize theoretically based research because it is of little practical use. However, this does not mean they are immune to research-based influence. Instead, they tend to "test the ideas they encounter in courses, conferences, and publications" (p. 10). This approach produces change in policies, programs, and organizations. However, it is not as comprehensive as theoretically based research might be. Practitioners often react and change selectively and situationally rather than in a more comprehensive manner. Gow finds that public administrators are likely to rely on intuition and creativity when dealing with policy problems and to learn from others in their professional area. Thus, he finds that an understanding of learning as a part of the diffusion of information is an important element of research on policy diffusion and innovation.

Gow continues to discuss the unique role of public administrators in policy diffusion by describing the "administrative culture in which innovations are or are not adopted" (p. 27). His study draws upon the expertise of four groups: (1) professors at a Canadian federal government management institute and the National School of Public Administration of Quebec, (2) members of the Institute of Public Administration of Canada, (3) Canadian public administration experts who are current practitioners; and (4) public sector consultants. Members of these four groups were surveyed to assess three primary topics: (1) the development of and nature of qualities of a good public administrator, (2) how change in public administration occurs and the obstacles to such; and (3) public administration problems and the search for solutions to such. The 
second topic, change and reform in public administration, is most relevant to the current study.

Gow portrays the public administrator's search for solutions to pressing problems as a process of adaptation to changing circumstances rather than an integrated, planned approach. Innovations and reforms are often seen as partially successful with organizational inertia, political pressures, and the natural tendency for people to resist change as primary obstacles to change. The key change agents who initiate administrative reforms are primarily higher level administrators rather than political and elected officials. Most importantly, however, Gow finds that public administrators see administrative reform as their purview rather than that of elected officials and politicians.

Gow's survey also identifies sources of information on innovation. He finds that colleagues and subordinates are viewed as the primary source of information on evolving problems and their solutions, while scientific and professional meetings, books, and journals also play an important role. A key finding that relates to the unique nature of public administration versus other institutional actors in innovation and diffusion is the importance of information transfer between public and private organizations, especially for demonstrating the feasibility of considered changes. In general, Gow confirms that no one source of innovation is prevalent among public administrators.

The reinventing government reforms that reshape public management are the focus of a study by Edward Kellough and Sally Coleman Selden (2003). They examine the diffusion of various personnel management reforms in recent years among U.S. states. The authors assert that a study of these reforms goes beyond the question of 
management but also considers the basic competing values found in models of public management. Specifically, what should be the balance between the neutral competence of administrators and their responsiveness to political and partisan goals?

Kellough and Selden develop an index of personnel reform in U.S. states composed of six specific functions that are considered to be important goals for public management under the reinventing government model. Two of the functions (decentralization of authority for personnel functions and contracting out of functions) are measured on an additive scale. Two are dichotomous (broad pay bands and use of labor-management partnerships). Another is the ratio of job classes to number of employees. The final component of the index is another index developed by Selden to measure the use of strategic workforce planning. In combination, these six components are used to assess each state's level of personnel reform.

In order to explain the wide variation in personnel reform found among U.S. states, Kellough and Selden consider two basic factors: the context within which personnel management systems operate, and each state's organizational framework. They conduct a multivariate analysis using the personnel reform index as the dependent variable. They find that three environmental variables (legislative professionalism, state public employee union density, and unemployment level) are statistically significant. More professional legislatures are more likely to adopt reforms. States with strong state employee union activity decrease the likelihood of reform adoption. Because higher levels of unemployment are often a sign of overall diminished state economic activity, states with higher unemployment rates are less likely to adopt reforms due to their initial 
costs. However, the authors do not find support for their hypothesis that more autonomous state personnel authorities will be positively associated with personnel reform. Overall, they find that a state's environmental context is more important in explaining the diffusion of government reinvention reforms.

Steven Balla (2001) takes an institutionalist view of the diffusion of policy innovations by examining whether or not participation in interstate professional associations by state officials affects policy diffusion. The case for his study is the adoption of a Health Maintenance Organization (HMO) Model Act as promoted by the National Association of Insurance Commissioners (NAIC). In an operationalization of Berry and Berry's model of policy adoption (1990), Balla argues that professional associations provide resources for overcoming "obstacles to innovation by facilitating communication among states that do not necessarily share borders" (p. 229). In the case of the NAIC, Balla measures professional association membership, based not on the overall organization, but on participation and leadership of a particular committee of the broader organization that deals with a specific area of insurance, in this case, the Accident and Health Insurance Committee. He finds that participation by a state's insurance commissioner on this committee of NAIC does increase the likelihood that a state will adopt the model act. This micro view of professional associations is important since there is often no variation in membership participation at the broader level. Generally, all states have a representative in the professional associations.

Balla also finds support for a regional diffusion hypothesis but argues that it is inconsistent with other work (i.e., Berry \& Berry, 1990, 1992, 1994) that theorizes that 
the driving force behind regional diffusion is competition among neighboring states for revenue. In the case of $\mathrm{HMO}$ reform, revenue is not as crucial as the cue taking that occurs from nearby states. Percentage of state expenditures devoted to health care, a characteristic of the problem environment, is also statistically significant in Balla's model. He finds that states with relatively high levels of health care spending are less likely to adopt the HMO reform act. With this exception, he does not find evidence that either characteristics of a state's health market, or other political factors such as liberalism, have the hypothesized positive effect on the likelihood of adoption by a state.

In a study of Canadian bureaucracy, James Desveaux, Evert Lindquist, and Glen Toner (1994) find that the organizational design of a bureaucracy contributes to or limits its ability to implement policy innovations to deal with public policy programs. Their focus is on complex, large-scale policy problems that require comprehensive solutions for success. The authors couch this issue in terms of the institution, stating that public bureaucracies, particularly departments that rely heavily on professional expertise and its application to solving problems on a routinized, programmed basis, are often incapable of developing "nonincremental interventions in response to complex policy problems unless new capacity is created" (p. 495). They argue that policy entrepreneurs are vital to policy innovation, but bureaucratic organizations with capacity to design innovations are also critical. They are concerned not only with existing bureaucratic expertise but also the development of the new expertise necessary to true innovation. 
The authors identify a number of obstacles to innovation that can be attributed to the design of bureaucracies. First, they argue that the very expertise that is often the strength of these institutions in the policymaking process can become an issue when the problem requires a broad intervention because this type solution often crosses institutional boundaries. Another concern is the limits on prospective policymaking. Bureaucracies are designed to deal with past policy problems, and their routinized administrative focuses on such. The authors also find that bureaucracies and professional groups are organized to best deal with problems that are already clearly understood, not new imperatives that are more ambiguous and unknown.

Borrowing a term from both Alvin Toffler and Henry Mintzberg, the authors describe adhocracy - an operational model that is necessary to the creation of bureaucratic capacity for policy innovation. It can be expressed as an overarching matrix organizational structure that crosses institutional boundaries. These broad range planning groups, the authors state, are better capable than traditional bureaucracies to design policy innovations. This research brings together the importance to policy innovation of a combination of bureaucratic expertise, organizational structure, and policy entrepreneurs.

Donald Smith (2002) examines a single policy, the adoption of right-to-die policies in U.S. states. Like the current study, Smith argues that a focus on legislative adoption is limiting. His study, however, considers judicial policy innovation and the relationship between judicial rulings and legislative action in states. Like Glick and Hays, his focus is policy reinvention, an examination of the way policy changes as it 
diffuses among jurisdictions and across time. He argues that this evolution of policy occurs not only as policy transfers among jurisdictions but also as interactions occur between judicial and legislative actors within a state.

Smith attempts to explain, as do some other policy transfer researchers, why some states adopt policy innovations when they do and why some remain nonadopters. He also examines policy reinvention and legislative renovation, the amendment of an existing policy by a state legislature to respond to changing needs or policy demands. His typology of core innovation, renovated reinvention, tangential innovation, and reinvented tangential innovation begins to address one of the primary measurement concerns of policy transfer research - that an underlying assumption is that all policy adoptions from state to state are equivalent when that is rarely the case.

Smith begins his study by theorizing that determinants other than those found to be related to legislative adoption are likely to be statistically significant in a model that examines judicial as well as legislative adoptions. For the adoption of living will laws by state legislature Smith finds that political variables are not determinants of adoption while some institutional variables (such as legislative professionalism) and degree of opposition or support for policy are important. Later tangential adoptions are less controversial than earlier adoptions, and there seems to be no evidence of interstate diffusion based on geographic proximity. He finds that when considering the judicial as well as legislative role, the determinants of policy adoptions vary somewhat from those found when solely considering legislative adoptions. He also provides evidence for the 
cross-pollination that occurs in policy transfer when two different institutions are involved in the same policy area over time.

In summary, there are numerous factors demonstrated to be factors in the innovation and diffusion of policies in U.S. states. These factors constitute both characteristics internal to a state and those external to the state. Some of the internal factors include economic condition, problem environment, political structure, and interest group activity. Communication venues and federal government influence are external factors. Geographic diffusion, particularly among neighboring states, is another example of an external determinant of policy diffusion. Policy entrepreneurs can represent both internal and external determinants. There is also evidence that factors important to policy innovation and transfer vary by policy type.

Various measurement techniques have also been used to ascertain the patterns and speed of policy diffusion. The most widely used method in recent years is event history analysis, a method that combines quantitative measures across time. While patterns of diffusion seem to differ somewhat between policy areas, some particular states are shown to be leaders in the adoption of innovations, no matter what the policy or program. This is closely related to overall economic condition of the state.

\section{Policy Transfer among Countries}

Studies of policy transfer among countries are often approached in a different manner. One of the advantages of comparative U.S. state policy research is the availability of 50 cases, a boon that greatly increases the number of applicable statistical tools. Functional equivalency of cases, programs, and measures of other 
variables can often be found among U.S. states, although care must be taken to not assume equivalency where it might not exist. However, functional equivalency is less of a concern in comparative U.S. state research than when comparing the policy, politics, and institutions of various countries. Thus, much of the research on cross-country policy transfer is limited to single examples of policy transfer or a limited series of multiple case studies (Mossberger \& Wolman, 2003). Study authors tend to begin with the assumption that policy transfer has occurred because they have identified two or more countries with similar programs or policies. The emphasis on qualitative research in these studies also leads to a focus on detailed narratives of the process of policy transfer.

One of the leading researchers in this area is Richard Rose (1993). Rose portrays policy borrowing as an area with both theoretical and practical implications. He argues that policy borrowing is inevitable both across time and space. His study, Lesson-Drawing in Public Policy, defines a broad theory of how policymakers use experience, both their own and of others, to develop policies. The importance of this study area is that it carefully analyzes the circumstances under which policy learning occurs so that future policy borrowing can be fruitful.

One of Rose's key points is that lesson drawing invariably occurs within single functional areas because policymakers are specialists. Because policymakers work within a single policy area, they also share common concerns or problems. This leads to an exchange of information among countries dealing within the same policy area as they search for solutions. Members of these policy communities are also more likely to 
recognize that policy decisions made by neighboring jurisdictions often influence not only their country but also those nearby. Communities of experts develop within each substantive area of public policy. The beginning point of these communities is that nonelected government officials within a particular policy area tend to have similar educational backgrounds. As they obtain degrees, often at the graduate level, they begin to be socialized into a particular mindset and community that is accustomed to sharing ideas and information. Later, membership in professional organizations, professional publications, and professional meetings reinforce this socialization and knowledge transfer. These linkages exist not only among agency officials from different jurisdictions, but also within the levels of intergovernmental systems and even beyond to non-governmental organizations with common policy interests.

Rose emphasizes that lesson-drawing is a normative but also a practical activity. To decide that a program in one locale should be drawn upon in developing a program for another jurisdiction assumes the policy should be transferred. The practical nature of lesson-drawing, however, deals with whether a lesson can be borrowed and successfully transferred to another locale or time. He returns to this theme by referring to lessons as "tools with practical application". Because bureaucrats represent the practical end of the policymaking spectrum, it can be argued that this further supports the importance of their role in policy transfer.

Colin Bennett, a Canadian political scientist, develops a theoretical perspective on policy convergence in a 1991(b) article. Policy convergence is the trend of growing similarities that often occurs among different societies and their public policies. This 
study relates to the literature on policy transfer because policy convergence would be the likely outcome of increasing occurrences of policy transfer. Bennett proposes a framework of four possible processes through which convergence might occur: elite networking, harmonization via international regimes, deliberate action on the part of state officials to copy other countries, and involvement by external actors.

Some researchers have argued that policy similarities among countries can be explained as a natural evolution that occurs when they share a similar socioeconomic base and system. Bennett, however, believes that a more micro-level analysis better explains policy convergence. He conducts a review of literature in this area to develop generalizable hypotheses of modes of policy convergence. His analysis leads to a theoretical understanding of policy convergence as best explained by specific processes where policy learning occurs.

One path through which convergence occurs is emulation. Emulation is deliberate lesson-drawing from other countries where a policy is seen as an exemplary model of policy that can "provide a blueprint that pushes a general idea on to the political agenda" (p. 221). Bennett emphasizes that the program model is emulated but not necessarily the specific content of the policy or program. He cautions researchers to be wary of drawing conclusions based simply on contact among policymakers. Instead he urges the need for careful content analysis of documentary evidence of policy emulation.

Another process that Bennett theorizes is important to policy convergence is the existence of policy issue networks or communities. Ideas are shared among members 
who have regular interaction with one another and whose network is fairly consistent over time and membership. These networks are important not only as conduits of information but also because they share a common experience of learning about common policy problems and solutions. Networks vary in size and strength among policy areas, but Bennett argues the large number of transnational professional organizations demonstrates their existence. The participants become energized around issues as they interact with one another, thus increasing the likelihood of attempting to influence policy decisions within their own country.

Bennett's third process of policy convergence is harmonization. Because countries increasingly recognize their interdependent nature of public policy, there is a growing need to cooperate in policy development. Institutions have developed that facilitate the intergovernmental relations that are necessary to facilitate policy cooperation. This process differs from the network explanation of convergence because it focuses more specifically on international regimes and state actors.

Unlike the cooperative view of described by harmonization, a contrasting stance can be argued. Convergence through penetration occurs when political actors from one country interject themselves into the policymaking of another country. Coercive efforts such as trade sanctions or regulations are sometimes used to force policy convergence upon laggard countries. Non-governmental actors such as multinational corporations are sometimes also involved in policy penetration.

Bennett concludes his discussion of policy convergence processes with two cautionary notes. While researchers in this area are quick to find instances of policy 
similarities and to develop theoretical explanations for their occurrence, they rarely give attention to instances of policy non-convergence. These cases are perhaps just as important as those of similar policy. Finally, as does Rose, he points out the need to model policy convergence as a dynamic rather than static process.

Bennett (1991a) returns to the idea of policy communities in a study of how the United States' Freedom of Information Act became both a positive and negative example of program transfer for different receiving countries. He argues that transnational communication networks are vital to the transfer of policy information and subsequent adoption or non-adoption by other countries. He cautions that it cannot be assumed that sequential adoption of program from one country to another is necessarily evidence of knowledge diffusion. While the temporal element is one type of evidence that policy diffusion has occurred, there might be other rational explanations, such as common problems or socioeconomic conditions, for apparent policy diffusion. He finds that three separate processes are necessary to rationally argue that policy transfer has occurred. These three conditions are (1) knowledge of the existence of a program in another country; (2) utilization of the knowledge by another country; and (3) actual program adoption by the receiving country.

In his discussion, Bennett describes five different political motives that might lead to the utilization of another country's policy experience. First, he finds that adoption of a policy by one country can increase the salience of that policy for other countries, moving it from the backburner to the forefront of attention. As this happens the policy problem may be seen as more urgent, and the program of another country offers a ready-made, 
tested solution. If the other country's policy is seen as a superlative policy solution, the political pressure for adoption may be even greater. If, however, the adopting government is in more of a problem-solving mode, a search might be undertaken for the best policy from among multiple possible solutions. Finally, political pressure might result in the search for a justification of policies or programs that have already been decided upon. Bennett stresses the role that information diffusion plays on the placement of issues on institutional agendas and subsequently with their movement to the systemic agenda. He argues that unless evidence exists that policy-relevant knowledge is transmitted among policymakers, it cannot be argued that policy diffusion has occurred.

The focus of Harold Wolman's 1992 study is the process of policy transfer and how policy transfer contributes to our understanding of the policymaking process. He differentiates policy transfer from policy diffusion studies. Based on Walker's work (1969), Wolman concludes that policy transfer is "imitation through interaction" (p. 29). A necessary condition for policy transfer, by his definition, is interaction among government officials that is facilitated by an increasingly specialized and complex system of communication, especially through professional associations. He describes the ways that policymakers learn of policies in other environments as both systematic and ad hoc, through both formal and informal means of communication.

Different types of policy learning have different advantages and disadvantages. For example, less systematic and unstructured information gathering often results in biased results, since most information sharing occurs among advocates with successful 
programmatic models. Rarely do those who failed or even those who have neutral experiences share that information with others. Policy learning is also heavily based on anecdote rather than systematic analysis.

Wolman's work emphasizes that policy transfer does not occur in a vacuum, but as part of the broader policy development process (p. 34). It recognizes the evolving nature of public policy - that problems continue to arise creating a demand for ever changing solutions. Policy transfer is one of the means by which solutions are proposed and examined. This leads to another question, that is, once a policy is under consideration, how do policymakers evaluate its possible success at solving a problem? Although it might seem prudent to pursue a systematic and analytical evaluation, in reality the opposite is true. Instead, policymakers search for and adopt those policies that have clever program designs. Policymakers seem to understand that there are different policy settings in different countries, but they struggle with a clear understanding of these differences and how they might have an impact upon successful policy transfer. In general, Wolman finds that policy transfer can rarely be characterized as rational, systematic, and incremental.

In study that expands upon a concept first introduced by Rose, Karen Mossberger and Harold Wolman (2003) consider another aspect of policy transfer, prospective policy evaluation. By this term, the researchers are referring to efforts to "assess the probable effects of a policy transferred from another country" (p. 428). In other words, policymakers go a step beyond simply borrowing policy ideas. They 
attempt to project the likelihood of successful program results as well as potential obstacles to such within their own country's context.

Mossberger and Wolman identify three major criteria that are used by policymakers to assess the possible transfer of program ideas as they conduct prospective policy evaluation. The first is awareness. By awareness, they refer to information gathering, not necessarily active or focused, that policymakers engage in through various mechanisms. Mossberger and Wolman believe that policy awareness occurs through networks of specialists, professional associations, entrepreneurs, the media, and even by chance. In some cases, the search for policy information is methodical and active. In others, it is somewhat happenstance. Information quality is important to this awareness, in particular the scope, adequacy, and accuracy of shared information.

Assessment is the second criterion important to prospective evaluation. By this, the authors argue that potential policy borrowers assess the similarity of their problems to other country's problems. They also consider how well the policy succeeds in the originating country and how their own policy setting is different from the initiating country. Finally, policymakers consider the application or whether the policymakers actually adopt the borrowed policy and if so, to what extent.

Based upon their analysis of existing cross-country policy transfer studies, Mossberger and Wolman find that in most instances, policy borrowers come up short when measured against their rational criteria for prospective evaluation. The search for information tends to be limited and focuses on the experience of a single other country 
that is perceived as achieving a successful policy result. Often this single example is identified through a site visit or the efforts of a policy entrepreneur. Assessment tends to be problematic because policies are borrowed before sufficient time has passed to measure success or there is a lack of systematic, research-based program evaluation. Finally, policymakers tend to neglect the incompatibility of program goals, limiting their search to the potential success of policy transfer. By examining these rational criteria for prospective evaluation in the context of various studies of policy transfer, the researchers hope to offer "recommendations for coping with the challenges of transfer" (p. 438).

David Robertson and Jerold Waltman (1993) establish the important of political factors in policy borrowing. The relationship of politics to policy borrowing lies primarily in problem definition. According to the authors, problem definition occurs within the context of political conflict. The proposed study is not as concerned with the political conflict which might be a part of agenda setting. However, the point of the authors is important since political factors will have an effect on the nature of the bureaucracy. Different political systems, as can be found in the U.S. and Canada, will naturally result in different bureaucratic structures and power.

Like Ingraham (1993), B. Guy Peters (1997) examines the diffusion of administrative reforms, but in this case, among highly industrialized countries, particularly those in Western Europe. He argues that the adoption of a wide variety of administrative reforms among various countries "whose aim is to make government work better and cost less" (p. 71) can be explained by policy transfer and diffusion. One 
key factor in the diffusion process is identified as the participation of countries in the Organisation for Economic Co-operation and Development (OCED) Public Management Group (PUMA), a think tank with membership from about 30 European countries. His cases have been identified as having a common socio-economic basis, allowing for an opportunity to focus on political and cultural factors that might affect the adoption of policy reforms.

Peters groups reforms into three categories: market-based, deregulatory, and participatory. Market-based administrative reforms are those that promote marketbased mechanisms like competitive contracting for the provision of services to lower costs and improve service delivery. Participatory reforms structure decision-making authority among program participants, including both clients and service providers. Other administrative reforms that reduce the number and type of bureaucratic procedures and rules are termed deregulatory.

Using a dichotomous measurement of adoption/non-adoption as the dependent variable and a Boolean algebra statistical analysis, Peters theorizes that a number of political and cultural factors might affect policy diffusion and transfer. He argues that previous researchers have tended to neglect political factors as an explanation for policy diffusion and transfer, yet in the case of administrative reforms political factors are likely to play an important role, since their end result is to directly change the form and nature of government. His first hypothesis is that governments controlled by conservative parties are more likely to adopt market-based reforms. He also hypothesizes that countries with strong public-sector labor unions will be less likely to 
embrace management reforms that might potentially reduce government employment or change the necessary job skills for existing employees. The third explanatory variable Peters considers is socio-economic based, whether a country has a higher than average national budget deficit. To measure the impact of culture, he categorizes countries as belonging to one of four particular administrative cultures: Anglo-American, Germanic, Napoleonic or Scandinavian. His central argument here is that countries with a common administrative culture not only share a common view of how government should be conducted but also represent another type of policy community for idea and information sharing (epistemic communities).

Peters' first conclusion is that the rate and patterns of administrative reform diffusion differ by reform. Some have been more readily embraced particularly those categorized as participatory reforms. He finds that Anglo-American countries (in the case of Western Europe, only Britain) are leaders in policy innovation and adoption. He concludes that this empirical evidence of the role of culture in policy diffusion further supports the concept of a family of nations used by other comparative politics and policy researchers. Contrary to his hypothesis, Peters finds a lack of evidence and political ideology and parties has an impact on administrative reform diffusion. He explains this as an issue that probably will be embraced by those from various points on the political spectrum. No one is likely to advocate for increased government waste.

Peters identifies shortcomings in this line of research. One is using countries for the level of analysis finding that much more significant administrative reform can be found at the sub-national level (for example, in Germany). Another problem central to 
this line of research is the balance between aggregated quantitative research that leads to more generalizable conclusions versus the case-study approach that enables researchers to examine the policymaking process in more detail.

In a study that returns to the question of the mechanisms that facilitate policy diffusion, Jacqui True and Michael Mintrom (2001) examine the rapid and far-reaching diffusion of gender mainstreaming. Their central argument is that this policy diffusion occurred primarily due to the impetus of transnational networks composed of non-state actors from the United Nations and other international non-governmental organizations. This network not only provided information on policy initiatives but also promoted various political strategies for policy change.

The purpose of gender mainstreaming policy is to identify gender inequalities within countries and promote the creation of permanent national-level bureaucracies that address these inequalities. True and Mintrom find that over a relatively short period of time (1975-1998) new gender mainstreaming bureaucracies were created in over 100 countries. They identify one of the initiating events in this transformation to be a proposal of the 1975 United Nations International Women's Year conference. The authors conclude that the most compelling explanation for the diffusion of gender mainstreaming is the role played by transnational networks among non-state actors ( $p$. 38). Networks of both women and women's organizations from the grassroots upward interact with both governmental actors and international organizations to put pressure on institutions, primarily governmental, to affect change. 
To test their hypothesis, True and Mintrom conduct an EHA of gender mainstreaming policy adoption or non-adoption in 157 countries over a 20-year time period. They find that exposure to the transforming event (attendance at the U.N. Conference on Women) and the presence within a country of international nongovernmental organizations that were also active in the women's conference are both statistically significant as explanatory variables. The authors describe the role of the transforming event as "lightening rods that have helped to channel the collective buzz of ideas and energy emanating from the global women's movement into prescriptions for and commitments to policy action at the level of the nation-state" (p. 48-49). This supports the idea that even when policymakers have common needs, interests, or ideas, some sort of impetus is required to move policy to the action agenda. In this case, it appears to be a combination of a conference (increasing issue salience and formation of networks) and the existence of nongovernmental organizations on the local level that contribute to the drive towards change.

Their model also shows that momentum was created that increased the likelihood of adoption over time - a snowball effect of sorts. Other factors that are related to policy adoption are the degree of democracy of a country, percentage of women as government ministers, and the proportion of women who gain formal education at an equivalent level to men in the country. Non-significant variables include membership of an individual country in intergovernmental, resources measures such as Gross Domestic Product, and aggregate education levels. 
One of the contributions of True and Mintrom is the multi-level analysis that is conducted of the dependent variable. Adoption of gender mainstreaming policy is not measured as a single dichotomous variable. Rather, they recognize that as policy is adopted across time, the adoption itself often is transformed. As this reinvention occurs, a country might readopt a different form of the policy, thus incurring more than one instance of policy adoption. In this research, the authors consider whether changes were made in either lower-level or higher-level governmental institutions. Of the 110 countries studies, 22 made more than one adoption, thus increasing the number of cases in the analysis.

True and Mintrom argue that the most important explanatory factor for the adoption of gender mainstreaming is the role of transnational networks. They not only increase the salience of related issues but also promote the use of specific policy strategies and instruments. Despite the ubiquitousness of women's issues on the global agenda for many years, they believe the women's conferences have created a setting for the formation and continuation of policy networks. They further find that "these networks provide both political momentum and societal pressure for meaningful institutional change" (p. 38). These polarizing events also have an impact upon global norms that often contribute to policy changes by various countries.

Another more recent study of cross-national policy transfer is by Donley Studlar (2002). This exploration of tobacco control policy examines policy transfer between the United States and Canada over a 20-year period beginning in the early 1960's. He considers several possible theoretical explanations for similarities and differences in 
tobacco policy between these two countries. He finds strong evidence to support lesson-drawing as a predominant explanation for policy development over time, especially in the 1990s. In particular, he finds that lesson-drawing accounts for policy convergence at the national level between these two countries. His study finds evidence for policy transfer between the two countries, between different levels of government, and among government and non-governmental (including cross-border) groups.

One focus of this study is the development of similar policy instruments in tobacco control policy in Canada and the U.S. Studlar finds many common instruments are used in both countries with the trend of similarity accelerating in recent years. He identifies three major types of policy instrument (regulation, finance, and capacity building) that can be broken down into eleven separate categories. However, he argues despite the evidence of convergence in policy one cannot necessarily assume that policy transfer has occurred. To verify transfer, further corroborating evidence is needed. One way that this is done is simply assessing which specific policies are put into place and identify when that policy is adopted. By comparing similar policy adoptions by the two countries, patterns of possible transfer are detected. Other evidence includes documented consulting by bureaucrats and non-governmental officials across the border, recorded talks, meeting reports, governmental reports, and sometimes legislation or bureaucratic rules. He also identifies key players in the transfer of policy information between the countries, including bureaucrats, advocacy groups and journalists. 
In general, Studlar finds that there is "considerable evidence that lesson drawing is occurring" (p. 239) between Canada and the U.S. in tobacco control policy. Lesson drawing occurs not only between the two governments at the federal level but also across different levels of government (for example, between the Canadian federal government and U.S. states). He states that lesson drawing needs to be broadly defined not only as transfer of particular policies but also transfer of policy instruments and political techniques for achieving policy goals. He also identifies important agents of policy transfer that facilitate the process such as bureaucrats, the media, and advocacy groups with the number and type of agents increasing as the range of policy instruments broadens. In the case of Canada and the U.S., who share a common language and easy accessibility to each other's published materials, he finds that researchers, especially those who participate in consultation with government and advocacy actors, also play a role in policy transfer. Bureaucrats are often key agents, in particular when transfer occurs directly from government to government. He even finds cases of policy entrepreneurs who have been employed by both U.S. and Canadian governmental and non-governmental organizations, an occurrence that would not be possible for elected officials. Furthermore, given multiple theories for policy similarities or convergence including political culture, agenda setting, interest groups, political institutions, parties and elections, and policy typologies, there is considerable evidence that lesson drawing is a predominant explanation. 


\section{Conclusion}

Despite differences, primarily in research approach (quantitative vs. case study), there are some common threads that can be identified from both comparative U.S. state and comparative country policy transfer research. The primary explanations for policy transfer are economic factors, geographic proximity, and political factors. In addition, comparative country research demonstrates that policy transfer is more likely to occur among those countries with similar cultures and languages.

Policy innovation and transfer is a complex process that has been studied by many different researchers. One of the contributions of this line of research is its enhancement of our knowledge of how public policy is made. Both internal and external factors that lead to policy innovation and transfer have been identified. Some of the internal factors such as socioeconomic conditions and active participation of policy actors such as interest groups dovetail nicely into the findings of other bodies of research such as that on U.S. state politics. Other factors that possibly explain policy transfer such as geographic diffusion patterns provide a unique outlook on public policymaking. In general, researchers have made numerous inroads into an examination of policy innovation and transfer among various types of political units and in different policy areas.

However, there are still areas that need further research. The focus of policy transfer research remains national and regional political units. Because the most convenient way to measure comparable policy adoption among political units is legislative adoption, this remains the standard measure of whether or not a policy has 
been adopted at any particular time. The emphasis on legislative adoption leads to a neglect of other important policymakers such as judicial bodies and bureaucracies. Policymaking is a temporal process, and some researchers use statistical techniques that include a time element in their models. However, the complexity of adding sufficiently long periods of time in a model often restricts researchers to the study of a single program or policy. Thus, the generalizibility of findings from these studies is limited.

Finally, the emphasis of these studies tends to be on inputs and outputs (the determinants and outcomes of policy transfer) with scant attention given to what is going on inside the box. While Mintrom begins to examine the process of policy innovation and transfer in his studies of policy entrepreneurs, it is only the first step. There remains a need for study of how other policy actors are specifically involved in the process of policymaking. This study will begin to consider some of these points, in particular, how state bureaucracies are involved in the process of policy innovation and transfer. 


\section{CHAPTER 4}

\section{THE PROFESSIONAL COMMUNICATION NETWORKS OF STATE BUREAUCRACIES}

The research component of this dissertation takes a two-fold approach. The common thread between the two is an examination of the bureaucratic role in policy transfer. Chapter four provides a description of the communication networks of state public health bureaucracies. This is an important addition to the literature on policy transfer. The existence of a network of policymakers who communicate ideas and information is presupposed but has not been formally documented or described other than in general terms.

Chapter five is quantitative and employs statistical analysis, primarily an OLS regression model. It begins by specifying a general model of policy transfer based upon the research findings that examine legislative policy adoptions and transfer. This model is compared to a different model that uses a composite index of bureaucratic policy innovation as the dependent variable. In the second model, the independent variables are those shown to be significant to legislative policy innovation and transfer as well as others hypothesized to be important to bureaucratic policy innovation and transfer. The primary purpose of this analysis is to demonstrate the shortcomings of policy transfer research that neglects the bureaucratic role in policymaking.

Professional communication networks are an essential element of the process of policy innovation and diffusion among states. This chapter examines the specific mechanisms of communication among state bureaucracies. It also demonstrates the 
relative importance of components of the communication network among state public health officials.

Innovation and diffusion studies have usually focused on the determinants and outcomes of policy transfer while giving little attention to the process of policy innovation and diffusion (Mintrom \& Vergari, 1998). This lack of attention toward the process has led to a focus on legislative adoption of policy while neglecting the important role that bureaucracies play in both agenda setting and program/policy development (Elling, 1996).

Berry and Berry (1999), as well as others (Rose, 1993; Walker, 1971), assert that policy transfer research based on a national interaction model assumes the existence of a national network of state public-sector officials who communicate with one another on new policy adoptions. Chi and Grady (1991) have also found that the lateral transfer of information between state administrative officials is an important source of information on innovative policies. However, these studies have neither empirically demonstrated the existence of these networks nor examined their composition.

\section{Professional Communication Networks}

In order to better understand the process of innovation and diffusion, an important first step is an examination of the infrastructure that allows for the diffusion of policy: the professional communication network. A variety of information sources are available through which policymakers learn of innovation in other states (Rose, 1993). According to Mintrom and Vergari (1998), there are two different networks: the internal and external. Policymakers are members of internal policy networks that establish 
connections between themselves and a local policymaking community. However, policymakers are more likely to utilize external policy networks to develop ideas for policy innovation. These networks are composed of interactions with counterparts in other states. This study provides a detailed examination of the external policy networks of state public health bureaucracies.

\section{Bureaucracies and Policy Transfer}

The importance of bureaucracies in the policymaking process has been established in a number of studies (Elling, 1996; Ripley \& Franklin, 1986; Rourke, 1984; Sharkansky, 1971; Wood \& Waterman, 1994). Given the limited capacity of many state legislatures (especially as initiators of policy) and the multitude of policy areas for which they are responsible (Thompson, 1986), it could be hypothesized that the bureaucracy is a highly active and important participant in the development of policy and programs (e.g., Desveaux, Lindquist, \& Toner, 1994; Dolowitz, 1996). Because legislatures and governors must be familiar with a wide array of policy areas, they become dependent on administrators specializing in single policy areas for information (Miller \& Moe, 1983; Sharkansky, 1971; Thompson, 1986). These administrators as policy experts become quite influential in the choice of policy alternatives and in the assessment of feasibility of alternatives in particular (Gow, 1994).

Any occurrence of policy transfer will ultimately involve the bureaucracy. In some instances, the bureaucracy may propose programs that are new to their state or even draft legislation. In other circumstances, the bureaucracy will be directed by a principal such as the Governor or state legislature (or even the federal bureaucracy or Congress) 
to implement programs that have been borrowed from other jurisdictions. Thus, it is important to consider the bureaucratic role in the policy innovation and transfer process.

Two major shortcomings exist in the U.S. state policy transfer literature. First, is the focus on legislatures. While several policy transfer studies have examined the role of the legislature in state policy (e.g., Berry \& Berry, 1990; Glick \& Hayes, 1991; Mooney \& Lee, 1995), few have considered the bureaucratic role. Most state policy transfer literature measures the dependent variable as the adoption of a particular piece of legislation. This implies that policy innovation and/or adoption is only made by legislatures through statutory procedures. However, the bureaucracy is also an active participant in the policymaking process, especially at the state level (Sharkansky, 1971). Agencies design and implement programs, write grant applications administer federally funded programs, draft legislation, and provide technical assistance to local government and legislators. All of these activities ultimately lead to the state bureaucracy as policymaker.

The role of state administrative agencies in the formation of public policy is increasingly important (Bowling \& Wright, 1998). Over the past thirty years, state agencies have grown in quality. Well-educated, experienced professionals head most agencies. The growing capacity of state administrative agencies is a function of both institutional (macro) and personal (micro) characteristics. Not only are state agencies being asked to do more, they are now capable of doing more (Bowman \& Kearney, 1988). 
The functional specialization that occurs in a bureaucracy is especially conducive to policy transfer (Rose, 1993; Sanford, 1967). Agency heads are likely to be much more interested in the activities of their counterparts in neighboring states than in the activities of other policy areas within their own state. Relationships grow from a perception on the part of these administrators that their counterparts in neighboring states are likely to have similar problems, tasks, and circumstances. For example, a state administrator of the federal maternal and child health $(\mathrm{MCH})$ block grant are like to have more in common with other state $\mathrm{MCH}$ directors than with the administrator of a federal transportation grant within their own state. State administrators see themselves as part of a unique profession; a specialist in the administration of particular state public health functions. They become an important part of policy communities who actively and regularly exchange information about policy ideas (Grady \& Chi 1990; Kirst, et al, 1984).

The other shortcoming of the policy transfer research is that studies primarily focus on the endpoints (the determinants and outcomes of policy transfer) while neglecting the middle. Yet, the process by which policy transfer occurs is perhaps the most important aspect of this line of inquiry (Mintrom \& Vergari, 1998). How does the transfer of policy actually occur? It has been established that policy transfer occurs and numerous hypotheses have been generated concerning the process by which it happens (e.g., Rose, 1993). Few studies, however, have provided strong evidence to support these hypotheses. The few exceptions to this are the comparative-national studies that provide rich descriptive evidence of the policy transfer process (Bennett, 
1990; Desveaux, Lindquist, \& Toner, 1994; Dolowitz, 1996; Studlar, 2002). Their generalizability, however, is limited because they often compare only two or three countries in a single policy area. Policymaking is a dynamic rather than static process that requires research that incorporates the notion of process as well as outcomes into the analysis.

\section{The Composition of Communication Networks}

Because bureaucracies tend to be composed of people who are experts in a single policy area, the communication network of those bureaucracies should reflect this specialization. However, within a single policy area, such as public health, a multitude of different specializations often exist. Public health policy actually has two major dimensions. It is both an area of scientific/technical policy and one of social welfare policy. The different primary functional areas of state public health can each be categorized into one of these areas. For example, the functional areas of epidemiology, occupational health, and laboratory services are highly technical and require employees who are not only specialists in public health but also in medicine, biochemistry, biostatistics, and epidemiology. In contrast, areas such as maternal and child health, rural health, chronic disease prevention, and health promotion focus on the provision of social welfare benefits and need specialists in social work, health education, and nursing.

The specialization of public health bureaucracies leads to the predominance of functional areas by particular professions. Most state epidemiologists are either medical doctors or have graduate-level training in epidemiology. The education of state 
laboratory directors is usually in chemistry or biology. In contrast, directors of maternal and child health often come from backgrounds such as social work and nursing. These state bureaucrats tend to identify with two specific professions - that of a public health administrator and of their academic specialty such as medicine or social work. It is likely, therefore, that they will depend on both of these avenues for professional information. The end result is that within a single state public health department different administrators receive policy information from both common sources (those related to public health in general) as well as differing sources (specific to their professions and/or functional specialty).

Another important question is how officials receive policy/programmatic information from other states. There are numerous mechanisms through which state health officials can communicate with one another. Some of them (e-mail, telephone, web pages, faxes) are available on a daily basis while others, such as meetings, conferences, travel to other states, and reading materials, provide less frequent opportunity for communication. There are also differences in cost. The low cost of electronic communication in combination with its near constant accessibility lead one to believe these mechanisms will be used more frequently and more widely than other types. It is plausible that most officials use all of these communication mechanisms although perhaps for varying purposes. For example, the communication of some public health information is of an urgent nature. If a state laboratory director identified a microorganism that caused a food-borne illness in the production facility of a product shipped from his state to other states, the timely dissemination of that information would 
be crucial to prevent spread of illness. By contrast, sharing the evaluation of a new workplace safety program with occupational health directors throughout the nation would be much less pressing, although perhaps just as important to their state counterparts.

The level of technical/scientific expertise held by administrators could also affect preferences for particular communication mechanisms. Those who direct programs and come from professions of a technical/scientific nature are likely to be more comfortable with computer-based communication such as e-mail and web pages. They are also quite accustomed to research and information sharing through professional journals.

\section{Hypotheses}

The above description of the professional backgrounds of state public health bureaucrats and potential mechanisms for the communication of policy/programmatic information provide some hypotheses regarding the state public health communication network.

1. Preferred communication mechanisms: Because they are less expensive and more constantly available, electronic mechanisms such as telephone, e-mail, and web pages will be used more often to share information than conference participation, journals, and site visits. In relation to electronic mechanisms, meetings will be less important for policy transfer due to their expense.

2. Technical communication mechanisms: Administrators of technical/scientific functions are more likely to use e-mail and journals for information sharing than the administrators of social welfare functions. 
Again, due to their professional affiliations and educational backgrounds, state epidemiologists, laboratory directors, and occupational health directors are likely to have more experience conducting research and gathering information through these mechanisms.

3. Multiple networks: There is not a single professional communication network among state public health administrators. Each functional area has its own unique communication network.

The distinctive networks will develop not only due to the predominance of different professions within functional areas but also because administrators share more common work tasks with their state counterparts than with other public health administrators within their state. For example, all administrators oversee federal grants but the differing requirements of each grant require expertise/knowledge in that particular grant - something shared with counterparts in other states.

\section{Data and Methods}

Data for this study were obtained in mid-1999 through a 50-state mail survey. Surveys were sent to the lead public health official and the primary official for seven major functional areas of public health in each state (laboratories, chronic diseases, maternal and child health, epidemiology, rural health, occupational, and health promotion/education). For the purpose of this study, major public health functions are those that encompass a number of different public health activities and that are common to the majority of state public health departments. By this definition, an immunization division would be too narrow because it contains a sole activity. However, 
a division of chronic diseases with multiple activities (such as cardiovascular disease prevention, cancer, hypertension prevention, and diabetes control) is included in the study.

Due to variations in organizational structure, some states identify a single individual as the lead official in more than one area (i.e., chronic disease and health promotion). In these cases, the survey was sent only once, resulting in a total of 380 surveys mailed. Forty percent of those surveyed replied with at least one response obtained from 49 of the 50 states. In addition, 20 telephone interviews with state public health officials from a variety of regions and functional areas were conducted prior to the mail survey.

\section{Results}

Analysis of survey data provides a number of interesting findings related to professional communication networks and their use to transfer policy information among state bureaucracies. Survey respondents were asked to identify their use of various communication mechanisms for the sharing of best practices information as well as indicate the importance of various specific communication mechanisms. Public officials use the term "best practice" to indicate an innovative, strong program unique to a particular organization or political unit. It is the bureaucratic term that best translates into the concept of policy innovation. This concept is important because it not only conveys a sense of a policy innovation but also implies a deliberate effort to identify and 
communicate well-designed and implemented programs that have measurable, positive outcomes.

TABLE 4-1

\section{MECHANISMS FOR SHARING OF INFORMATION ON PUBLIC HEALTH BEST PRACTICES}

\begin{tabular}{|c|c|c|c|c|c|}
\hline FUNCTION & E-MAIL & $\begin{array}{c}\text { INTERNET } \\
\text { LISTSERVE } \\
\text { MAIL LISTS }\end{array}$ & TELEPHONE & $\begin{array}{c}\text { STATE } \\
\text { PUBLIC } \\
\text { HEALTH } \\
\text { WEB } \\
\text { PAGES }\end{array}$ & $\begin{array}{c}\text { PROFESIONAL } \\
\text { ORGANIZATION } \\
\text { WEB PAGES }\end{array}$ \\
\hline $\begin{array}{c}\text { Chronic } \\
(\mathrm{n}=19)\end{array}$ & $52.7 \%$ & $40.0 \%$ & $36.8 \%$ & $30.0 \%$ & $21.1 \%$ \\
\hline $\begin{array}{c}\text { Director } \\
(\mathrm{n}=22)\end{array}$ & 47.6 & 9.5 & 28.6 & 22.7 & 18.2 \\
\hline $\begin{array}{c}\text { Epidemiology } \\
(\mathrm{n}=23)\end{array}$ & 45.5 & 47.8 & 34.8 & 13.0 & 4.3 \\
\hline $\begin{array}{c}\text { Health } \\
\text { Promotion } \\
(\mathrm{n}=11)\end{array}$ & 54.6 & 27.3 & 45.5 & 27.3 & 18.2 \\
\hline $\begin{array}{c}\text { Laboratory } \\
(\mathrm{n}=19)\end{array}$ & 84.3 & 63.2 & 61.1 & 36.8 & 52.6 \\
\hline $\begin{array}{c}\text { Maternal \& } \\
\text { Child Health } \\
(\mathrm{n}=22)\end{array}$ & 36.4 & 76.2 & 9.1 & 33.3 & 40.9 \\
\hline $\begin{array}{c}\text { Occupational } \\
(\mathrm{n}=15)\end{array}$ & 46.6 & 42.9 & 33.3 & 14.3 & 21.4 \\
\hline $\begin{array}{c}\text { Rural Health } \\
(\mathrm{n}=17)\end{array}$ & 83.4 & 44.4 & 68.8 & 35.3 & 35.3 \\
\hline $\begin{array}{c}\text { All Functions } \\
(\mathrm{n}=147)\end{array}$ & 55.8 & 44.9 & 38.0 & 26.5 & 26.5 \\
\hline
\end{tabular}




\section{Communication Mechanisms}

The percentage of state officials using specific communication mechanisms to share best practices information varies not only by mechanism but also among functional areas. Table 4-1 shows aggregated data regarding this topic from the survey.

E-mail is the most commonly used means of communication with 56 percent of respondents indicating that they use it to share information with their counterparts in other states on common problems or best practices. The use of e-mail is highest for laboratory directors and rural health directors where 84 percent responded positively. E-mail is used least commonly by maternal and child health directors (36 percent). Interestingly, this group shows the highest use of Internet listserve mail lists with 76 percent of respondents listing the receipt of at least one mail list. It is possible that the high usage of mail lists diminishes the use of one-on-one e-mail message and telephone calls. The lowest use of mail lists was found among directors of public health with 9 percent receiving best practices information this way. Among all state health officials, 45 percent indicated the use of Internet mail lists making this the second most commonly used communication mechanism.

Another commonly used mechanism of communication on best practices is the telephone. Of all state health officials, 38 percent indicated that they use the telephone on a daily or weekly basis to communicate with their counterparts in other states. For other respondents, telephone use occurred monthly or less frequently. Directors of maternal and child health were the least likely to use the telephone with only 9 percent 
indicating that they do so. It is possible that the common use of electronic mail lists among this group limits the necessity of other forms of communication such as direct email and telephone calls. Telephone use was highest among rural health directors (69 percent) and laboratory directors (61 percent).

Of those communication mechanisms available on a daily basis, the least used was web pages. Only 27 percent of respondents indicated that they used the web pages of other state health departments or professional organizations to obtain information on state best practices. The use of other state public health web pages was highest among laboratory directors with 37 percent signifying their use. It was lowest among state epidemiologists and directors of occupational health. The use of professional organization web pages was highest among laboratory directors with 53 percent indicating that they obtained best practices information from such. Maternal and child health directors (41 percent) also had high usage of professional association web pages. Epidemiologists had the lowest use at 4 percent. Of those who indicated the use of professional organization web pages, 63 examples were given representing 40 different web pages of either government agencies, non-governmental organizations such as the National Governors Association, nonprofit organizations, or professional public health organizations. Only eight of the web pages were listed by more than one official with the highest common use found for the Centers for Disease Control and Prevention (six respondents) and the Association of State and Territorial Health Officers (five respondents). A similar lack of common use was found for learning of best practices from other states' web pages. This inconsistency indicates that there may not 
be clear evidence of a coherent communication network, at least using electronic communication mechanisms.

There is clear variation among functional areas in the use of various informationsharing mechanisms. Not only are different mechanisms used at varying rates among different functional areas, but also the number of officials communicating about best practices through any mechanism is higher in some functional areas than others. Overall, 38 percent of state health officials indicate use of these five communication mechanisms. However, communication on best practices information is much higher among lab directors (60 percent) and rural health directors (54 percent). The lowest level is found among state health directors ( 25 percent). One explanation for this low level of communication is the nature of the state health directors' job. Officials at the functional level are much more involved on a day-to-day basis with programmatic issues and are, therefore, in need of programmatic and technical information. State health directors, however, are more heavily involved in broad policymaking and interactions with elected state officials. Their positions require less interaction with their counterparts in other states and more interaction with officials within their own state. 
TABLE 4-2

TYPES OF INFORMATION SHARED BY TELEPHONE AND E-MAIL

\begin{tabular}{|l|c|c|}
\hline TYPE OF INFORMATION SHARED & $\begin{array}{c}\text { E-MAIL } \\
(\mathrm{n}=156)\end{array}$ & $\begin{array}{c}\text { TELEPHONE } \\
(\mathrm{n}=207)\end{array}$ \\
\hline Technical issues & 30.1 & 31.4 \\
\hline Programmatic information & 30.1 & 27.5 \\
\hline Problem solving & 5.1 & 8.7 \\
\hline Funding/grant/budgetary information & 3.2 & 7.2 \\
\hline $\begin{array}{l}\text { Policy; agency/state legislature } \\
\text { relations }\end{array}$ & 6.4 & 6.3 \\
\hline Miscellaneous & 5.8 & 6.3 \\
\hline Federal activities - Congress & 3.2 & 4.3 \\
\hline Inquiry response & 5.1 & 3.4 \\
\hline Planning for meetings & 4.5 & 2.9 \\
\hline Surveys & 3.8 & 1.0 \\
\hline Federal activities - federal agencies & 2.6 & 1.0 \\
\hline
\end{tabular}

* The $\mathrm{n}$ for these variables exceeds the total number of respondents in the survey because of multiple responses from some officials.

\section{Types of Information Shared}

Given these interactions among state health officials, what kinds of information do they share via e-mail and telephone? When asked this question, almost one-third of the responses indicated sharing of technical information. Examples include disease outbreak information, laboratory licensing issues, and regulatory issues. Another onethird of responses indicated information sharing on programmatic issues such as details 
of the implementation of a specific program or grant in a state, program descriptions, and ideas for new resources or materials. Other types of information sharing, though cited less frequently, include activities at the federal level, responses to inquiries, problem solving, survey response, funding/budgetary information, meeting planning, and public policy and state legislature/agency relations. This focus on programmatic/technical information provides further evidence that communication among administrators focuses on issues specific to their functional area rather those related to a broader public health mission. 
TABLE 4-3

\begin{abstract}
MEETINGS/CONFERENCES ATTENDED BY $30 \%$ OR MORE OF SURVEY RESPONDENTS IN A FUNCTIONAL AREA
\end{abstract}

\begin{tabular}{|l|c|l|}
\hline \multicolumn{1}{|c|}{ MEETINGS/CONFERENCE } & $\begin{array}{c}\text { PERCENT OF } \\
\text { FUNCTIONAL } \\
\text { AREA }\end{array}$ & FUNCTIONAL AREA \\
\hline American Society for Microbiology & $30 \%$ & laboratory \\
\hline $\begin{array}{l}\text { Association of State and Territorial Chronic } \\
\text { Disease Prevention Directors }\end{array}$ & 85 & $\begin{array}{l}\text { chronic disease } \\
\text { health promotion }\end{array}$ \\
\hline $\begin{array}{l}\text { Association of State and Territorial Directors } \\
\text { of Health Promotion and Public Health } \\
\text { Education }\end{array}$ & 45 & health promotion \\
\hline Association of Public Health Laboratories & 55 & laboratory \\
\hline $\begin{array}{l}\text { Association of Maternal and Child Health } \\
\text { Programs }\end{array}$ & 95 & maternal and child \\
\hline $\begin{array}{l}\text { Association of State and Territorial Health } \\
\text { Officers }\end{array}$ & 74 & state directors \\
\hline $\begin{array}{l}\text { Conference of State and Territorial } \\
\text { Epidemiologists }\end{array}$ & 74 & epidemiology \\
\hline $\begin{array}{l}\text { Epidemic Intelligence Service Officers } \\
\text { Conference } \\
\text { (Centers for Disease Control and } \\
\text { Prevention) }\end{array}$ & 52 & epidemiology \\
\hline $\begin{array}{l}\text { National Organization of State Offices of } \\
\text { Rural Health }\end{array}$ & 74 & rural health \\
\hline National Rural Health Association & 79 & rural health \\
\hline
\end{tabular}

\title{
Other Sources of Information
}

State officials have two other means through which they communicate on public health practices on a less frequent basis: meeting and conference attendance and 
reading materials. During telephone interviews, many state officials emphasized the importance of meetings/conferences as a way to develop contacts with their counterparts in other states. For them, meetings serve a twofold purpose in the sharing of practices. First, the formal program often includes state officials who present descriptions of specific public health programs in their states as well as lessons learned through the implementation of these. However, the informal contacts made with their counterparts in other states are also important because they lay the groundwork for future opportunities to share programmatic information.

The participation of state public health officials in these activities is shown in Table 4-3. Ninety-four percent of survey respondents listed one or more meetings when asked, "Which professional conferences and meetings do you attend on a regular basis?" These responses provided a total of 145 separate meetings/conferences that they attend. The meetings/conferences fall into four categories: (1) medical professional association meetings; (2) public health professional association meetings; (3) regional or state public health meetings; and (4) meetings sponsored by federal agencies. Ninety percent of the 145 meetings/conferences were listed by only one to three respondents. However, 30 percent or more of survey respondents within a single functional area attended ten particular meetings. Six meetings showed very high attendance by officials who administer a common function, providing the best evidence to date of a more comprehensive, although infrequent, communication network. The highest attendance rate was found among maternal and child health directors, 95 percent of whom attend the Association of Maternal and Child Health Program 
(AMCHP) meeting. At least 74 percent of rural health officials indicated attendance at two meetings: the National Rural Health Association and the National Organization of State Offices of Rural Health. State epidemiologists, chronic disease directors, and state public health directors also indicate very high attendance rates at the meeting of their professional organizations (Conference of State and Territorial Epidemiologists, the Association of State and Territorial Chronic Disease Prevention Directors, and the Association of State and Territorial Health Officers). Only one functional area of state public health, occupational health, did not have a single meeting or conference that was attended by at least 30 percent of respondents in that area. The best explanation for this is the nature of occupational public health. For the other functional areas as well as state health directors, there is a clearly delineated relationship between federal and state officials. The role of occupational health, however, is not as clearly defined at the state level. Because occupational health is primarily a regulatory/compliance issue, the relationships in this area of public health exist primarily between federal agencies and other non-state actors such as labor unions and industries. In addition, occupational health is the only area of state public health under study that does not have a professional association devoted strictly to state public health officials within the functional area.

It is also important to note that none of the meetings listed by state health officials were attended by at least 30 percent of state health officials across the board. The closest exception is the annual meeting of the American Public Health Association that is attended by 23 percent of total respondents. This finding not only supports the 
idea of increased specialization and professionalization within functional levels of state public health but provides evidence for the importance of studying communication networks at this functional, rather than policy area level.

TABLE 4-4

JOURNALS, NEWSLETTERS AND PUBLICATIONS READ BY $20 \%$ OR MORE OF SURVEY RESPONDENTS IN A FUNCTIONAL AREA

\begin{tabular}{|l|c|l|}
\hline \multicolumn{1}{|c|}{ READING } & $\begin{array}{c}\text { PERCENT OF } \\
\text { FUNCTIONAL } \\
\text { AREA }\end{array}$ & \multicolumn{1}{|c|}{ FUNCTIONAL AREA } \\
\hline American Journal of Health Promotion & $36 \%$ & health promotion \\
\hline American Journal of Public Health & 35 & all functional areas \\
\hline $\begin{array}{l}\text { Association of Public Health Laboratories } \\
\text { newsletter }\end{array}$ & 35 & Laboratories \\
\hline $\begin{array}{l}\text { Association of State and Territorial Health } \\
\text { Officers newsletters/publications }\end{array}$ & 52 & $\begin{array}{l}\text { state directors } \\
\text { all functional areas }\end{array}$ \\
\hline $\begin{array}{l}\text { Association of Maternal and Child Health } \\
\text { Directors newsletters/updates }\end{array}$ & 35 & $\begin{array}{l}\text { maternal and child } \\
\text { health }\end{array}$ \\
\hline $\begin{array}{l}\text { Chronic Disease Notes and Reports } \\
\text { (CDC publication) }\end{array}$ & 20 & chronic diseases \\
\hline $\begin{array}{l}\text { Journal of the American Medical } \\
\text { Association }\end{array}$ & 26 & $\begin{array}{l}\text { epidemiology } \\
\text { all functional areas }\end{array}$ \\
\hline $\begin{array}{l}\text { Journal of Public Health Management and } \\
\text { Practice }\end{array}$ & 27 & health promotion \\
\hline monthly newsletters from other states & 27 & all functional areas \\
\hline Morbidity and Mortality Weekly Report & 43 & $\begin{array}{l}\text { epidemiology } \\
\text { all functional areas }\end{array}$ \\
\hline
\end{tabular}


As is the case with conferences/meetings, state health officials read a wide variety of journals, newsletters, and publications that help them learn of best practices used in other states. Table 4-4 shows the primary reading sources for state public health officials. When asked to name these, 131 respondents identified a total of 98 different sources of information. As was the case with meetings/conferences, the majority of readings were mentioned only once or twice. This is consistent with Gow's (1994) survey of Canadian public administrators that also indicates a wide variety of journals and written publications are used as sources of policy information. As shown in Table 4-4, however, there are eight sources that are read by at least 20 percent of respondents in a single functional area. There are also five sources read by at least 10 percent of respondents in all functional areas. It is again noticeable that some functional areas do not cite any publications read by at least 10 percent of their officials (occupational health and rural health). However, these officials are included among those who read the publications that exceed 10 percent in all functional areas. 
TABLE 4-5

SOURCES OF INFORMATION ON PUBLIC HEALTH BEST PRACTICES

(percentage of respondents; $n=153{ }^{*}$ )

\begin{tabular}{|c|c|c|c|c|}
\hline & $\begin{array}{c}\text { VERY } \\
\text { IMPORTANT }\end{array}$ & IMPORTANT & $\begin{array}{l}\text { SOMEWHAT } \\
\text { IMPORTANT }\end{array}$ & $\begin{array}{c}\text { NOT } \\
\text { IMPORTANT }\end{array}$ \\
\hline $\begin{array}{l}\text { Meetings sponsored by federal } \\
\text { agencies }\end{array}$ & $51 \%$ & $40 \%$ & $9 \%$ & $0 \%$ \\
\hline $\begin{array}{l}\text { Regional meetings with } \\
\text { counterparts in other states }\end{array}$ & 41 & 37 & 16 & 6 \\
\hline $\begin{array}{l}\text { ASTHO and affiliates annual } \\
\text { meeting }\end{array}$ & 36 & 33 & 20 & 11 \\
\hline $\begin{array}{l}\text { Telephone calls with counterparts } \\
\text { in other states }\end{array}$ & 32 & 39 & 24 & 5 \\
\hline $\begin{array}{l}\text { E-mail or Internet List-server mail } \\
\text { lists with counterparts in other } \\
\text { states }\end{array}$ & 30 & 30 & 27 & 13 \\
\hline $\begin{array}{l}\text { Professional association annual } \\
\text { meetings }\end{array}$ & 28 & 45 & 23 & 4 \\
\hline Professional association journals & 28 & 42 & 25 & 5 \\
\hline Federal agency publications & 28 & 41 & 27 & 4 \\
\hline $\begin{array}{l}\text { ASTHO (or its affiliates) } \\
\text { newsletters or reports }\end{array}$ & 27 & 39 & 22 & 12 \\
\hline $\begin{array}{l}\text { Newsletters/reports from other } \\
\text { state health departments }\end{array}$ & 16 & 38 & 35 & 11 \\
\hline $\begin{array}{l}\text { Professional association web } \\
\text { pages }\end{array}$ & 11 & 19 & 41 & 29 \\
\hline $\begin{array}{l}\text { Site visits to my state by public } \\
\text { health officials from other states }\end{array}$ & 9 & 25 & 36 & 30 \\
\hline Non-governmental organizations & 8 & 30 & 30 & 32 \\
\hline $\begin{array}{l}\text { Newspapers and news } \\
\text { magazines }\end{array}$ & 7 & 27 & 42 & 24 \\
\hline $\begin{array}{l}\text { Sites visits to other state health } \\
\text { departments }\end{array}$ & 7 & 25 & 33 & 35 \\
\hline $\begin{array}{l}\text { Web pages from other states' } \\
\text { health departments }\end{array}$ & 6 & 21 & 41 & 32 \\
\hline
\end{tabular}

* Non-response varies from 6-11\% per item 


\section{Most Important Communication Mechanisms}

State public health officials have a wide variety of means through which they learn of other states' best practices. In order to assess the wide range of importance of various sources of information, state officials were asked to rate 16 different information sources as very important, important, somewhat important, or not important. Meetings, including those sponsored by federal agencies, professional associations, and regionally with their counterparts in other states, are ranked as Avery important" by the highest percentage of respondents. This further verifies the importance of meetings as shown by the high percentage of state officials who regularly attend particular meetings (Table 4-3). Thus, evidence is lacking to support the hypothesized diminishing importance of meetings/conferences for the sharing of programmatic information vital to policy transfer.

The next most important sources of best practices information are telephone calls with counterparts in other states, ranked as "very important" by 32 percent of respondents and e-mail (30 percent). Those sources that were ranked very low

included web pages (professional association and state public health departments), site visits to and from other state health departments, non-governmental organizations, and newspapers and news magazines. So, the expected importance of e-mail and telephone calls is confirmed.

Elite telephone interviews provide some insight into why these particular sources are ranked in such a manner. The demands of day-to-day program administration limit the amount of time that many officials have to acquaint themselves with other states' 
public health programs. Meetings/conferences were often portrayed as the place they could get the most valuable information for the time and money spent. Conference content usually consists of very specific information on public programs, including presentations by health officials from various states, that portrays design and implementation of limited, specific programs. Examples might include a cardiovascular prevention program for chronic disease officials or a "how to" on teenage pregnancy prevention programs for maternal and child health directors. Federal agency publications also tend to be focused in both content and audience. In contrast, e-mail and professional association journals tend to be broader in content and audience, thus requiring a culling of information that is relevant to a particular state and public health function. Many state officials indicated through telephone interviews that site visits between them and their counterparts in other states rarely occurred. This is due to very restricted travel budgets and/or travel regulations. An examination of state health web pages finds them to generally be broad in nature and lacking specific programmatic information that would be useful for other health officials. 
TABLE 4-6

MOST IMPORTANT SOURCES OF INFORMATION ON BEST PRACTICES

(percentage of respondents within function; $n=153$ )

\begin{tabular}{|c|c|c|c|c|c|c|c|c|c|}
\hline & $\mathrm{CHR}$ & DIR & EPI & HPR & LAB & $\mathrm{MCH}$ & OCC & RUR & ALL \\
\hline $\begin{array}{l}\text { Meetings sponsored by } \\
\text { federal agencies }\end{array}$ & 25.5 & 9.3 & 20.6 & 18.5 & 7.8 & 16.7 & 30.6 & 19.4 & 18.0 \\
\hline $\begin{array}{l}\text { Regional meetings with } \\
\text { counterparts in other states }\end{array}$ & 5.9 & 22.2 & 19.0 & 18.5 & 13.7 & 16.7 & 11.1 & 25.0 & 16.4 \\
\hline $\begin{array}{l}\text { ASTHO and affiliates annual } \\
\text { meeting }\end{array}$ & 11.8 & 25.9 & 6.3 & 18.5 & 9.8 & 12.5 & 8.3 & 2.8 & 12.0 \\
\hline $\begin{array}{l}\text { Telephone calls with } \\
\text { counterparts in other states }\end{array}$ & 7.8 & 5.6 & 9.5 & 14.8 & 15.7 & 4.2 & 8.3 & 11.1 & 9.3 \\
\hline $\begin{array}{l}\text { Professional association } \\
\text { annual meetings }\end{array}$ & 0 & 1.9 & 12.7 & 3.7 & 9.8 & 10.4 & 13.9 & 13.9 & 8.2 \\
\hline Federal agency publications & 11.8 & 5.6 & 12.7 & 3.7 & 5.9 & 6.3 & 8.3 & 0 & 7.4 \\
\hline $\begin{array}{l}\text { E-mail or Internet List-server } \\
\text { mail lists with counterparts in } \\
\text { other states }\end{array}$ & 15.7 & 1.9 & 7.9 & 3.7 & 9.8 & 6.3 & 5.6 & 5.6 & 7.4 \\
\hline $\begin{array}{l}\text { Professional association } \\
\text { journals }\end{array}$ & 5.9 & 7.4 & 4.8 & 14.8 & 7.8 & 10.4 & 5.6 & 2.8 & 7.1 \\
\hline $\begin{array}{l}\text { ASTHO (or its affiliates) } \\
\text { newsletters or reports }\end{array}$ & 3.9 & 11.1 & 1.6 & 3.7 & 3.9 & 8.3 & 2.8 & 2.8 & 4.9 \\
\hline $\begin{array}{l}\text { Newsletters/reports from } \\
\text { other state health } \\
\text { departments }\end{array}$ & 3.9 & 0 & 4.8 & 0 & 7.8 & 0 & 2.8 & 5.6 & 3.3 \\
\hline $\begin{array}{l}\text { Non-governmental } \\
\text { organizations }\end{array}$ & 2.0 & 5.6 & 0 & 0 & 2.0 & 4.2 & 0 & 0 & 1.9 \\
\hline $\begin{array}{l}\text { Newspapers and news } \\
\text { magazines }\end{array}$ & 0 & 1.9 & 0 & 0 & 0 & 0 & 2.8 & 8.3 & 1.4 \\
\hline $\begin{array}{l}\text { Sites visits to other state } \\
\text { health departments }\end{array}$ & 3.9 & 1.9 & 0 & 0 & 0 & 2.1 & 0 & 0 & 1.1 \\
\hline $\begin{array}{l}\text { Professional association web } \\
\text { pages }\end{array}$ & 0 & 0 & 0 & 0 & 2.0 & 2.1 & 0 & 2.8 & 0.8 \\
\hline $\begin{array}{l}\text { Site visits to my state by } \\
\text { officials from other states }\end{array}$ & 0 & 0 & 0 & 0 & 3.9 & 0 & 0 & 0 & 0.5 \\
\hline $\begin{array}{l}\text { Web pages -other states' } \\
\text { health departments }\end{array}$ & 2.0 & 0 & 0 & 0 & 0 & 0 & 0 & 0 & 0.3 \\
\hline
\end{tabular}


Our understanding of how state officials communicate with one another on program innovations can be further developed if we examine which sources of information are most important to them. When asked to specify which three sources of information on best practices are most important, state officials again named meetings most frequently. Across all functions areas, 18 percent of respondents listed meetings sponsored by federal agencies as one of the three most important sources. Regional meetings with counterparts were named by 16 percent of respondents and 12 percent of respondents named ASTHO and their affiliates' annual meetings. As was the case when individual sources were rated from very important to not important, site visits to and from other state health departments and professional organization and state health department web pages appear to be important to very few officials. Fewer than 2 percent of all respondents selected sites visits or web pages as one of the top three sources for information on other states' best practices.

Some variation is found within functional areas with regards to the most important sources of information. For state public health directors, the highest ranked source was ASTHO and its affiliates' meetings, chosen by 26 percent of them as one of the most important sources. Only 3 percent of rural health directors chose ASTHO and its affiliates' annual meetings. This is not surprising, since there is no affiliate for rural health. There is also not an affiliate for occupational health officials, 8 percent of whom chose it, but many of these officials are trained as epidemiologists and participate in the organizations of that profession (including the Council of State and Territorial Epidemiologists). The source chosen by the highest number of chronic disease 
directors (26 percent), state epidemiologists (21 percent), maternal and child health directors (17 percent), and occupational health directors (30 percent) was meetings sponsored by federal agencies. For health promotion/education directors, the most commonly listed important source was meetings (federal, regional, and professional association all at 19 percent). Telephone calls with counterparts in other states was listed most frequently by state laboratory directors (16 percent), the only group that did not list meetings most often as the most important source of information on best practices. This variation may be due to the more specific and technical nature of their information needs.

One possible explanation for the attendance of meetings to some groups is the source of funding for these areas. In most states, many public health programs are funded primarily through federal grants. Most state maternal and child health program funding comes through the federal Maternal and Child Health Services Block Grant, a formula-based grant administered by the Health Services Resources Administration. The bulk of chronic disease programs are also funded by federal agencies, primarily categorical grants by the Centers for Disease Control and Prevention. Examples include funding for cardiovascular prevention, tobacco control/prevention, and diabetes prevention and treatment. Many of these grants, in particular categorical grants, not only make funds available for state representatives of these programs to attend periodic meetings but often require attendance. The involvement of federal agencies in this manner affects the communication patterns in particular functional areas. 


\section{Conclusion}

Professional communication networks provide an important means by which state administrators communicate with their counterparts in other states. The results of this empirical analysis indicate that state officials use a variety of communication mechanisms to learn of other states' program design, for problem solving, and to share technical information. As hypothesized, the largest number of administrators used electronic mechanisms (e-mail and telephone). However, this did not hold true for web pages, the most infrequently used communication tool. Despite their expense and limited state travel budgets, meetings/conferences are the most importance source of information for state administrators.

The use of communication networks by these officials appears to be occurring on a regular basis throughout various functional areas of public health and throughout the country. However, interactions among officials seem to occur primarily on an ad hoc basis. There does not appear to be a comprehensive, integrated network that can be used to methodically share program innovations, design, and implementation successes and failures. This is especially true as state public health is seen as a single policy community communicating with one another across functional boundaries. The lack of such a comprehensive, routinized network that reaches all state officials within a particular functional area not only limits the sharing of information among these officials but also curtails the ability of other policy actors such as federal agencies, legislative bodies, and non-governmental and professional organizations to communicate within broader policy networks. 
It is clear that other organizations, such as federal agencies and professional organizations, play an integral role in the facilitation of professional communication networks among state administrators. They not only provide mechanisms of communication but also develop and fund important network development. In many of these functional areas, federal health agencies are the primary funders of state health official professional associations. Further study in this area could lead to a better understanding of policy networks and their role in agenda setting and policy implementation.

Another important finding of this study is the need to examine state public policy at a functional/programmatic level. Some areas of state public health administration appear to have much more centralized networks for policy diffusion than other areas. The true nature of state public health communication networks would not be apparent if the study population only included directors of public health. It is likely that these differences in the diffusion process will ultimately have an impact of the products of diffusion.

This study demonstrates the role of state bureaucrats in policy innovation and diffusion. As policymakers, they interact on an ongoing basis with their counterparts in other states, sharing programmatic and policy information. However, further study is needed to determine if professional communication networks are actually what we envision them to be: facilitators of policy innovation and diffusion. 


\section{CHAPTER 5}

\section{AN EXPLANATORY MODEL OF STATE PUBLIC HEALTH INNOVATION}

The central question of this chapter is, do policies/programs adopted by state bureaucracies have different determinants of adoption than those adopted by state legislatures? Researchers have done numerous studies whose central goal is to establish the determinants of policy transfer. However, due to the limited conceptualization of the dependent variable as legislative policy adoption, it is possible that important determinants have been neglected or left undiscovered. In this chapter, a model is built using the determinants of policy transfer found to be statistically significant in previous studies of legislatively driven adoptions, and it will be compared to a model that tests other possible determinants theorized as possible determinants of bureaucratic adoptions. The intent of this comparison is to ascertain if factors found to influence legislative policy innovation also determine policy innovations adopted by state bureaucracies.

\section{Bureaucracies and Policy Transfer}

According to Sabatier and Jenkins-Smith (1999), one of the impacts of the increasing complexity of policymaking is the requirement that actors specialize in particular policy areas if they are to have any influence. Because the very nature of bureaucrats' jobs requires specialization, they become influential policymakers. This occurs not only because they have direct influence on policy through agenda setting and implementation, but also because other less specialized actors such as elected officials become reliant on their advice. As experts, bureaucrats often play a prominent 
role in formulating the very directives they receive from legislators and governors (Kaufman, 2001).

\section{Hypothesis and Methods}

This section of the study will test a specific hypothesis: Administrative capacity and regional diffusion will play a more important role in bureaucratic policy innovation than will political and economic factors. The underlying assumption of this hypothesis is that policy networks are the key factor in the transfer of policy and programs among state agencies. The evidence on regional diffusion as a determinant of policy transfer among state legislatures is mixed. However, during interviews with state health officials, many cite the importance of partnerships, meetings, and informal communication among regional public health counterparts. Administrative capacity is a reflection of the power of bureaucratic policy actors. Their influence on policymaking is not about their political connections or the general state of a state's economy as it is about their expertise and ability to develop and promote good public policy. Thus, the determinants of bureaucratic policy transfer are likely to differ from those that influence legislative-driven policy transfer.

Two models of policy transfer will be compared to test this hypothesis. The first model will be based on the factors found in other research to be statistically significant factors that explain transfer among U.S. states. The second model will focus on state agencies by also including administrative capacity and regional diffusion as independent variables. An index of state health policy innovation is developed for use as the dependent variable. Regression analysis is used to determine which factors (problem 
environment, resources, administrative capacity, political environment, regional diffusion) best explain policy innovation by U.S. states.

\section{Dependent variable}

The dependent variable for this study is an additive index based on whether or not each state has or has not adopted ten particular programmatic innovations with a potential range of 0 to 10 (Appendix $A$ and Table 5-1). The programs included in the index represent all of the functional areas of state public health. The actual range of the index is 0 to 8 with a mean of 4.26 and a standard deviation of 1.98 . The index has an approximately normal distribution with a skewness statistic of $-.262($ s.e. $=0.337)$ and a kurtosis statistic of -.121 (s.e. $=0.662)$. The following discussion will describe the specific measures used to create the innovation index.

TABLE 5-1

\section{STATE HEALTH INNOVATION INDEX}

Potential score of 0 to 10

\begin{tabular}{|l|c|}
\hline California, New York, Rhode Island & 8 \\
\hline Colorado, Maine, Minnesota & 7 \\
\hline Alabama, Massachusetts, New Mexico, Vermont, Washington & 6 \\
\hline $\begin{array}{l}\text { Arkansas, Connecticut, Florida, Georgia, Illinois, Louisiana, Michigan, } \\
\text { North Carolina, Nebraska, New Jersey, Oklahoma, Oregon, Utah, } \\
\text { Wisconsin, West Virginia }\end{array}$ & 5 \\
\hline $\begin{array}{l}\text { Arizona, Indiana, Maryland, Missouri, Ohio, South Carolina, Texas, } \\
\text { Virginia }\end{array}$ & 4 \\
\hline Hawaii, Iowa, Idaho, Mississippi, New Hampshire, Texas & 3 \\
\hline Delaware, Kansas, Kentucky, Pennsylvania, South Dakota, Wyoming & 2 \\
\hline Alaska & 1 \\
\hline Montana, Nevada, North Dakota & 0 \\
\hline
\end{tabular}




\section{Occupational Health}

Two programs are used to measure innovation in occupational health. First, does the state have an office devoted specifically to occupational health issues? Although every state has an occupational health liaison with the CDC, only some of them have a department or division devoted specifically to occupational health. In some cases the occupational health function is combined with another unit, most commonly environmental health. Any state with a unit that can be identified specifically as focusing on occupational health is considered to have an office of occupational health.

The second occupational health program included in the index is ABLES, a surveillance system that identifies elevated lead levels among adults, identifies possible sources of lead exposure, and develops prevention programs (CDC, 2000a). This is an important occupational health issue because approximately 95 percent of adults with elevated blood levels of lead are exposed to lead through their occupations.

\section{Chronic Disease Prevention}

All states have a division with responsibility for chronic disease prevention and control. In some states this unit is independent, and in others it is combined with the health promotion function. However, there is much variation among states in the activities conducted through this unit. In many states, the only programs are those funded by federal grants, primarily through CDC. Examples include cardiovascular disease prevention, breast and cervical cancer prevention, and diabetes control.

One of the more recent chronic disease initiatives at the state level is the development and strengthening of capacity related to public health arthritis activities. Arthritis is becoming a higher priority public health initiative because of its increasing 
incidence due in the aging U.S. population. Prior to 1999, eight state health departments had existing arthritis activities. Since that time 30 additional states have received CDC funding to establish arthritis activities. Those states with established programs prior to 1999 are coded "one" in the index variable.

Another important state-level chronic disease activity is cancer surveillance. The heart of any science-based public health program is accurate data on the occurrence of particular diseases and conditions in a population. By gathering data on the incidence of a wide variety of cancers within a state, public health administrators can better plan intervention and prevention programs.

\section{Epidemiology}

Strong epidemiologic capacity is vital to all functions of public health. Historically, however, the focus of state public health epidemiology has been on infectious diseases and emergency or crisis response. At the core of epidemiology is disease/condition surveillance.

In 1992 the Council of State and Territorial Epidemiologists (CSTE) in collaboration with the CDC, National Center for Chronic Disease Prevention and Health Promotion (NCCDPHP), developed a strategic plan with a goal of developing chronic disease epidemiology capacity in each state (CSTE, 1999). Currently, 39 states have at least one full-time chronic disease epidemiologist. Approximately half of these have received establishment support through the CDC State-based Epidemiology for Public Health Support activity.

\section{Maternal and Child Health}

One of the key components of any child health program is immunization to prevent transmittable diseases. These immunizations not only benefit the children who are vaccinated but also provide "herd immunity" that protects unvaccinated persons as 
well. Through federally funded programs, state and local health departments have a long history of providing needed vaccinations. State legislatures have also played a key role by passing legislation that requires vaccinations for most children prior to school entry. Until recently, consistency was found in the required immunizations among the 50 states. However, only some states have revised their school-entry requirements to reflect newer vaccinations recommended by the Advisory Commission on Immunization Practice. Thus, one measure of an innovative maternal/child health program is a change in state legislation to incorporate newly developed vaccinations. Although this does require legislative action in all states, the impetus for such changes is likely to come from the state health department given the technical nature of the program.

Another development in child health that is related to immunization is the development of community and state-based electronic immunization registries. Two circumstances often prevent the full and timely immunization of children to prevent communicable diseases. First, many children receive immunization from multiple types of providers such as private physicians, public health clinics, and school-based clinics. The mobility of the U.S. population and inadequate personal vaccination records also contributes to this problem. In some cases, the result is under or un-immunized children. Other times, children are re-vaccinated due to lack of proof of immunization upon school or daycare entry, a waste of immunization resources. In cooperation with CDC, many states are developing electronic immunization registries that can be accessed by all health care providers to assess the immunization status of individual children.

A primary goal of maternal and child health is reduction of infant mortality rates. Currently, 22 states participate in a federal program called the Pregnancy Risk Assessment Monitoring System (PRAMS) (CDC, 2000c). Through the monitoring of birth certificates and gathering of pregnancy-related data from questionnaires administered to mothers who have recently given birth, states are able to collect 
information that is vital to the planning of programs devoted to the improvement of the health of mothers and infants. States with PRAMS programs are able to develop and/or improve programs related healthy mothers and infants.

\section{Rural Health}

In part due to the inception of a federal grant program in 1991 (HRSA, 2000), all 50 states now have a state office of rural health. These offices are primarily responsible for developing policy and administering programs related to rural health services. Much of their work involves providing linkages among communities and interests throughout their state that are interested in providing and improving rural healthcare services. Despite their importance to such areas as physician recruitment for underserved areas, the financial stability of small, rural hospitals, and telemedicine, only 35 states have placed their office organizationally as part of the state health department. Others are located at research universities and other administrative units. Because those that are located at state health departments have better ability to integrate their programs with other state health programs, this is used as a measure of an innovative state rural health program.

\section{Health Promotion}

Despite the concerted efforts of federal and state public health agencies, public interest groups, and many other policy actors, smoking is still the leading cause of preventable illness and death in the United States (CDC, 2000b). In addition to state appropriations, all states also receive funds from at least one of three categorical grant programs for activities related to the prevention of tobacco product use. CDC funds the (IMPACT) program, the National Cancer Institute (NCI) funds the (ASSIST) program, and a private foundation, the Robert Wood Johnson Foundation funds the SmokeLess State program. Of these three, the ASSIST program is the most extensive. Thus, ASSIST is used to measure innovative smoking prevention programs. 


\section{Overview of Dependent Variable}

As seen in Appendix A and Table 5-1, there is variation from state to state in the index of state health innovation. As demonstrated in Figure 1, there is some evidence of geographical clustering of innovation with states in the northeast and on the West coast having higher innovation scores. One exception to this pattern, Alabama, can be explained by the presence of a very strong state health director who is a policy entrepreneur and leader within his profession. Low innovation scores are found primarily in the West and mid-Atlantic region. There are many possible explanations for these patterns of health policy innovation. The following models will consider some of these.

\section{Independent Variables}

One of the central arguments of this chapter is that there are likely to be different determinants of policy innovation and transfer than those found by previous research if the dependent variable is bureaucratic rather than legislative policy adoptions. In order to test this hypothesis, two different models are developed.

The first model (Table 5-2) includes dependent variables that have been found to be determinants of legislative adoption of innovations. These include political factors (Democratic control of the lower house, legislative professionalism), economic factors (intergovernmental revenues per capita and per capita income), and regional factors (average innovation index for states in the same Census region).

The model presented in Table 5-3, however, incorporates some of those predictors previously found to be significant predictors of state policy innovation and transfer but also others more closely related to state agencies. These additional variables will be discussed below. 
FIGURE 5-1

\section{STATE HEALTH INNOVATION INDEX}

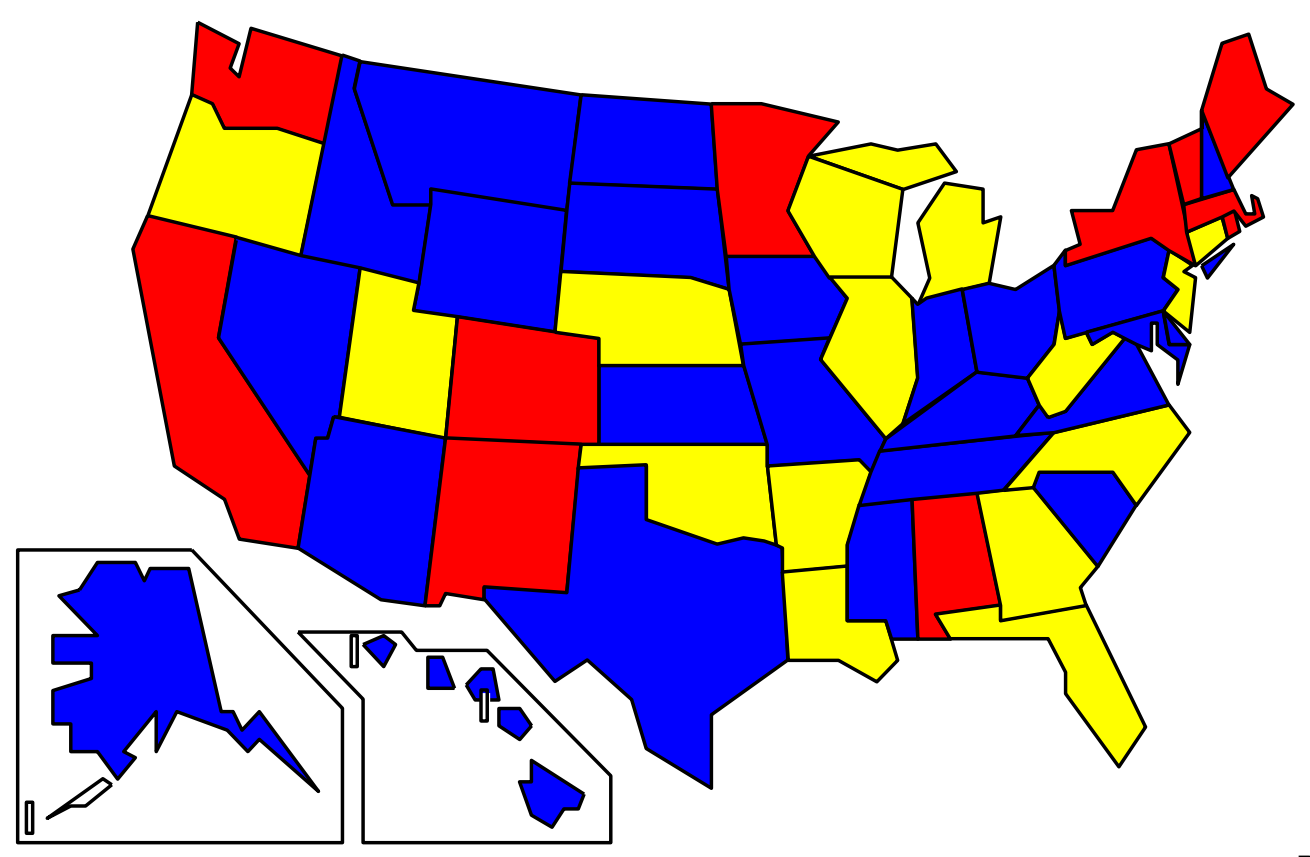

RED - HIGH

YELLOW - MODERATE

BLUE - LOW 


\section{Problem Environment}

The motivation to innovate can be viewed in many different ways. Often policy entrepreneurs provide the motivation for particular policy innovations (Mintrom, 1997). Such studies, however, usually focus on a single policy adoption. The identification of particular policy entrepreneurs across fifty states and the range of program innovation contained in the health innovation index of this study would be extremely difficult. Another way to conceptualize motivation, however, is the problem environment. It is expected that states with more health concerns should be motivated to introduce programs to address these concerns and thus have higher innovation scores.

Public health researchers use a variety of measure to assess the overall health status of a population. The measures are of two types: survey-based and outcomesbased surrogates. Those based on survey data of individuals within the population assess citizens for particular health conditions (such as that collected through the National Health Interview Survey or the Behavior Risk Factor Surveillance system). Other studies use a surrogate such as infant mortality rate to measure the health of a population. While these measures are useful when studying particular diseases or conditions, they are not broad enough for a study that examines state public health innovation across a variety of functional areas. A better measure is one commonly referred to as "state health rankings." This is a composite measure that incorporates a variety of indicators that represent a broad range of issues affecting a population's health including lifestyle health practices (such as smoking), the access to health services, occupational safety and disease, occurrence of specific diseases (such as heart disease), and death rates (United Health Group, 2001). Because the problem 
environment must precede the adoption of innovative programs, this variable is measured five years prior (1995) to the programs in the innovation index.

\section{Political Environment}

Much of the power of a state agency to set the agenda and play an instrumental role in the introduction of programs to their state is delegated to the agency by the legislature. Through both statutory and fiscal mechanisms, agencies are given resources to develop programs. This role, however, is shared with the legislature.

There is much variation from state to state in the resources and strength of state legislatures. This is often measured by considering legislative professionalism, a composite index based on such items as legislative salary, length of session, and size of staff (Squire, 1992). It is expected that in states with strong, professionalized legislatures state agencies are also likely to be more innovative due to some of the same underlying phenomenon that make these legislatures more innovative.

Another predictor of bureaucratic innovation is whether or not the Democratic Party controls the lower house of the state legislature. In general, Democrats are more likely than Republicans to provide resources and support programs related to social welfare policy (Keefe \& Hetherington, 2003). Also, most social welfare policy is made by state rather than federal government actors (Dobelstein, 2003). Because public health policy is a component of social welfare policy, I hypothesize that Democraticallycontrolled state legislatures are more likely to support innovative public health policy not only through their own action but also by providing necessary resources for bureaucratic innovation. 


\section{Resource Availability}

Much of the implementation of public programs is performed by state administrative agencies. These agencies control a large portion of public funds either through direct appropriation from state legislatures or as the recipient of federal grants. In some cases, the state agencies directly deliver program activities and in others, they allocate monies to local agencies to do so. State agencies also generally set out specific program guidelines including rules and performance standards and provide oversight. This is especially the case in the current era of devolution when many federal programs give broad latitude to state agencies to determine specific program implementation strategies. Thus, the administrative capacity of a particular state agency should be related to their ability to implement public policy/programs. Those states which have high levels of administrative capacity should be more capable of developing and implementing programs that are new to their state. Thus, they are also more likely to be actively involved in policy transfer.

Numerous studies have attempted to develop a reliable measure of state administrative capacity (Barrilleaux, Feiock \& Crew, 1992; Bowman \& Kearney, 1988; Grady, 1999; Sigelman, 1976). For the most part, these studies use proxy measures that are readily available such as percentage of employees under a merit system, educational level of employees, etc. Two recent studies have developed more direct measures of administrative capacity (Burke \& Wright, 2002). The Government Performance Project (1999) rates all fifty states on five specific measures: capital management, financial management, human resources, information technology, and managing for results. (The original report assigns letter grades of $A$ to $F$ to particular 
functions. These grades have been converted to a numerical scale with state scores ranging from 15 to 55.) Given its components, this measure focuses on management aspects of state agencies. It is also compiled on a comparative basis (state in comparison to other states). Brudney, et al. (1999) used survey data to determine if eleven particular government reinvention techniques had been implemented in various state agencies.

These measures are, however, somewhat problematic. Unlike various measures of legislative professionalism (King, Squire, legislative salary) that correlate at the 0.85 to 0.95 range, these two measures of administrative capacity have a Spearman rankorder correlation of only 0.45 . This brings into question whether the measures are tapping the same latent variable. For this study, the Government Performance Project is used to measure administrative capacity. It is expected that as administrative capacity increases, so will the innovation index. However, because the two measures of administrative capacity differ to such a degree, an additional measure of capacity, the number of state health employees per thousand population, is also used. 


\section{Table 5-2}

Determinants of Legislative Policy Innovation

Dependent Variable: Index of Policy Innovation

\section{Estimated Coefficients}

\section{Regionalism}

Average regional innovation index

$-0.103$

$(0.297)$

\section{Political Environment}

Democratic control of lower house

0.360

$(0.530)$ **

Legislative professionalism

0.305

$(2.331)$ *

Economic Environment

Per capita income

0.066

$(0.000)$

Intergovernmental revenue per capita

$-0.042$

$(0.001)$

Constant

2.808

(2.361)

R-squared

.260

Adj. R-squared

.176

F test

3.100 *

Standard errors in parentheses.

${ }^{*} p<.05 \quad$ ** $p<.01 \quad$ (one-tailed test) 


\section{Findings}

The model presented in Table 5-2 uses the bureaucratic innovation index as the dependent variable and includes as independent variables those factors found in previous research to be predictors of state policy innovation and transfer. Unlike other research, neither political nor economic factors are found to be statistically significant predictors of bureaucratic policy innovation. Intergovernmental revenue moves in the opposite direction than would be expected based on previous research (as intergovernmental revenue increases, innovation decreases). There is also no evidence that a regionalism influence exists - that states in regions with high average innovation index values will also be more innovative and vice versa.

The only predictor of policy innovation and transfer for both legislative adoption and bureaucratic adoption is the political environment. In this model, both Democratic control of the lower house and legislative professionalism are statistically significant. States with Democratic houses are more likely than those with Republican-controlled houses to have higher innovation index scores. Likewise, as legislative professionalism increases, the bureaucratic innovation index also increases.

In general, this model is a very poor predictor of bureaucratic policy innovation with only two statistically significant independent variables and explaining only seventeen percent of the variation in innovation among states.

Table 5-3 displays the results of a regression analysis that tests the various hypotheses concerning determinants of state bureaucratic policy innovation that are likely to differ than those that explain legislative policy innovation. It also includes regionalism, legislative professionalism, and per capita income to determine if they are 
predictors of bureaucratic policy innovation as well as legislative innovation. Thus, this regression model contains seven independent variables: administrative capacity, average regional innovation index, state health ranking, Democratic control of lower house of state legislature, legislative professionalism, per capita income, and the number of state health employees per 1,000 population. Overall, the model explains 29 percent of the variation in state administrative innovation and is statistically significant with an $\mathrm{F}$ value of 3.914 . 


\section{Table 5-3}

\section{Determinants of Bureaucratic Policy Innovation}

Dependent Variable: Index of Policy Innovation

\section{Estimated Coefficients}

$\begin{array}{lc}\text { Regionalism } & \\ \text { Average regional innovation index } & -0.111 \\ \text { Political Environment } & (0.272) \\ \text { Democratic control of lower house } & 0.334 \\ & (0.505) \text { ** } \\ \text { Legislative professionalism } & 0.296 \\ \text { Economic Environment } & (2.322)^{*} \\ \text { Per capita income } & -0.036 \\ \text { Resource Availability } & (0.000) \\ \text { Administrative capacity } & -0.260 \\ & (.030)^{*} \\ \text { State health employees per } 1,000 & -0.237 \\ \text { Problem Environment } & (.004) \text { * } \\ \text { State health ranking } & 0.307 \\ & (0.29)^{*} \\ \text { Constant } & 7.764 \\ & \end{array}$

R-squared $\quad .395$

Adj. R-squared $\quad .294$

F test 3.914 **

Standard errors in parentheses.

${ }^{*} p<.05 \quad{ }^{* *} p<.01 \quad$ (one-tailed test) 
Of the seven variables, all were found to be statistically significant except for the average regional innovation index and per capita income. This finding is particularly striking because these two factors (regionalism and economic environment) have been found to be determinants of legislative policy innovation by numerous researchers. Both variables also move in the opposite direction from what would be expected. As the regional average increases, the innovation index for a particular state decreases. Similarly, as per capita income increases, bureaucratic innovation decreases.

In this model, the political environment also plays an important role. Both measures of this are found to be statistically significant. As legislative professionalism increases, so does innovation. States with a Democratically-controlled lower house have higher innovation scores than those controlled by Republicans.

This model is enhanced by the addition of three other variables not included in legislative adoption models: administrative capacity, state health employees per 1,000 population, and the problem environment. All three variables are statistically significant. However, all three move in the opposite direction from what is hypothesized. It was expected that those states with more public health problems (as indicated by a lower state health ranking) would be more likely to adopt new public health policies and programs. This model demonstrates, however, that as a state's health ranking increases so does its innovation index. One possible explanation for this is the existence of a third confounding variable. For example, both might be linked to the overall socioeconomic status of the population. However, the inclusion of per capita income in the model should have controlled for this.

The two measures of resource availability also move in the opposite direction than that hypothesized. As both administrative capacity and state health employees increase, the innovation index decreases. It is difficult to explain the direction of this relationship with regard to number of employees. Not only should a larger number of employees increase slack resources available to aid in the adoption of innovative 
programs, but states with more health programs should also have more public health employees. One possible explanation is that poorer states hire more employees in social service agencies. It is also possible that those states with strong administrative capacity already have sound overall public health programs and do not see a need to innovate or change existing policy.

The unexpected direction of the relationship between administrative capacity and bureaucratic innovation may be one of measurement error. While both currently predominant measures of administrative capacity are improvements on previous measurement devices, both are problematic for this study. One problem is that the measure used is one for overall state administrative capacity while this project is specific to public health. It is possible that existing capacity within state agencies is not evenly distributed among them. The measures used also may not capture the latent variable of interest to this study. The focus of the measure used is on management practices. An agency with strong management practices may or may not also have the capacity to be innovative. Further study is needed in this area to identify a measurement of administrative capacity that is more appropriate for this study. The inclusion of the number of state health employees in the model was an attempt to use another surrogate measure, but as previously stated, this measure also moved in the opposite direction from that which was hypothesized.

\section{Results}

The predictors of bureaucratic policy innovation are not the same as those found by previous research to predict innovation measured by legislative adoption. The political environment is a predictor while regionalism and the economic environment are not. A regression model based on these independent variables explains only $17 \%$ of the variation in state bureaucratic public health innovation.

A more complete model of bureaucratic policy innovation exists that explains $29 \%$ of the variation between states. For this model, the political environment, the 
problem environment, and resource availability are statistically significant. Regionalism and economic environment are not statistically significant. However, resource availability, as measured by administrative capacity and number of state health employees moves in the opposite direction than hypothesized.

\section{Future Research}

As is the case with many studies, one of the most difficult aspects of this one is measurement. The dependent variable needs further development by the inclusion of additional programs. While many of the states that are thought of as particularly strong or innovation examples of state public health have high innovation index scores, others fall in the middle range (such as Pennsylvania). Similarly, some states have higher scores than might be expected (for example, West Virginia). To improve this index, however, programs must be identified that are not only innovative but also are functionally equivalent among the states.

Further work is also needed in the measurement of administrative capacity. Legislative professionalism that is essentially a measure of resource and capacity is a good model for this measure. However, other researchers (see Barrilleaux) who have attempted to create a comparable index have run into many difficulties obtaining the appropriate data from all 50 states. It is particularly troublesome that different measures of administrative capacity are so poorly correlated not only with each other but also with possible surrogated measures such as number of state health employees and salary of lead state health administrator and average salary of state health employee.

The moderate $r$ square value indicates that the model specification could be improved. Possible variables that might further explain variation in innovation include other resource measures, other measures of the relationship between state agencies and other policy actors, and additional measures of the problem environment. It would also be interesting to compare models based on single innovations as the dependent variable as the legislative adoption studies do. Although the findings will be less 
generalizable to public health and public agencies in general, it may provide further enlightenment on the process of administrative policy innovation.

\section{Conclusions}

In general, this study provides some interesting findings that expand our understanding of state policy innovation. In particular, it shows the value of examining policy innovation from a perspective other than of legislative adoption. Some of the findings seem to support those of previous research with legislative adoptions as the dependent variable. In particular, it confirms the importance of the political environment. The finding that neither regionalism nor economic status are good predictors of bureaucratic innovation is very important, since this conflicts with studies of legislative policy innovation. This finding is quite inconsistent with that of other researchers.

It is also quite interesting that some of the relationships between the dependent and independent variables, while statistically significant, are not in the hypothesized direction. As discussed previously, one explanation of this might be measurement error. In the case of the problem environment measure, the unexpected direction of the relationship may speak to the causal direction. Despite the time lag between the two measurements, it may be a "chicken or the egg" question: does a state's overall health status improve because it tends to be innovative in public health policy?

At least in the case of state public health agencies, the factors that predict whether or not a state is likely to adopt innovative policies/programs differ than those that predict legislative adoption. The one dimension that holds true for both political actors is the importance of the political environment, in particular legislative professionalism. This perhaps raises a question of whether legislative professionalism is a surrogate measure for some other underlying latent variable such as state resources that cross the boundaries of various state-level actors. In general, this research not only contributes to our knowledge of state policy innovation but also 
emphasizes the importance of considering multiple policy actors when studying agenda setting and policy adoptions. 


\section{CHAPTER 6}

\section{CONCLUSION}

The bureaucracy is often the neglected partner in policymaking studies undertaken by political scientists. This may be due to the separation of public administration as a distinct subfield of political science - a subfield that tends to focus on the administrative and management aspects of agencies rather than their role in policymaking. State government has also received less attention than the national government by researchers in the past. Understandably, this occurs in part due to the difficulty of obtaining data and information necessary to conduct comprehensive comparative U.S. state research. Questions also arise concerning functional equivalencies among states. Yet the combination of devolution of programmatic responsibilities from the federal to state governments and the growing capacity of state institutions and political power means that state public policy research should receive increased attention.

This study attempts to close some of these knowledge gaps. First, the unit of analysis for this study is state administrative agencies, both the bureaucratic structure and the administrative officials who make policy and programmatic decisions within them. As demonstrated in chapter 2, there is very little research material available on state administrative agencies. What does exist has a public administration and management focus rather than contributing to our understanding on bureaucracies in policymaking. Second, this study presents a close examination of the professional communication networks of state public health officials. Previous policy transfer research presumes the existence of this communication network, yet it has never been 
explored in depth. This enriches our understanding of policy transfer by exploring in detail the mechanisms used by state public health agencies to share important policy and programmatic information. Lastly, this study compares the determinants of bureaucratic policy transfer with the determinants of legislative policy transfer to distinguish between the roles played by each in the policy transfer process. This provides insights into institutions, state policymaking, and public health policy. It also broadens and contributes to our theoretical understanding of policy transfer and the mechanisms by which it occurs.

\section{Professional Communication Networks and Why They Occur}

This study further enhances our theoretical understanding of policy transfer among U.S. states. The study of professional communication networks, in particular, advances our understanding of the process of policy innovation. A process focus, as opposed to a determinants and adoption focus, allows us to recognize the temporal nature of policymaking. These networks will be multifaceted with communication among different levels of government and among states with a focus on a single policy area. One question not yet addressed is why professional communication networks develop in the first place. The very nature of bureaucrats and bureaucracies make it likely that they will develop and utilize long-standing networks of counterparts. With the exception of appointed agency heads, bureaucrats tend to have long careers within a single agency. They are the most stable of the branches of government protected by civil service systems and sheltered from the volatility of the electorate. State bureaucrats tend to spend an entire career working within a single policy area, and their academic training contributes to their role as professional experts. As specialists, they 
also develop expertise in the operations of a policy area network. Over time, these officials develop a clear understanding of the important policy actors, their policy preferences, and the overall policymaking environment. These combined expertises enhance bureaucratic capability to be policymakers.

The stability of agencies is another reason bureaucracies are likely to establish long-term communication networks. Even if key employees within the agency leave, the institutional stability of the agency makes it likely that "memories" will exist of the communication network. This network will quickly be utilized and adapted by other employees. State agency reorganization is rare, and the institutions tend to take on their own characteristics. Agency budgets generally change only incrementally. This is also true of levels of other resources. Thus, bureaucratic agencies and bureaucrats have more reason than other policy actors to invest in the establishment of policy networks. It represents another source of bureaucratic power. The communication network is also another institutional resource to be maintained and maximized.

The existence of communication networks to support and facilitate policy transfer benefits state agencies. The tasks of these agencies are complex and many. Truly rational decision-making is not feasible. Thus, policy transfer is another way for bureaucrats to satisfice while meeting program and political demands.

\section{The Structure of Policy Communication Networks}

The existence of a complex bureaucratic communication network in the public health community has been confirmed and described in this research. The network appears to serve a number of purposes for this community. State agency representatives share information on program design, problem solving, technical 
information, and funding in particularly as it relates to intergovernmental monetary transfers. Communication among health officials from different states occurs on a regular basis through a variety of mechanisms but in particular via e-mail and telephone. Federal agencies encourage the development of communication networks in different ways. Written and electronic newsletters, journals, and other information sources are provided to state officials. One of the primary ways they assist state officials is by providing some or most of the funding for function-specific professional associations such as the Association of State and Territorial Chronic Disease Directors. A federal agency, Centers for Disease Control and Prevention, funds conferences and meetings for this agency and sometimes uses the association to administer or allocate grants to state health agencies. This symbiotic, intergovernmental relationship exists for all functional areas of public health that are part of this study. Federal agencies use these associations as conduits to distribute programmatic and policy information to states.

However, the communication network is loosely configured. Communication occurs as needed with only a few routinized systems in place to bring conformity to either the information shared or to provide comprehensiveness in the recipients of such information. Strong evidence is found that that the most important level of communication is within functional areas of public health, thus the description of a single public health communication network becomes problematic. It is much more appropriate to conceptualize the policy network as comprised of a number of smaller networks that coalesce around narrow and specialized areas often related to professional specializations such as epidemiology. 
Clearly, professional associations are often a critical element in each of these smaller, functional communication networks. Both interviews with public health officials and survey evidence support this view. Very purposive information sharing among states occurs through these associations. For example, one program of the Association of State and Territorial Chronic Disease Directors states as its purpose "The mission of a CDD council/committee mentoring program is to build the capacity of chronic disease staff in state and territorial health departments through a transfer of knowledge and expertise among members. Each committee or council should use this framework as a guideline to develop a mentoring program that meets the needs of its members" (CDD, 2002). This is a clear example of an infrastructure devoted to policy and information transfer. Attendance at annual meetings, sometimes funded by a federal agency, is also a primary mechanism for information sharing among states and between federal and state officials.

Studlar's study (2002) of tobacco control policy asserts that non-governmental actors such as researchers and interest groups play an important role in transnational policy transfer. Even if not formal members of specific professional associations, associate membership is often an option for non-state agency bureaucratic participants in the policymaking arena. Their influence is also evident in some of the mechanisms for information transfer scrutinized in this study such as professional journals. Many of these associations maintain headquarters in Washington, D.C., where they have ready access to national elected officials, lobbyists, and representatives of interest groups.

Gow (1994) presents a theory of why professional associations play an important role in information exchange. Individuals with more commonality than differences can 
more easily communicate with one another (E. Rogers cited in Gow). Gow believes that professional associations help influence or shape the world outlook of its members thus bringing some standardization to their values and standards. This "common outlook" enhances the ability of individuals from within the group to communicate with one another. Professional associations not only provide common ground among members but also are often the coordinating mechanism for much of the communication that occurs that is broader and more systematic as opposed to the shorter term or more technical information transfer that occurs through e-mail and telephone. There is a close relationship between professional associations and federal agencies that often, at least in the case of public health, provide much of the financial resources of the associations. The importance of these associations as conduits of communication cannot be underestimated.

\section{A Model of Bureaucratic Policy Transfer}

One of the central premises of this research is that because previous studies of U.S. state policy transfer have focused on the role of the legislature and neglected other policy actors, models may have been misspecified. The current research considers bureaucratic adoptions rather than legislative adoptions in order to determine whether the same predictors of innovation exist when different policy actors are emphasized. Earlier work on legislative adoptions finds that both political characteristics and socioeconomic factors determine the occurrence of policy transfer among U.S. states with socioeconomic factors being the strongest predictor. Other studies further develop this area of research by examining more closely the diffusion of innovations and find 
that regional factors, policy entrepreneurs, and information sharing are important explanatory variables.

When an index of bureaucratic policy adoptions is used as the dependent variable in a model that includes those independent variables previously found to be significant predictors of legislation policy adoption, most of the explanatory variables are no longer statistically significant. The only variables that remain significant in both legislative and bureaucratic adoption models are those that measure the political environment. States with Democratic-controlled legislatures (a reflection of the overall state political environment) continue to be more likely to adopt innovations than those controlled by Republicans. Legislative professionalism is also statistically significant. In the bureaucratic adoption model, economic factors appear to be unimportant in contrast to the findings of the legislative policy transfer literature. In fact, the opposite occurs. In the bureaucratic model, innovation decreases as per capita income increases. There is also no evidence that a regional diffusion model exists, a finding that contradicts qualitative research findings where, anecdotally, public health officials frequently reported information sharing with counterparts in nearby states. However, this is consistent with the findings of Mooney (2001) that question the geographic dispersion model of policy transfer among neighboring states. The overall model based on determinants found to be significant for legislative adoption is a very poor predictor of policy adoption as measured by the bureaucratic dependent variable instead of legislative adoption.

However, a model of policy transfer that incorporates factors that are likely to predict bureaucratic adoptions, as is the case here, explains 29 percent of the variation 
among U.S. states. The individual components that explain state bureaucratic policy adoption are: the role of political environment, Democratic control of the lower house of the legislature, and legislative professionalism. All are found to be statistically significant. Other measures that also predict bureaucratic policy innovation are overall state administrative capacity as measured by the Government Performance Project, administrative resources as measured by the number of state health employees per capita, and the problem environment as measured by a state health ranking. However, these measures all move in the opposite direction than that hypothesized. In general, states with more administrative resources and a seemingly more urgent public health problem environment are less likely to be health policy innovators. As discussed earlier, it is possible that measurement problems within the model may contribute to this finding. It may also be that when resources are more limited, indicative of a state with low overall socioeconomic status, the available resources are directed towards providing health care to individuals rather than broader public health programs. The most important research result is that neither regionalism (a measure of innovation by neighboring states) nor economic condition (as measured by per capita income) are statistically significant predictors of bureaucratic innovation. This is in direct opposition to the findings of research on legislative innovation.

\section{Directions for Future Research}

\section{Differences between state bureaucracies and legislatures}

Insight into the communication networks of state bureaucracies has been gained through this research. While in itself this information is important, it tends to focus on a single aspect of health policy networks, state agencies. In order to further understand 
the communication networks in state health policy, it would be useful to extend this research by doing a similar study on the health-related committees of state legislatures. It could be expected that both similarities and differences would be found when comparing these two. Similar communication networks also exist among other policy actors and ultimately within the broader public health policy network.

It is reasonable to assume that a similar communication network exists for state legislators working in this policy area. In any year, examples can be found of similar programs and/or laws adopted by legislatures in different and widespread states over a short period of time. It is also known that some of the elements that are important to the bureaucratic network also exist for state legislatures. For example, a primary professional association exists, the National Conference of State Legislatures (NCSL), that serves both legislators and their staff members (National Conference of State Legislatures, 2004). Although this organization is not specific to health policy, it provides numerous health-focused resources. It has a standing health committee for legislators with membership from most states and a health staff network, prepares health policy reports, suggests state-level initiatives and legislation, sponsors webcasts, conducts an annual health policy conference, and provides health e-newsletters. This institutional infrastructure has many elements in common with the functional professional associations for state public health agency officials. Other NCSL resources that are for a general audience often address health-related topics including their monthly publication, State Legislatures. In 2002, articles in this journal covered 34 different health topics. At least one public health topic is usually included on the agenda of its annual meetings. All of these activities are similar to the activities that state health 
agency personnel report as important to the dissemination of health policy information within their professional associations.

Other non-governmental associations also provide state-focused health policy information. One health-specific organization that tracks health policy developments at the state level is the Robert Wood Johnson Foundation (RWJF, 2004). The National Academy for State Health Policy is a "non-profit, non-partisan organization dedicated to helping states achieve excellence in health policy and practice" (National Academy for State Health Policy, 2004). In addition to conducting policy analysis, producing informational resources, and providing training and technical assistance to state legislatures, this organization conducts an annual state health policy conference. The Rutgers University Center for State Health Policy is an example of an organization that provides information to the broader state health policy community including state legislatures. Like NASHP, its activities include research, training, and consultation on state health policy (Center for State Health Policy, 2004). Another university-based research center is the Duke Center for Health Policy, Law and Management. These organizations and other similar ones are important components of the health policy communication network for state legislatures.

Federal government agencies are also likely to communicate policy information to state legislatures although probably not as often or in the quantity given to state agencies. Some of the communication occurs through direct communication such as journals, newsletters, and e-newsletters. As is the case for state bureaucracies, the federal government also uses professional associations and health-care nonprofits as conduits for research and information. This intertwined communication relationship can 
be seen in a recent RWJF report that shows that their health policy tracking service is funded by RWJF, federal agencies including the Centers for Disease Control and Prevention, the Center for Mental Health Services, Department of Health and Human Services, and other agencies including the California Health Care Foundation (Robert Wood Johnson Foundation, 2004).

Despite the existence of the foundation for a policy communication network for state legislatures that is similar to the one that exists for state bureaucracies, there is reason to believe that the networks of legislatures and agencies might differ. Structurally it might be quite comparable. However, while some common elements exist between the legislative network and the bureaucratic network (in particular federal health agencies), the specific information sources are likely to be different. The professional associations that are vital to the bureaucratic communication network are particularly composed of state agency officials. The same can be said for state legislative professional organizations. State bureaucrats and legislators usually have different professional orientations. The level of technicality of language will vary as well as the need for information.

Another possible difference exists due to the nature of the type of information being communicated. State legislatures are focused on what bills are being considered or have been passed in other states. Their focus is legalistic, statutory, and perhaps constitutional. State agencies, on the other hand, will have a programmatic focus. Because they share common professional orientations, agency officials will also be able to share more complicated and technical information than legislative generalists. While 
similar salient issues might exist for both agencies and legislatures, their choice of policy instrument is likely to be different.

This leads to the reason why a study of this nature is important. If the communication network and its participants differ, it is likely that the information being conveyed to state legislatures is sometimes going to be different, perhaps even conflictual, with that given to state bureaucracies. Because the state bureaucrats are specialists, the information given to them is likely to be framed in more technical terms and based on a medical model since it is the predominant language of public health. State legislators, however, as generalists are likely to receive information of a less technical nature and also have a selective perception that filters out highly technical and medically based information. Yet, these two groups are expected to cooperate in the formation of public health policy for their state. A study of the legislative communication networks will lead to insights into how these parties might better work together to make good health policy for their constituents. The work by Smith (2002) begins to address some of these issues by examining judicial rather than legislation adoption of policy.

There is reason to believe that some of Smith's findings might also be applicable to bureaucratic policy transfer. First, the relationship between legislatures and bureaucracies has similarities to that between the legislative and judicial branches within a state. All three are likely to be co-policymakers with differing levels of influence across time. He also argues, as does this study, that the determinants of legislative innovation are likely to differ from those of other political institutions. Smith finds that horizontal variables (such as model legislation proposed by interest groups or national associations) influence policy innovation in state legislatures but are less influential with 
state judiciaries. This is consistent with the finding of the present study of the role of national professional associations on policy adoption by bureaucracies. He also concludes that since different state institutions make policy in conjunction with one another or sequentially as part of larger policy networks, it is important to study the interaction among different state institutions.

However, other of Smith's findings may not translate as well into bureaucratic policy transfer. It is very difficult to separate the federal influence on state policy from the influence that one state may have upon another. Fiscal federalism entwines the state and federal funding for some health programs to such an extent that is not always easy to determine if a state has borrowed policy from other states or simply has similar policies because both receive funds from the same federal source. Although this can be easily traced if the policy innovation can be directly linked to a program grant, the intergovernmental policy aspects of broader financial transfers are less evident. Because the federal court system is mostly separate from state court systems, this question of intergovernmental versus state-to-state transfer will be less of an issue for a judicial/legislative study.

Another difference is how dependent variables are measured. Both legislative and judicial policies are fairly transparent. Legislatures pass statutes; judicial bodies publish rulings. When dealing with a single policy, it is possible to compare these written documents across states searching for evidence of policy transfer and reinvention. The ability to do this with bureaucratic policymaking is limited. The closest correlate for the bureaucracy is rulemaking. However, this is only one aspect of bureaucratic policymaking. It is not as simple to compare policies adopted by 
bureaucracies across states, as it is to trace and compare similar statutes among states.

\section{The Dependent Variable - Policy Adoption}

There are shortcomings in the innovation index used for this study. The potential range of the index is zero to ten. As operationalized, however, it has a range of zero to eight. Thus, the index probably does not fully reflect the amount of variation in policy innovation from state to state that actually exists. This could possibly be improved by extending the study to include additional programs of possible innovation so that the potential range was wider.

In general, this points to one of the difficulties of policy innovation and transfer research. Many studies focus on the transfer of a single program or policy usually measured as legislative adoption in the comparative U.S. state literature. Smith (2002) argues essentially that measurement error of the dependent variable exists in studies that focus on legislative adoption, as does the current study. Yet he too focuses on a single program. This limits the generalizability of the findings. Case studies such as those found in some of the comparative country literature are sometimes broader with a focus on an entire program. However, again generalizability of findings is limited because the case studies only consider transfer between a few countries. The development of studies that use event history analysis improve the generalizability because they broaden and specify the temporal nature of the policy transfer process. However, this research still raises generalizability questions because the studies focus on single policy adoptions. This body of literature can be improved by continued focus on the generalizability issue. Considerations should include how to broaden the 
dependent variable beyond a single policy adoption, how to include a wide variety of cases, and to do this while continuing to model the temporal aspect that is so important to the policy process.

\section{Measurement of Administrative Capacity}

An issue that must be considered when conducting comparative U.S. state policy research is that resource availability differs among states. These differences, as argued by many, affect the ability of government officials to make policy and ultimately to govern. One of the great understatements of this body of research is that states with higher levels of per capita economic resources are often found to be leaders in making policy. However, this is not always the case. In some situations, a state with fewer resources can be a leader due to other factors such as the existence of a policy entrepreneur, favorable political conditions, or issue salience among the public.

Both Squire (1988) and King (2000) have developed legislative professionalism indices that are used by many researchers as a measure of legislative capacity to, among other things, govern and make policy. In studies similar to the current one, a measure of bureaucratic or administrative capacity could be equally as helpful. While an adequate surrogate, the two measures used in this study for administrative capacity have limitations. One was focused primarily on purely administrative and financial resources while the other measured human resource capacity in the public health agencies. Neither is as precise a measurement of the latent variable, public health agency resources, as would be desired.

Attempts have been made (Grady, 1996; Barrileaux, et al., 1992) to develop an administrative capacity measure that is more like that used in the comparative U.S. 
state legislature literature. However, there is still not a widely used measurement of bureaucratic or administrative capacity that fully represents the various aspects of the latent variable. Development of a well-conceptualized measure, especially one that could be broken down by policy area, would enhance research that studies the bureaucracy as a policy actor.

\section{Generalizability to Other Policy Areas}

One of the questions that follows this research is "how generalizable are the findings to other policy areas?" Because this research examines a policy process, innovation and transfer of ideas, which is found in policy areas other than public health, it would be possible to attempt to replicate the research findings in other policy areas. There are many commonalities between public health and other policy arenas in U.S. states. For example, all policy areas within a state share the basic Constitutional structure of government, institutions of government, federalism issues, and budgetary process. Similarly, socioeconomic and demographic characteristics will stay constant within a study population across policy areas.

However, it is likely that the findings of this study will be more applicable to some areas of public policy than to others. According to Lowi (1964), public policies can be differentiated according to type such as regulatory, distributive, and redistributive policy. Public health policy is difficult to categorize, perhaps because the federal role differs substantially from the state role. Most public health policy at the national level can be characterized as regulatory, involving primarily regulatory and research agencies. At the state level, however, public health policy is an example of redistributive policy because it involves "deliberate efforts by the government to shift the allocation of 
wealth, income, property, or rights among broad classes or groups of the population, such as the haves and have-nots ..." (Anderson, 2003, p. 10). Lowi and others have argued that policies within a single type, such as redistributive policies, share commonalities such as politics, and these policies often behave in similar ways. Thus, one could predict that other types of redistributive policy, such as other social welfare and education programs, might share some of the characteristics of bureaucratic policy transfer found in the current study.

It can also be argued that similar patterns might be found in bureaucratic policy transfer among public health agencies and within other technical or regulatory policy areas such as environmental or communication policy. The commonality between these policy areas is the level of expertise and information required of bureaucrats within this policy community. Thus, the identification of policy type for public health is quite complex and makes prediction of similar policy areas difficult.

In addition, the possibility exists that research findings will not be consistent across policy areas. Public health policy might be unique in a number of ways. First, it is a combination of both a highly technical area (predominated by professionals trained in medicine) and of social welfare policy (since much of public health policy is about redistribution of resources). It is also a very broad policy area with a multitude of policy actors. The professional associations of public health are highly specialized and are closely representative of the federalism nature of public health spending. In ways, the professional associations might be thought of as surrogates for the policy entrepreneurs identified as important to policy transfer in some research. Thus, the vital importance of professional associations might not be found in transfer of other policies. The use of 
this research design to test similar hypotheses about policy transfer in other policy areas would greatly contribute to the generalizability of this study of the policy networks that exist in the United States.

\section{Evidence of Knowledge Diffusion}

Although this study has demonstrated the existence of conduits for information transfer, the question remains, to what extent do these conduits actually affect policy transfer? The mere presence of policy/information networks is not sufficient evidence of transfer nor is the existence of similar, even duplicate public policy. Knowledge transfer can rarely be directly traced through an information network (Studlar, 2002). One way to attempt such a study would be to do content analysis of written materials from professional associations such as journals, conference programs, and grant applications. However, the availability of such materials, other than published journals, is limited. Even if such a study were untaken, it would only be the tip of the iceberg with much of the knowledge diffusion that occurs through less formal channels untapped. However, it remains an important point that researchers too often assume knowledge diffusion and policy transfer simply because similar policies exist and the possibility of information exchange is evident.

\section{Concluding Remarks}

The study of public policymaking is and should be a core focus of political scientists. While political issues and institutions shape decisions, policymaking is the mainstay of governmental activity in a broader society. Those who examine policymaking not only explain how and why public policies are made but also can illuminate how good policy is prescribed and implemented. Policy transfer research is 
but one of the lenses through which we attempt to explain the actions of the governmental sector. As we continue to expand government's capacity to deal with society's problems and dreams, the role of public policymaking will play a role in dealing with these demands. As political scientists, we should be at the forefront of this growing force. 


\section{References}

Abney, G., \& Lauth, T.P. (1986). The Politics of State and City Administration. Albany: State University of New York Press.

Administrative Procedure Act. 5 U.S.C. 51.

Almond, G. A., \& Verba, S. (1965). The Civic Culture: Political Attitudes and Democracy in Five Nations. Boston: Little, Brown \& Co.

Anderson, J. E. (2003). Public Policymaking. (5th ed.). Boston: Houghton Mifflin Company.

Balla, S. J. (2001). Interstate Professional Associations and the Diffusion of Policy Innovations. American Politics Research, 29, 221-245.

Barrilleaux, C., \& Berry, F. S. (1996, August). Measuring State Government Scope, Efficiency, and Professionalism, 1969-1994. Paper presented at the meeting of the American Political Science Association, San Francisco, CA.

Barrilleaux, C., Feiock, R., \& Crew, R. E., Jr. (1992). Measuring and Comparing American States' Administrative Characteristics. State and Local Government Review, Winter, 12-18.

Baum, L. (1990). Courts and Policy Innovation. In J. B. Gates, \& C. A. Johnson (Eds.), The American Courts: A Critical Assessment. Washington, D.C.: Congressional Quarterly Press.

Bennett, C. J. (1990). The Formation of a Canadian Privacy Policy: The Art and Craft of Lesson Drawing. Canadian Public Administration, 33, 331-570.

Bennett, C. J. (1991a). How States Utilize Foreign Evidence. Journal of Public Policy, $11,31-54$. 
Bennett, C. J. (1991b). What is Policy Convergence and What Causes it? British Journal of Political Science, 21, 215 - 233.

Bernick, E. L. (1979). Gubernatorial Tools: Formal and Informal. Journal of Politics, 41, $656-665$.

Berry, F. S. (1992). Tax Innovation in the States: Capitalizing on Political Opportunity. American Journal of Political Science, 36, 715 - 742.

Berry, F. S., \& Berry, W. D. (1990). State Lottery Adoptions as Policy Innovations: An Event History Analysis. American Political Science Review, 84, 395 - 415.

Berry, F. S., \& Berry, W. D. (1999). Innovation and Diffusion Models in Policy Research. In P. Sabatier (Ed.), Theories of the Policy Process. Boulder, CO: Westview Press.

Beyle, T. L. (1968). The Governor's Formal Powers: A View from the Governor's Chair. Public Administration Review, 28, 540 - 545.

Bingham, R. D. (1976). The Adoption of Innovation by Local Government. Lexington, MA: D.C. Heath and Company.

Bowling, C. J., \& Wright, D. S. (1998). Chance and Continuity in State Administration: Administrative Leadership Across Four Decades. Public Administration Review, $8,429-444$.

Bowman, A. O., \& Kearney, R. C. (1988). Dimensions of State Government Capability. Western Political Quarterly, 41, 341 - 62.

Brown, B. V. (1998). Tracking the Well-being of Children within States: The Evolving Federal Role in the Age of Devolution. Retrieved August 12, 2004, from http://newfederalism.urban.org/html/anf21.html 
Browne, W. (1985). Variations in the Behavior and Style of State Lobbyists and Interest Groups. Journal of Politics, 47, 450-468.

Brudney, J. L., Hebert, F. T., \& Wright, D. S. (1999). Reinventing Government in the American States: Measuring and Explaining Administrative Reform. Public Administration Review, 58, 19 - 30.

Burke, B. F., \& Wright, D. S. (2002). Reassessing and Reconciling Reinvention in the American States: Exploring State Administrative Performance. State and Local Government Review, 34, 7 -19.

Canon, B. C., \& Baum, L. (1981). Patterns of Adoption of Tort Law Innovations: An Application of Diffusion Theory to Judicial Doctrines. American Political Science Review, 75, 975 - 987.

Centers for Disease Control and Prevention. (2000a). The Adult Blood Lead Epidemiology and Surveillance Program. Retrieved October 12, 2000, from www.cdc.gov/niosh/ables.htm

Centers for Disease Control and Prevention. (2000b). New Surgeon General's Report Provides Strategies for Halving U.S. Smoking Rates by Year 2010. Retrieved October 25, 2000, from http://www.cdc.gov/tobacco/sgr_pressrel_00.htm Centers for Disease Control and Prevention. (2000c). Pregnancy Risk Assessment Monitoring System. Retrieved October 24, 2000, from http://www.cdc.gov/nccdphp/drh/srv_prams.htm\#1

Centers for Disease Control and Prevention. (2005). CDC: Protecting Health for Life: The State of the CDC, Fiscal Year 2004. Retrieved March 10, 2005, from http://www.cdc.gov/od/oc/media/pressrel/ProtectingHealth_ForLife_04.pdf 
Chi, K. S., \& Grady, D. O. (1991). Innovators in State Governments: Their Organizational and Professional Environment. In The Book of the States. Lexington, Kentucky: The Council of State Governments.

Chronic Disease Directors. (2002). Model Mentoring Programs: A Framework for CDD. Retrieved June 16, 2002, from http://www.chronicdisease.org/CDD_Mentoring_Framework_Final.rtf Clark, J. (1985). Policy Diffusion and Program Scope: Research Directions. Publius: The Journal of Federalism, 15, 61 - 70.

Cooper, P. J. (2000). Public Law and Public Administration (3 $3^{\text {rd }}$ ed.). Itasca, Illinois: F.E. Peacock Publishers, Inc.

Council of State and Territorial Epidemiologists. (1999). Position Statements 2000 CD1. Retrieved October 21, 2000, from www.cste.org/ps2000/2000-CD-1.htm Council of State Governments. (2004). Homepage. Retrieved March 17, 2004, from www.csg.org/CSG/Policy/health/default.htm

Dahl, R. A. (1956). A Preface to Democratic Theory. Chicago: University of Chicago Press.

Dawson, R. E., \& Robinson, J. A. (1963). Inter-Party Competition, Economic Variables, and Welfare Policies in the American States. Journal of Politics, 25, 265 - 289.

Desveaux, J. A., Lindquist, E. A., \& Toner, G. (1994). Organizing for Policy Innovation in Public Bureaucracy: AIDS, Energy and Environmental Policy in Canada. Canadian Journal of Political Science, 27, 493 - 528.

Dilger, R. J. (1995). A Comparative Analysis of Gubernatorial Enabling Resources. State and Local Government Review, 27, 118 - 126. 
Dobelstein, A.W. (2003). Social Welfare: Policy and Analysis. (3rd ed.). Pacific Grove, Ca.: Brooks/Cole-Thomson Learning.

Dolowitz, D., \& Marsh, D. (1996). Who Learns What from Whom: A Review of the Policy Transfer Literature. Political Studies, 44, 343 - 357.

Durant, R. F. (1991). Whither Bureaucratic Influence? A Cautionary Note. Journal of Public Administration Research and Theory, 1, $461-476$.

Dye, T. R. (1966). Politics, Economics, and the Public: Policy Outcomes in the American States. Chicago: Rand McNally.

Dye, T. R. (1979). Politics vs. Economics: The Development of Literature on Policy Determinism. Policy Studies Journal, 7, 652 - 662.

Elazar, D. J. (1984). American Federalism: A View from the States (3rd ed.). New York: Harper and Row.

Elling, R. C. (1996). Bureaucracy: Maligned Yet Essential. In V. Gray, \& H. Jacob (Eds.), Politics in the American States: A Comparative Analysis. Washington, DC: Congressional Quarterly Press.

Elling, R. C. (1999). Administering State Programs: Performance and Politics. In V. Gray, R. L. Hanson, \& H. Jacob (Eds.), Politics in the American States: A Comparative Analysis. Washington, D.C.: Congressional Quarterly Press.

Eyestone, R. (1977). Confusion, Diffusion, and Innovation. American Political Science Review, 71, 441 - 447.

Fox, D. M. (1997). The Competence of States and the Health of the Public. In H. M. Leichter (Ed.), Health Policy Reform in American: Innovations from the States. Armonk, New York: M.E. Sharpe. 
Gill, J. (1995). Formal Models of Legislative/Administrative Interaction: A Survey of the Subfield. Public Administration Review, 55, 99 - 106.

Glick, H. R. (1992). Judicial Innovation and Policy Re-Invention: State Supreme Courts and the Right to Die. The Western Political Quarterly, 45, 71 - 92.

Glick, H. R., \& Hays, S. P. (1991). Innovation and Reinvention in State Policymaking: Theory and the Evolution of Living Will Laws. Journal of Politics, 53, 835 - 850.

Goodnow, F. J. (1900). Politics and Administration. New York: Macmillan.

Gormley, W. T. (1989). Taming the Bureaucracy: Muscles, Prayers, and Other Strategies. Princeton: Princeton University Press.

Gow, J. I. (1994). Learning from Others: Administrative Innovations Among Canadian Governments. Monographs on Canadian Public Administration \#16. Toronto, Ontario: The Institute of Public Administration of Canada.

Grady, D. O. (1996). Devolution and Local Administrative Capacity: The Case of American States. Korean Review of Public Administration, 1, 209 - 235.

Grady, D. O. (1999). State Government Administrative Capacity and Welfare Reform Implementation. Paper presented at Annual Meeting of the American Political Science Association. Atlanta, Georgia.

Gray, V. (1973a). Innovation in the States: A Diffusion Study. American Political Science Review, 67, 1174 - 1185.

Gray V. (1973b). Rejoinder to 'Comment' by Jack L. Walker. American Political Science Review, 67, 1192 - 1193. 
Gray, V. (1999). The Socioeconomic and Political Context of States. In V. Gray, R. L. Hanson, \& H. Jacob (Eds.), Politics in the American States: A Comparative Analysis. Washington, D.C.: Congressional Quarterly Press.

Gray, V., \& Lowery, D. (1988). Interest Group Politics and Economic Growth in the U.S. States. American Political Science Review, 82, 109 - 131.

Hays, S. P. (1996). Influences on Reinvention During the Diffusion of Innovations. Political Research Quarterly, 49, 631 - 650.

Hays, S. P., \& Glick, H. R. (1997). The Role of Agenda Setting in Policy Innovation: An Event History Analysis of Living-Will Laws. American Politics Quarterly, 25, 497 516.

Health Services and Resources Administration. (2000). States Offices of Rural Health. Retrieved October 24, 2000, from www.ruralhealth.hrsa.gov/sorh.htm Heclo, H. (1978). Issue Networks and the Executive Establishment. In A. King (Ed.), The New American Political System. Washington, D.C.: American Enterprise Institute.

Hill, L. B. (1992). Public Bureaucracies and the American State. In L. B. Hill (Ed.), The State of Public Bureaucracy. Armonk, New York: M.E. Sharpe, Inc.

Hill, L. B. (1995). Is American Bureaucracy an Immobilized Gulliver or a Regenerative Phoenix? Reconsidering the Alleged Demise of Federal Bureaucratic Power. Administration and Society, 27, $322-360$.

Institute of Medicine of the National Academies. (2002). The Future of the Public's Health in the 21st Century. Washington, D.C.: The National Academies Press. 
Ingraham, P. W. (1993). Of Pigs in Pokes and Policy Diffusion: Another Look at Pay-forPerformance. Public Administration Review, 53, 348 - 356.

Kaiser Family Foundation. (2005). State Health Facts. Retrieved March 10, 2005, from http://statehealthfacts.kff.org

Karnig, A. K., \& Sigelman, L. (1975). State Legislative Reform and Public Policy: Another Look. Western Political Quarterly, 28, 548 - 552.

Kaufman, H. (2001). Major Players: Bureaucracies in American Government. Public Administration Review, 61, 18 - 42.

Keefe, W. J., \& Hetherington, M. J. (2003). Parties, Politics, and Public Policy in America. Washington, D.C.: Congressional Quarterly Press.

Kellough, J. E., \& Selden, S. C. (2003). The Reinvention of Public Personnel Administration: An Analysis of the Diffusion of Personnel Management Reforms in the States. Public Administration Review, 63, 165 - 177.

Kerwin, C. M. (2003). Rulemaking: How Government Agencies Write Law and Make Policy. ( $3^{\text {rd }}$ ed.). Washington, D.C.: Congressional Quarterly Press.

King, J. (2000). Changes in Professionalism in U.S. State Legislatures. Legislative Studies Quarterly, 25, $327-343$.

Kingdon, J. W. (1995). Agendas, Alternatives, and Public Policies. (2 ${ }^{\text {nd }}$ ed.). New York: Harper Collins.

Kirst, M. W., Meister, G., \& Rowley, S. R. (1984). Policy Issue Networks: Their Influence on State Policymaking. Policy Studies Journal, 23, 247 - 263.

Kronenfeld, J. J. (2002). Health Care Policy: Issues and Trends. Praeger Publishers: Westport, Connecticut. 
Leichter, H. M. (1997). Health Policy Reform in America: Innovations from the States. (2nd ed.). Armonk, New York: M.E. Sharpe.

Lipsky, M. (1968). Standing the Study of Policy Implementation on Its Head. In W. D. Burnham, \& M. W. Weinberg (Eds.), American Politics and Public Policy. Cambridge: MIT Press.

Lowi, T. J. (1964). American Business, Public Policy, Case-Studies, and Political Theory. World Politics, 16, $687-691$.

Lowi, T. J. (1972). Four Systems of Policy, Politics, and Choice. Public Administration Review, 33, $298-310$.

Meier, K. J. (1993). Politics and the Bureaucracy: Policymaking in the Fourth Branch of Government. (3 $3^{\text {rd }}$ ed.). California: Wadsworth Publishing Company.

Meier, K. J. (2000). Politics and the Bureaucracy: Policymaking in the Fourth Branch of Government. (4th ed.). Fort Worth, Texas: Harcourt College Publishers.

Miller, G., \& Moe, T. (1983). Bureaucrats, Legislators, and the Size of Government. American Political Science Review, 77, 297 - 322.

Mintrom, M. (1997). Policy Entrepreneurs and the Diffusion of Innovation. American Journal of Political Science, 41, 738 - 770.

Mintrom, M., \& Vergari, S. (1997). Charter Schools as a State Policy Innovation: Assessing Recent Developments. State and Local Government Review, 29, 43 49.

Mintrom, M., \& Vergari, S. (1998). Policy Networks and Innovation Diffusion: The Case of State Education Reforms. Journal of Politics, 60, 126 - 148. 
Mohr, L. B. (1969). Determinants of Innovation in Organizations. American Political Science Review, 63, 111 - 126.

Mooney, C. Z. (2001). Modeling Regional Effects on State Policy Diffusion. Political Research Quarterly, 54, 103 - 124.

Mooney, C. Z., \& Lee, M. (1995). Legislating Morality in the American States: The Case of Pre-Roe Abortion Regulation Reform. American Journal of Political Science, $39,599-627$.

Mosher, F. C. (1982). Democracy and the Public Service. New York: Oxford University Press.

Mossberger, K., \& Wolman, H. (2003). Policy Transfer as a Form of Prospective Policy Evaluation: Challenges and Recommendations. Public Administrative Review, $63,428-440$.

Nakamura, R. T., \& Smallwood, F. (1980). The Politics of Policy Implementation. New York: St. Martin's Press.

National Academy for State Health Policy. (2002). Homepage. Retrieved March 17, 2004, from www.nashp.org

National Association of State Budget Officers. (2004). 2003 State Expenditure Report. Retrieved March 10, 2005, from http://nasbo.org National Conference of State Legislatures. (2004). Homepage. Retrieved March 17, 2004, from www.ncsl.org

National Governors Association. (2004). Homepage. Retrieved March 17, 2004, from www.nga.org 
National Governors Association. (2005). NGA Winter Meeting Highlights. Retrieved March 10, 2005, from http://www.nga.org

Nice, D. C. (1994). Policy Innovation in State Government. Ames: Iowa State University.

Nownes, A. J., \& Freeman, P. (1998). Interest Group Activity in the States. Journal of Politics, 60, 86 - 112.

Peters, B. G. (1997). Policy Transfers between Governments: The Case of Administrative Reforms. West European Politics, 20, 71 - 88.

Peterson, P. E., Rabe, B., \& Wong, K. (2000). When Federalism Works. Washington, D.C.: Brookings Institution Press.

Plotnick, R. D., \& Winters, R. F. (1985). A Politico-Economic Theory of Redistribution. American Political Science Review, 79, 458 - 473.

Pressman, J. L., \& Wildavsky, A. (1973). Implementation. Berkeley: University of California Press.

Reeves, M. M. (1990). The States as Polities: Reformed, Reinvigorated, Resourceful. The Annals of the American Academy of Political and Social Science, 509, 83 93.

Ripley, R. B. (1988). Congress: Process and Policy. ( $4^{\text {th }}$ ed.). New York: W.W. Norton \& Company.

Ripley, R. B., \& Franklin, G. A. (1986). Policy Implementation and the Bureaucracy. Chicago: Dorsey Press.

Ripley, R. B., \& Franklin, G. A. (1987). Congress, The Bureaucracy, and Public Policy. ( $4^{\text {th }}$ ed.). Chicago: The Dorsey Press. 
Ritt, L. (1973). State Legislative Reform: Does It Matter? American Politics Quarterly, 1, $499-510$.

Robert Wood Johnson Foundation. (2004). RWJF Grant Results Report. Retrieved March 17, 2004, from www.rwjf.org/reports

Robertson, D. B., \& Waltman, J. L. (1993). The Politics of Policy Borrowing. In David Finegold, Laurel McFarland, and William Richardson (Eds.), Something Borrowed, Something Learned? The Transatlantic Market in Education and Training Reform. Washington: Brookings Institution Press.

Roeder, P. W. (1979). State Legislative Reform: Determinants and Policy Consequences. American Politics Quarterly, 7, 51 - 70.

Rose, R. (1993). Lesson-drawing in Public Policy: A Guide to Learning across Time and Space. Chatham, NJ: Chatham House Publishers, Inc.

Rourke, F. E. (1984). Bureaucracy, Politics, and Public Policy. ( $3^{\text {rd }}$ ed.). New York: Harper Collins Publishers.

Rourke, F. E. (1991). American Bureaucracy in a Changing Political Setting. Journal of Public Administration Research and Theory, 1, 111 - 129.

Rourke, F. E. (1993). Whose Bureaucracy is This Anyway? Congress, the President, and Public Administration (the 1993 John Gaus Lecture). PS: Political Science and Politics, 26, $687-692$.

Rushefsky, M. E. (2002). Public Policy in the United States: At the Dawn of the Twenty-First Century, $3^{\text {rd }}$ edition. M.E. Sharpe: Armonk, New York. Rutgers Center for State Health Policy. (2004). Homepage. Retrieved March 17, 2004, from www.cshp.rutgers.edu/ 
Sabatier, P. A. (1993). Policy Change over a Decade or More. In P. A. Sabatier, \& H. C. Jenkins-Smith (Eds.), Policy Change and Learning: An Advocacy Coalition Approach. Boulder: Westview Press.

Sabatier, P. A., \& Jenkins-Smith, J. C. (1999). The Advocacy Coalition Framework: An Assessment. In P. A. Sabatier (Ed.), Theories of the Policy Process. Boulder, Colorado: Westview Press.

Sanford, T. (1967). Storm Over the States. New York: McGraw-Hill Book Company.

Satterthwaite, S. B. (2002). Innovation and Diffusion of Managed Care in Medicaid Programs. State and Local Government Review, 34, 116 - 126.

Savage, R. L. (1978). Policy Innovativeness as a Trait of American States. The Journal of Politics, 40, 212 - 224.

Sharkansky, I. (1970). Regionalism in American Politics. Indianapolis, Indiana: BobbsMerrill.

Sharkansky, I. (1971). State Administrators in the Political Process. In H. Jacob, \& K. N. Vines (Eds.), Politics in the American States: A Comparative Analysis. Boston: Little, Brown, and Company.

Shipan, C. R., \& Volden, C. (2004). The Diffusion of State-Level Antismoking Policies in a Federal System. Presented at Midwest Political Science Association Annual Meeting, Chicago, Illinois. Retrieved from http://www.uiowa.edu/ c030310/Shipan\&Volden\%20MPSA2004.pdf

Sigelman, L. (1976). The Quality of State Administration: An Exploration in the American States. Administration and Society, 8, 107 - 144. 
Sigelman, L., \& Dometrius, N. C. (1988). Governors as Chief Administrators: The Linkage Between Formal Powers and Informal Influence. American Politics Quarterly, 16, 157 - 170.

Smith, J. D. (2002). Right-to-Die Policies in the American States: Judicial and Legislative Innovation. New York: LFB Scholarly Publishing LLC.

Squire, P. (1988). Career Opportunities and Membership Stability in Legislatures. Legislative Studies Quarterly, 13, $65-82$.

Squire, P. (1992). Legislative Professionalism and Membership Diversity in State Legislatures. Legislative Studies Quarterly, 17, 69 - 79.

Studlar, D. T. (2002). Tobacco Control: Comparative Politics in the United States and Canada. Orchard Park, New York: Broadview Press.

Thompson, J. A. (1986). State Legislative Reform: Another Look, One More Time, Again. Polity, 19, 27 - 41.

True, J., \& Mintrom, M. (2001). Transnational Networks and Policy Diffusion: The Case of Gender Mainstreaming. International Studies Quarterly, 45, 27 - 57.

Truman, D. (1955). The Governmental Process. New York: Alfred A. Knopf. United Health Group.(2001). State Health Ranking - Selection of Components. Retrieved February 5, 2001, from http://www.unitedhealthgroup.com/sr2000/summary.html

U.S. Census Bureau. (2004). Government Finance and Employment Data. Retrieved November 5, 2004, from http://www.census.gov/govs/www/ 
Volden, Craig. (2003). States as Policy Laboratories: Experimenting with the Children's Health Insurance Program. Presented at American Political Science Association Annual Meeting, Philadelphia, Pennsylvania. Retrieved from http://archive.allacademic.com/publication/getfile.php?file=docs/ apsa_proceeding/2003-08-19/2754/apsa_proceeding_2754.pdf\&PHPSESSID $=3 \mathrm{be} 8 \mathrm{e} 2 \mathrm{ec} 6074 \mathrm{~b} 33 \mathrm{~d} 94 \mathrm{cb} 0824 \mathrm{cc0} 027655$

Walker, J. L. (1969). The Diffusion of Innovations Among The American States. American Political Science Review, 63, 880 - 899.

Walker. J. L. (1971). Innovation in State Politics. In H. Jacob, \& K. N. Vines (Eds.), Politics in the American States: A Comparative Analysis (2nd ed.). Boston: Little, Brown, and Co.

Walker. J. L. (1973). Comment: Problems in Research on the Diffusion of Policy Innovations. American Political Science Review, 67, 1186 - 1191.

Walker, J. L. (1981). The Diffusion of Knowledge, Policy Communities and Agenda Setting: The Relationship of Knowledge and Power. In J. E. Tropman, M. J. Dluhy, \& R. M. Lind (Eds.), New Strategic Perspectives on Social Policy. New York: Pergamon Press.

Welch, S., \& Thompson, K. (1980). The Impact of Federal Incentives on State Policy Innovation. American Journal of Political Science, 24, 715 - 729.

Wiggins, C. W., \& Browne, W. P. (1982). Interest Groups and Public Policy Within a State Legislative Setting. Polity, 14, 548 - 558.

Wilson, W. (1887). The Study of Administration. Political Science Quarterly, 2, 197 222. 
Wolman, H. (1992). Understanding Cross National Policy Transfers: The Case of Britain and the US. Governance: An International Journal of Policy and Administration, 5, 27 - 45.

Wood, B. D., \& Waterman, R. W. (1994). Bureaucratic Dynamics: The Role of Bureaucracy in a Democracy. Boulder, Colorado: Westview Press.

Wright, D. S. (1988). Understanding Intergovernmental Relations. Pacific Grove, California: Brooks/Cole.

Yates, D. (1982). Bureaucratic Democracy: The Search for Democracy and Efficiency in American Government. Cambridge: Harvard University Press. 
Appendix A

State Administrative Innovation Index

\begin{tabular}{|c|c|c|c|c|c|c|c|c|c|c|c|}
\hline STATE & INDEX & DV1 & DV2 & DV3 & DV4 & DV5 & DV6 & DV7 & DV8 & DV9 & DV10 \\
\hline$A L$ & 6 & 0 & 1 & 0 & 1 & 1 & 1 & 1 & 1 & 0 & 0 \\
\hline AK & 1 & 0 & 0 & 0 & 0 & 0 & 0 & 0 & 1 & 0 & 0 \\
\hline$A Z$ & 4 & 1 & 1 & 0 & 0 & 1 & 0 & 1 & 0 & 0 & 0 \\
\hline AR & 5 & 0 & 0 & 0 & 0 & 1 & 1 & 1 & 1 & 0 & 1 \\
\hline CA & 8 & 1 & 1 & 1 & 1 & 1 & 1 & 1 & 0 & 0 & 1 \\
\hline $\mathrm{CO}$ & 7 & 1 & 0 & 1 & 0 & 1 & 0 & 1 & 1 & 1 & 1 \\
\hline CT & 5 & 0 & 1 & 1 & 0 & 1 & 0 & 1 & 0 & 0 & 1 \\
\hline DE & 2 & 0 & 0 & 0 & 0 & 0 & 1 & 1 & 0 & 0 & 0 \\
\hline FL & 5 & 0 & 0 & 0 & 1 & 1 & 1 & 0 & 1 & 0 & 1 \\
\hline GA & 5 & 0 & 0 & 0 & 1 & 1 & 1 & 1 & 1 & 0 & 0 \\
\hline $\mathrm{HI}$ & 3 & 0 & 0 & 0 & 0 & 1 & 1 & 0 & 1 & 0 & 0 \\
\hline ID & 3 & 1 & 0 & 0 & 0 & 0 & 1 & 1 & 0 & 0 & 0 \\
\hline IL & 5 & 1 & 0 & 0 & 1 & 1 & 1 & 0 & 1 & 0 & 0 \\
\hline IN & 4 & 0 & 0 & 0 & 0 & 1 & 1 & 1 & 0 & 1 & 0 \\
\hline IA & 3 & 0 & 1 & 0 & 0 & 1 & 1 & 0 & 0 & 0 & 0 \\
\hline KS & 2 & 0 & 0 & 0 & 0 & 1 & 1 & 0 & 0 & 0 & 0 \\
\hline KY & 2 & 1 & 0 & 0 & 0 & 1 & 0 & 0 & 0 & 0 & 0 \\
\hline LA & 5 & 0 & 0 & 0 & 0 & 1 & 1 & 1 & 1 & 0 & 1 \\
\hline ME & 7 & 0 & 1 & 1 & 0 & 1 & 1 & 1 & 1 & 1 & 0 \\
\hline $\mathrm{MD}$ & 4 & 0 & 1 & 0 & 0 & 0 & 1 & 0 & 1 & 0 & 1 \\
\hline MA & 6 & 0 & 1 & 1 & 0 & 1 & 1 & 0 & 0 & 1 & 1 \\
\hline MI & 5 & 0 & 1 & 0 & 0 & 1 & 0 & 1 & 0 & 1 & 1 \\
\hline $\mathrm{MN}$ & 7 & 1 & 1 & 1 & 1 & 1 & 1 & 0 & 0 & 1 & 0 \\
\hline MS & 3 & 0 & 0 & 0 & 0 & 1 & 1 & 1 & 0 & 0 & 0 \\
\hline MO & 4 & 0 & 0 & 0 & 1 & 1 & 1 & 0 & 0 & 1 & 0 \\
\hline MT & 0 & 0 & 0 & 0 & 0 & 0 & 0 & 0 & 0 & 0 & 0 \\
\hline $\mathrm{NE}$ & 5 & 1 & 1 & 0 & 0 & 1 & 1 & 0 & 1 & 0 & 0 \\
\hline NV & 0 & 0 & 0 & 0 & 0 & 0 & 0 & 0 & 0 & 0 & 0 \\
\hline $\mathrm{NH}$ & 3 & 0 & 1 & 0 & 0 & 0 & 1 & 1 & 0 & 0 & 0 \\
\hline $\mathrm{NJ}$ & 5 & 1 & 1 & 1 & 0 & 1 & 0 & 0 & 0 & 1 & 0 \\
\hline NM & 6 & 0 & 1 & 0 & 0 & 1 & 1 & 0 & 1 & 1 & 1 \\
\hline NY & 8 & 0 & 1 & 1 & 0 & 1 & 1 & 1 & 1 & 1 & 1 \\
\hline NC & 5 & 0 & 1 & 1 & 0 & 0 & 1 & 0 & 1 & 1 & 0 \\
\hline ND & 0 & 0 & 0 & 0 & 0 & 0 & 0 & 0 & 0 & 0 & 0 \\
\hline $\mathrm{OH}$ & 4 & 0 & 1 & 0 & 0 & 1 & 1 & 0 & 1 & 0 & 0 \\
\hline OK & 5 & 0 & 1 & 0 & 0 & 1 & 1 & 0 & 1 & 0 & 1 \\
\hline OR & 5 & 1 & 1 & 0 & 0 & 1 & 0 & 1 & 0 & 0 & 1 \\
\hline PA & 2 & 0 & 1 & 0 & 0 & 1 & 0 & 0 & 0 & 0 & 0 \\
\hline RI & 8 & 1 & 1 & 1 & 0 & 1 & 1 & 1 & 0 & 1 & 1 \\
\hline SC & 4 & 0 & 1 & 0 & 0 & 1 & 0 & 0 & 1 & 1 & 0 \\
\hline SD & 2 & 0 & 0 & 0 & 0 & 0 & 1 & 0 & 0 & 0 & 1 \\
\hline TN & 3 & 0 & 0 & 0 & 0 & 1 & 1 & 1 & 0 & 0 & 0 \\
\hline TX & 4 & 0 & 1 & 0 & 0 & 1 & 0 & 1 & 0 & 0 & 1 \\
\hline UT & 5 & 0 & 1 & 0 & 1 & 1 & 1 & 0 & 1 & 0 & 0 \\
\hline VT & 6 & 0 & 1 & 1 & 0 & 1 & 1 & 1 & 1 & 0 & 0 \\
\hline VA & 4 & 0 & 0 & 0 & 0 & 1 & 1 & 0 & 0 & 1 & 1 \\
\hline WA & 6 & 1 & 1 & 0 & 0 & 1 & 1 & 0 & 1 & 1 & 0 \\
\hline WV & 5 & 0 & 0 & 0 & 0 & 1 & 1 & 1 & 1 & 1 & 0 \\
\hline WI & 5 & 1 & 1 & 1 & 0 & 1 & 0 & 0 & 0 & 1 & 0 \\
\hline WY & 2 & 0 & 1 & 0 & 0 & 0 & 1 & 0 & 0 & 0 & 0 \\
\hline
\end{tabular}


DV1 - cancer registry - achieved CDC completeness standard, CDC.gov; 10/12/00

DV2- ABLES - surveillance system for elevated blood lead levels, occupational health; $10 / 12 / 00$

DV3 - separate office of occupational health per designated CDC contact; 10/12/00

DV4 - arthritis activity; CDC/gov; 10/17/00

DV5- position dedicated to chronic disease epidemiology; CSTE, e-mail; 10/23/00

DV6- state office of rural health located in state health dept;

http://www.ruralhealth.hrsa.gov/sorhreports2000.htm; 10/23/00

DV7 - immunization registry authorized

DV8 - PRAMS; http://www.cdc.gov/nccdphp/drh/pramstates.htm; 10/24/00

DV9 - ASSIST; http://www.cdc.gov/tobacco/statehi/pdf/program.pdf; 10/25/00

DV10- required school-entry immunization updated with varicella; www.immunize.org/laws; 10/25/00 


\section{Appendix B}

\section{Survey Cover Letter}

June 4, 1999

Name

Address

City, State

Dear :

I am conducting research on the role of state bureaucracies in public policymaking. The participation of state health administrators like yourself in the State Health Policy Innovation Survey is an important part of this research. Would you please take a few minutes to complete and return the enclosed survey?

This study is conducted in partial fulfillment of the requirements for my Ph.D. dissertation. Participation in this survey is voluntary, and your refusal to participate will not affect my degree completion. You may choose to omit answers to any questions. All responses will remain strictly confidential, and information from this survey will only be released in aggregate form.

If you have any questions concerning this survey, please contact me or my dissertation director, Dr. Donley Studlar, at (304) 293-3811 (rklase@wvu.edu or dstudlar@wvu.edu). Thank you for your assistance.

Sincerely,

Rebecca Tatman Klase

Department of Political Science

West Virginia University 
Appendix C

Survey Instrument 


\section{STATE HEALTH POLICY INNOVATION SURVEY}

NAME:

POSITION/TITLE:

STATE:

1. What are some of the public health activities that your state does particularly well?

2. Have you presented information on a "best practice" from your state: at a national or regional conference/meeting?

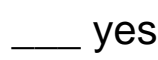
no

in a newsletter or publication for state health officials?

through a list-serve or other e-mail communication?

in person as a consultant for another state?

on your state health department web page?

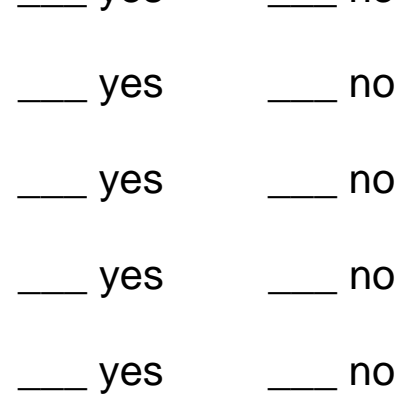

3. Briefly, please give one or two examples of instances where other states have consulted with your state on public health problems or activities? 
4. Please list other states that you think of as leaders in specific public health activities. 
5. How important are the following for the initiation of new public health activities in your state?

1=VERY IMPORTANT 3=SOMEWHAT IMPORTANT

\section{2=IMPORTANT \\ 4=NOT IMPORTANT}

SI

$\underline{\text { NI }}$

A strong state public health director

The availability

of state funding

The availability of federal funding

$\begin{array}{llll}1 & 2 & 3 & 4\end{array}$

A strong division director

$\begin{array}{llll}1 & 2 & 3 & 4\end{array}$

Interest from state legislators

$\begin{array}{llll}1 & 2 & 3 & 4\end{array}$

Interest from the governor

$\begin{array}{llll}1 & 2 & 3 & 4\end{array}$

Presence of a university school of public health

$\begin{array}{llll}1 & 2 & 3 & 4\end{array}$

Other (please specify)

$\begin{array}{llll}1 & 2 & 3 & 4\end{array}$

6. Which professional conferences and meetings do you attend on a regular basis?

7. Which journals, newsletters, and publications help you learn about best practices used in other states' health departments? 
8. By numbering 1 thru 6 , rank the following in terms of importance when your state public health department makes decisions about which federal categorical grants to pursue.

$$
1=\text { most important } \quad 6=\text { least important }
$$

availability of staff resources within my department to implement the grant public health problems within my state gubernatorial interest state legislative interest availability of state matching funds other (please specify)

9. How frequently do you use the telephone to share information with public health officials in other states on common problems or best practices? daily _ weekly _ monthly _ never _ other

What kinds of information do you share on the telephone?

10. Have you ever learned of best practices from other states' web pages? no yes

If yes, can you give examples? 
11. Have you ever learned of other states' best practices from the web pages of professional organizations? no yes

If yes, can you give examples?

12. How frequently do you use e-mail to share information with public health officials in other states on common problems or best practices?

_ daily weekly monthly never other

What kinds of information do you share?

13. Do you subscribe to any Internet list-serves that provide information on the public health activities of other states? no yes

Which list-serves? 
14. Are the following sources of information on state public health best practices:

1=VERY IMPORTANT 2=IMPORTANT 3=SOMEWHAT IMPORTANT 4=NOT IMPORTANT
VI
SI
$\underline{\text { NI }}$

ASTHO (or its affiliates) annual meeting
1
2
3
4

Meetings sponsored by federal agencies

$\begin{array}{llll}1 & 2 & 3 & 4\end{array}$

Regional meetings with my counterparts in other states
1
2
3
4

Other professional association meetings/conferences

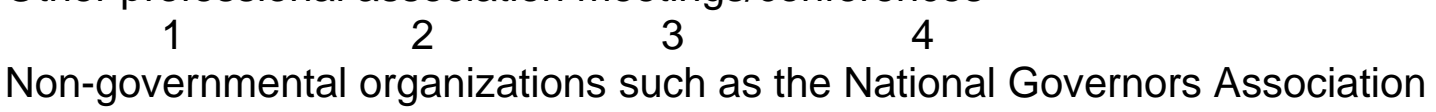
1
2
3
4

Site visits to other state health departments

1234

_ Site visits to my state by public health officials from other states

$\begin{array}{llll}1 & 2 & 3 & 4\end{array}$

Professional association journals

$\begin{array}{llll}1 & 2 & 3 & 4\end{array}$

ASTHO (or its affiliates) newsletters or reports

$\begin{array}{llll}1 & 2 & 3 & 4\end{array}$

Newsletters/reports from other state health departments

$\begin{array}{lllll}1 & 2 & 3 & 4\end{array}$

Newspapers and news magazines

$\begin{array}{llll}1 & 2 & 3 & 4\end{array}$

_ Federal agency publications

$\begin{array}{llll}1 & 2 & 3 & 4\end{array}$

_ Telephone calls with my counterparts in other states

- $\begin{array}{llll} & 1 & 2 & 3\end{array}$

_ E-mail or Internet list-serves with my counterparts in other states
1
2
3
4

_ Web pages from other states' health departments
1
2
3
4

Professional association web pages

1

2

3

4

Please check mark the three that you consider most important. 
15. Do you strongly agree, agree, disagree, or strongly disagree with the following statements?

1=STRONGLY AGREE 2=AGREE 3=DISAGREE 4=STRONGLY DISAGREE
S모
$\underline{A}$
$\underline{\mathbf{D}}$
$\underline{\text { SD }}$

State legislators request my advice on policy matters.

1

2

3

4

State legislators request draft legislation from my department.

$\begin{array}{llll}1 & 2 & 3 & 4\end{array}$

When considering public health legislation, legislators consult with my department for technical assistance.
1
2
3
4

My advice on public health policy is valued by state legislators.

$\begin{array}{llll}1 & 2 & 3 & 4\end{array}$

In my state, legislators request the testimony of public health

officials at important legislative hearings on public health.
1
2
3
4

State legislators seriously consider budget submissions from the public health department.

$\begin{array}{llll}1 & 2 & 3 & 4\end{array}$

Legislation drafted by my department is given serious consideration by the state legislature.

$\begin{array}{llll}1 & 2 & 3 & 4\end{array}$

When considering the state public health budget, legislators consult with my department for technical assistance.
1
2
3
4

The travel budget for my office limits my ability to learn the "best practices" of other states' health departments.
1
2
3
4

The demand of dealing with day-to-day public health activities within my state limit my ability to learn of other states' best practices.

$\begin{array}{llll}1 & 2 & 3 & 4\end{array}$

My advice on public health policy is valued by the governor's office. 
The governor's office seriously considers budget submissions from the public health department.

$\begin{array}{llll}1 & 2 & 3 & 4\end{array}$

The governor's office requests my advice on policy matters.

1

2

3

4

In order to provide further information on the professional communication networks of state administrators, please attach a resume which includes your education, work experience, and membership in professional associations. Information from your resume, as well as other survey responses will remain confidential.

Please check here if you would like to receive a copy of the results of this survey. Thank you for completing the survey.

Return to: Rebecca Tatman Klase; WVU, Department of Political Science; PO Box 6317; Morgantown, WV 26506-6317 


\section{Curriculum Vitae \\ Rebecca Tatman Klase}

\section{Education}

Ph.D., Political Science 2005

West Virginia University, Morgantown, West Virginia

Exam fields: Public Policy, Public Health Policy, Research Methodology

Dissertation:

State Policy Innovation and Transfer: The Role of Bureaucratic Professional

Communication Networks

Committee: Donley T. Studlar (director), Nancy Adams, Allan S. Hammock, Kevin M.

Leyden, Neil B. Berch

M.A., Political Science (Public Policy Emphasis) 1998

West Virginia University, Morgantown, West Virginia

ICPSR Summer Program in Quantitative Methods 1997

The University of Michigan, Ann Arbor

Graduate study in Public Administration 1982-83

The University of Georgia, Athens, Georgia

Bachelor of Music, cum laude 1978

Wesleyan College, Macon, Georgia

\section{Professional Experience}

Assistant Professor 2004 - present

Lecturer 2002 - 2004

Greensboro College, Division of Social Sciences

Department of Political Science and Legal Administration

Adjunct lecturer Spring 2001

West Virginia University, Department of Political Science

Assistant Director Fall 2000

Council of International Programs

Direct program for mid-career international internships 
Visiting lecturer Spring 2000

West Virginia University, Division of Public Administration

Graduate instructor 1997-1999

West Virginia University, Department of Political Science

Graduate teaching assistant 1996-97

West Virginia University, Department of Political Science

Graduate research assistant 1982-83

University of Georgia, Department of Political Science

Administrative assistant 1979-82

Centers for Disease Control and Prevention

Recruitment assistant 1978-79

Peace Corps/VISTA

\section{Courses Taught}

American National Government; State and Local Government

Public Administration; Public Policy (Senior Seminar)

Judicial Process; Administrative Law

American Presidency; Women and Politics; Political Behavior, Parties and Elections Empirical Political Analysis; Quantitative Methods; Computer Applications for Political Research

Methods for Public Administration (graduate level)

Applied Research in Public Administration (graduate level)

\section{Department and Community Service}

$2004-05$

Co-advisor Pi Sigma Alpha (political science honorary)

Member of Institutional Assessment Committee

Assist in preparation of department annual assessment report

Presenter, Ethics Across the Curriculum, October 04, "Has Politics Lost Its Civility" Panel Member, Writing Across the Curriculum, February 05, "Critical Book Reviews"

Coordinate campus-wide activities related to national/state elections Interviews with WFMY - election coverage/political analysis

Invited presenter, City of Greensboro, Commission on the Status of Women, Empowering Women Workshop 


\section{$2003-04$}

Coordinator, Social Studies Secondary Licensure program

Member of Teacher Education Committee

Co-advisor Pi Sigma Alpha (political science honorary)

Assist in preparation of department annual assessment report and five-year review

Panel Chair, North Carolina Political Science Association; "Course Assessment in Political Science"

Invited speaker, Greensboro Optimist Club; "Has Politics Lost Its Civility"

\section{$2002-03$}

Interviews with WFMY - election coverage

Discussant, North Carolina Political Science Association; Judicial Process and Politics panel

Guest lecturer on election topics; Aycock Middle School

\section{Other}

Member, League of Women Voters of the Piedmont Triad, 2001 - present

Graduate student representative to Political Science Department colloquium committee, 1997-98, 1999

Political Science Graduate Student Association; President, 1999

Member, Board of Directors, West Virginia Council of International Programs, 1992-2001 


\section{Conference Papers}

"Model of Bureaucratic State Policy Transfer." Presented at North Carolina Political Science Association Meeting, Salisbury, North Carolina; April 2002.

"State Policy Transfer: Do Bureaucracies Matter?" Presented at Conference on the Study of Politics in the American States, College Station, Texas; March 2001.

Supported participation (\$500).

"State Policy Transfer: The Role of Bureaucracies" Presented at West Virginia Political Science Association Meeting, Morgantown, West Virginia; October 2000.

"The Role of State Bureaucracies in Policy Innovation and Transfer." Presented at Southern Political Science Association Meeting, Savannah, Georgia; November 1999.

"The Role of Professional Communication Networks in the Transfer of State Health Programs." Presented at West Virginia Political Science Association Meeting, Huntington, West Virginia; October 1999.

"Professional Communication Networks among State Bureaucracies." Presented at American Political Science Association Meeting, Atlanta, Georgia; September 1999.

"An Analysis of the Use of Web Pages by State Health Departments." Presented at West Virginia Political Science Association Meeting, Morgantown, West Virginia; October 1997.

"The Structural Dynamics of Committee Jurisdictions in Immigration Policy." Coauthored with Alfred M. Olivetti, Jr. Presented at Midwest Political Science Association Meeting, Chicago, Illinois; April 1997.

"Immigration: Issue Salience and Venue Change." Coauthored with Alfred M. Olivetti, Jr. Presented at West Virginia Political Science Association Meeting, Huntington, West Virginia; October 1996. 


\section{Academic Honors}

Outstanding Graduate Teaching Assistant, Department of Political Science, 1997-98

Outstanding Graduate Teaching Assistant, WVU Pi Sigma Alpha, 1997-98

Graduate Teaching Assistantship, 1996-99

Recipient of APSA Advanced Graduate Student travel grant, 1999

Recipient of WVU Dissertation grant to administer State Health Policy Innovation Survey, 1999

Recipient of Clifford C. Clogg scholarship - ICPSR summer program, 1997

Wesleyan Scholar Award - full tuition scholarship for undergraduate degree, 1974-78 Membership in Pi Sigma Alpha, Pi Alpha Alpha, and Sigma Alpha lota

\section{Professional Memberships}

American Political Science Association

Southern Political Science Association

North Carolina Political Science Association 